\title{
Meaningful stakeholder involvement in decision making processes on sustainability issues -
}

-

$$
3=2 .+2 x
$$
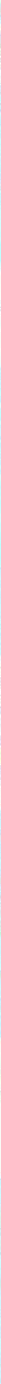



\section{Propositions}

1. Joint knowledge generation is a prerequisite for participatory and meaningful decision making processes on sustainability issues.

(this thesis)

2. Inclusion of stakeholders in decision making processes reduces unequal footing between the stakeholders involved.

(this thesis)

3. Responsibilities for "science for impact" are clearly defined for science, not for impact.

4. BSc Honours Programmes create optimal conditions for educating future leaders.

5. Professional facilitators are rarely appreciated: facilitators are regarded as unneeded when facilitation is successful and are blamed when facilitation fails.

6. Cycling changes climate.

Propositions belonging to the thesis, entitled

Meaningful Stakeholder Involvement in Decision Making Processes on Sustainability Issues

Astrid Hendriksen

Wageningen, 17 September 2019 



\section{Meaningful Stakeholder Involvement in Decision Making Processes on Sustainability Issues}




\section{Thesis committee}

\section{Promotor}

Prof. Dr A.P.J. Mol

Professor of Environmental Policy

Wageningen University \& Research

\section{Co-promotor}

Dr B.J.M. van Vliet

Associate professor, Environmental Policy Group

Wageningen University \& Research

\section{Other members}

Dr T. Acevedo Guerrero, IHE Delft Institute for Water Education

Prof. Dr A.R.P.J. Dewulf, Wageningen University \& Research

Dr T.T.M. Dieu, Van Lang University, Ho Chi Minh City, Vietnam

Prof. Dr H.J. Lindeboom, Wageningen University \& Research

This research was conducted under the auspices of the Wageningen Institute for Environment and Climate Research 


\section{Meaningful Stakeholder Involvement in Decision Making Processes on Sustainability Issues}

Astrid Hendriksen

\section{Thesis}

submitted in fulfilment of the requirements for the degree of doctor at Wageningen University

by the authority of the Rector Magnificus

Prof. Dr A.P.J. Mol,

In the presence of the

Thesis Committee appointed by the Academic Board

to be defended in public

on Tuesday 17 September 2019

at 4 p.m. in the Aula 
Astrid Hendriksen

Meaningful Stakeholder Involvement in Decision Making Processes on Sustainability Issues

197 pages

PhD thesis, Wageningen University, Wageningen, the Netherlands (2019)

With references, with summary in English

DOI: $10.18174 / 496901$

ISBN 978-94-6395-053-4 


\section{Table of Contents}

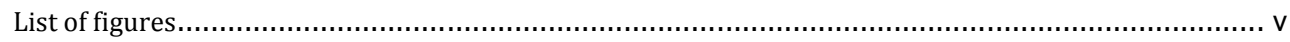

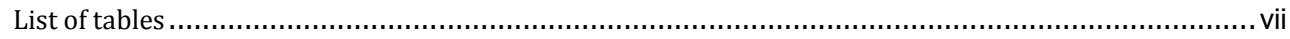

List of boxes

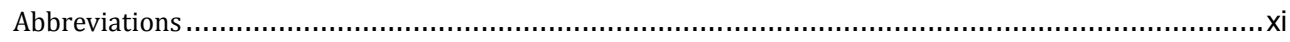

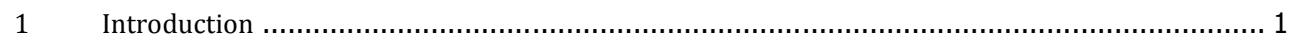

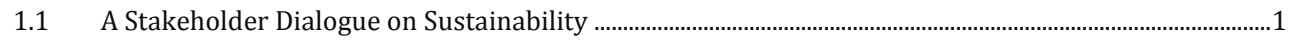

1.2 Stakeholder Positions in the Field of Decision Making on Sustainability Issues ......................................... 4

1.3 Dilemmas of Stakeholder Participation in Decision Making Processes on Sustainability Issues ........10

$1.4 \quad$ Research Objective and Methodology ………...............................................................................................18

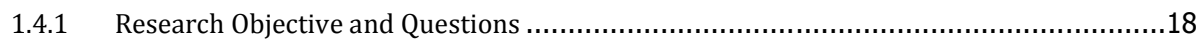

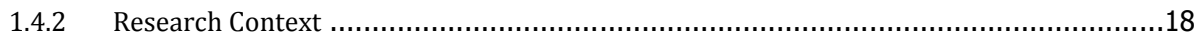

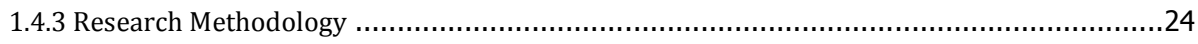

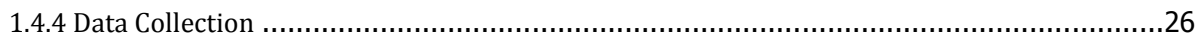

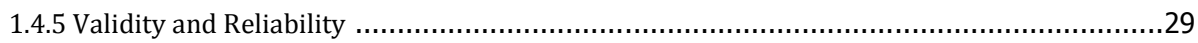

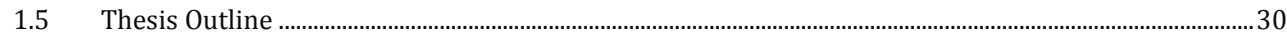

2 Participatory Decision Making for Sanitation Improvements in Unplanned Urban Settlements

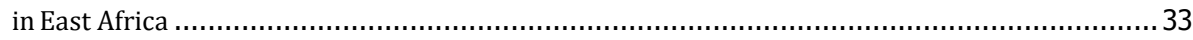

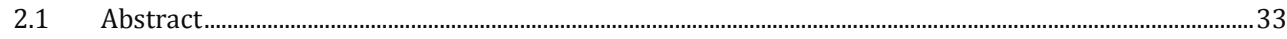

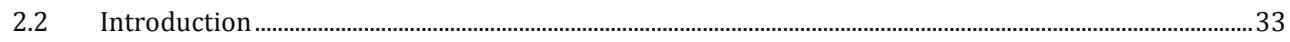

2.3 Stakeholder Involvement in the Modernized Mixtures Approach …………………................................36

2.4 Participatory Decision Making Methods .....................................................................................................

2.5 Participatory Sanitation Planning Tools …………….................................................................................

2.6 Proact: A Multi Criteria Decision Analysis Method for Sanitation Policy ....................................................4

$2.7 \quad$ Testing Proact 2.0 in Katanga Slum, Kampala ...................................................................................................... 47 


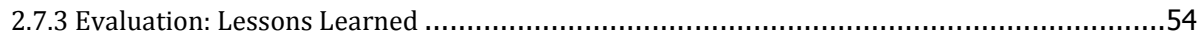

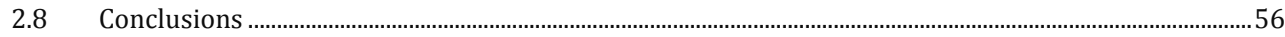

3 How to dance? The Tango of Stakeholder Involvement in Marine Governance Research ..............59

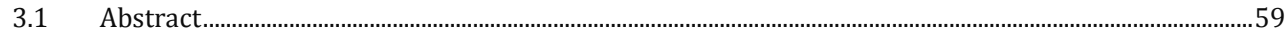

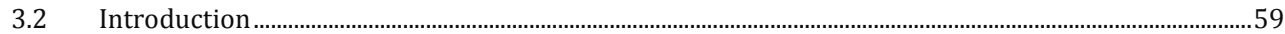

3.3 Best Practices of Stakeholder Involvement in Scientific research.........................................................62

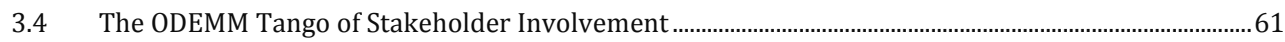

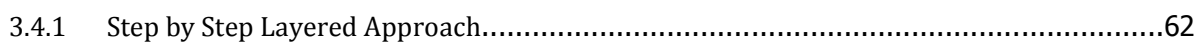

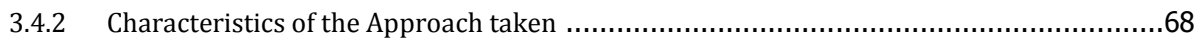

3.5 Lessons Learned: Reflection on Stakeholder Involvement in ODEMM's Governance Research.........72

4 Sometimes you cannot make it on your own; Drivers and Scenarios for Regional Cooperation in Implementing the EU Marine Strategy Framework Directive .........................................75

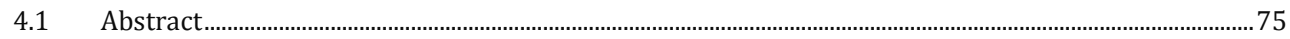

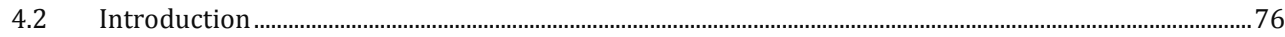

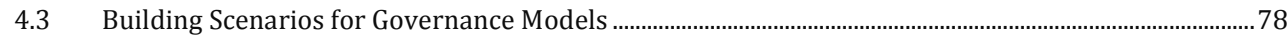

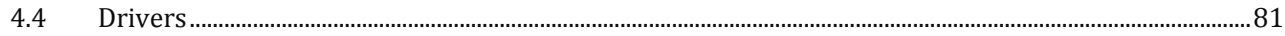

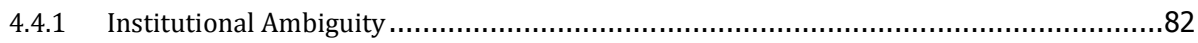

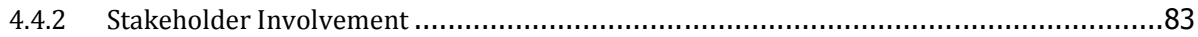

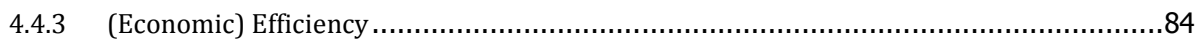

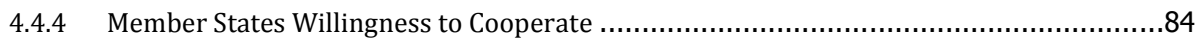

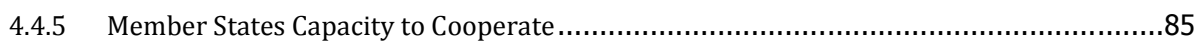

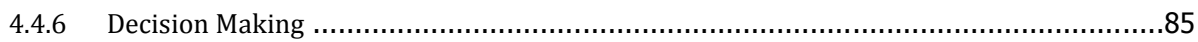

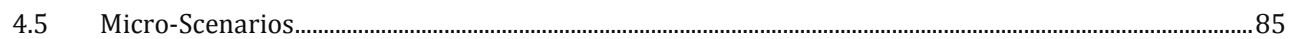

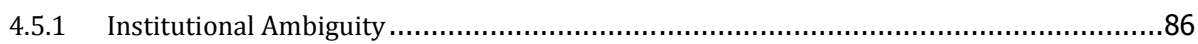

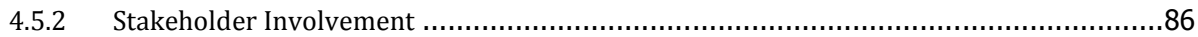




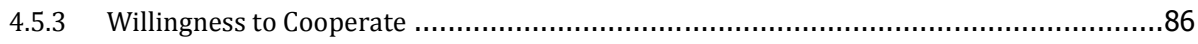

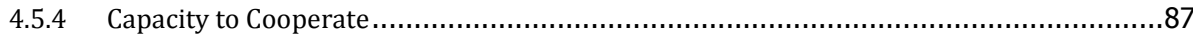

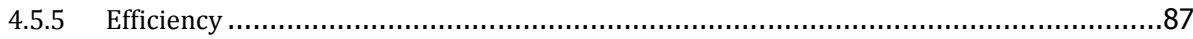

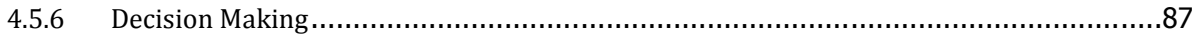

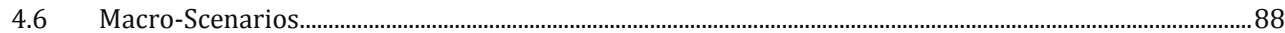

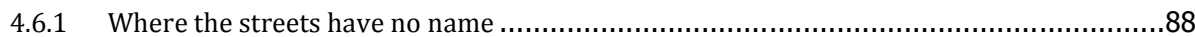

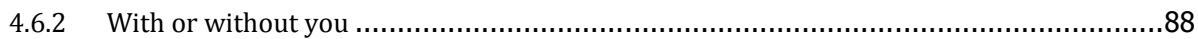

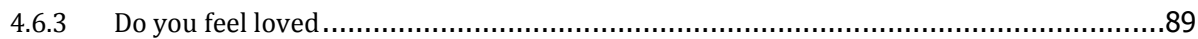

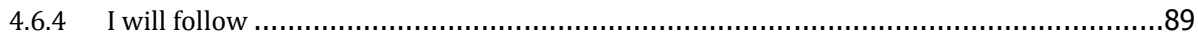

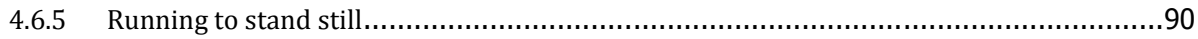

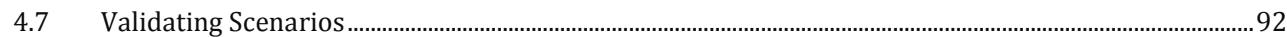

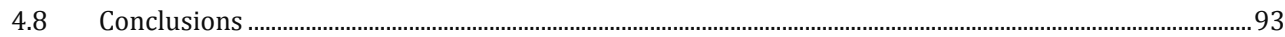

5 Fishing for Opinions: Stakeholder Views on Marine Strategy Framework Directive Implementation

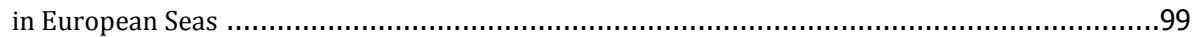

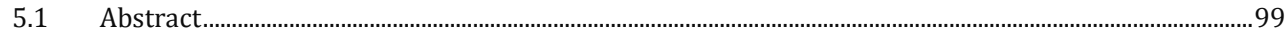

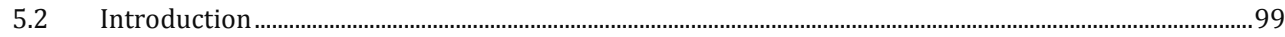

5.3 Stakeholder Involvement in European Marine Environmental Policy-making.................................101

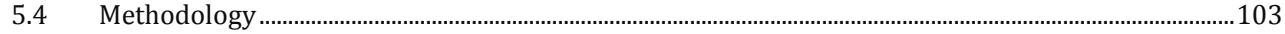

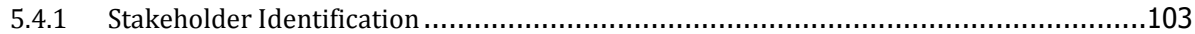

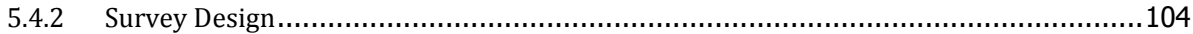

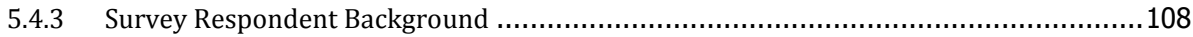

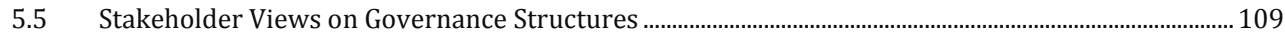

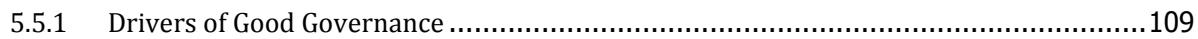

5.5.2 Propositions for the Current-, the Foreseen- and the Ideal Situation .........................110

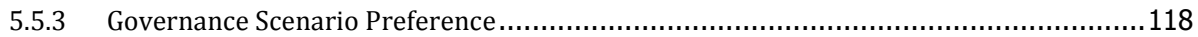

5.6 Perspectives for Future Governance Structures.................................................................................. 122

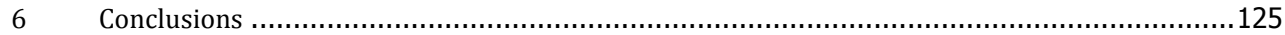




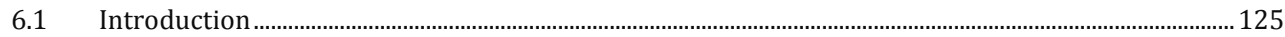

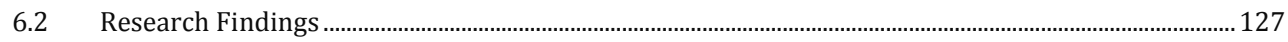

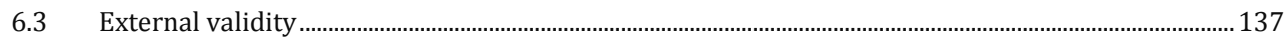

6.4 Participatory and Meaningful Decision Making Processes on Sustainability Issues: a Research

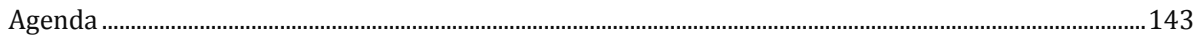

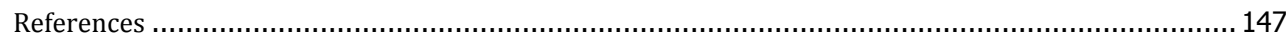

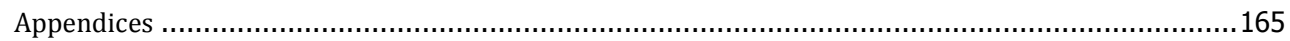

Appendix 1 ODEMM Survey on Marine Regional Cooperation .................................................................... 165

Appendix 2 Governance Models for Regional Cooperation upon Ecosystem-Based Management ........ 187

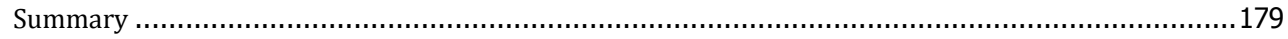

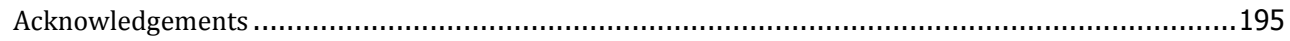

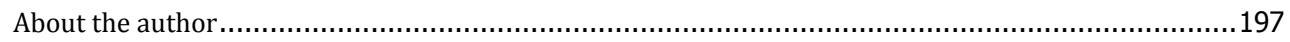




\section{List of figures}

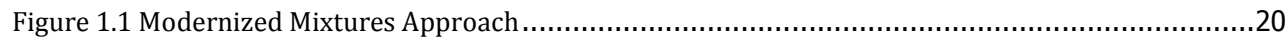

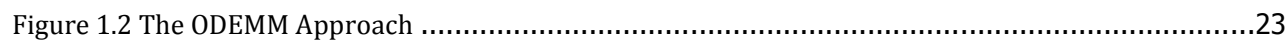

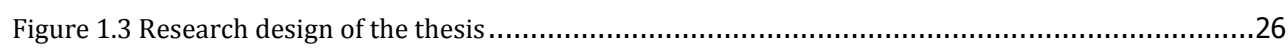

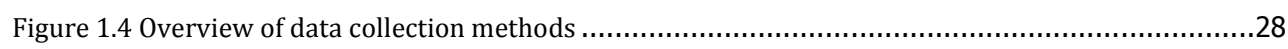

Figure 2.1 Administrative map of Central Kampala, Uganda .......................................................

Figure 2.2 Preferred options for sanitation improvement (in percentages) ......................................54

Figure 3.1 Overview of stakeholder involvement in the different steps of the ODEMM approach .............65

Figure 3.2 Step 1: Selecting driving forces by identifying the current institutional MSFD framework and

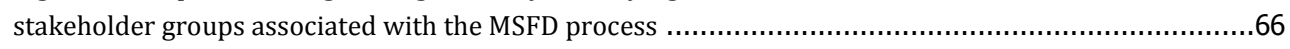

Figure 3.3 Step 2: Building and testing scenarios based on the 6 driving forces ...............................66

Figure 3.4 Step 3: Building and testing governance models based on the results of the survey ..............67

Figure 3.5 Step 4: Testing the governance models in 5 roundtables and writing the policy brief based on

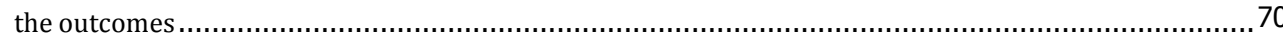

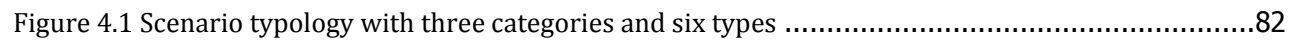

Figure 4.2 Drivers for scenario 'Where the streets have no name' ...............................................92

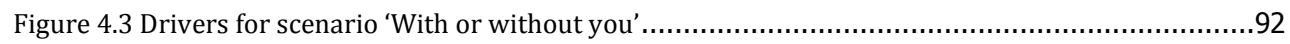

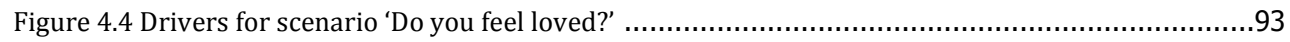

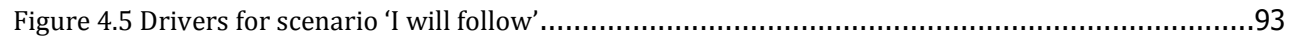

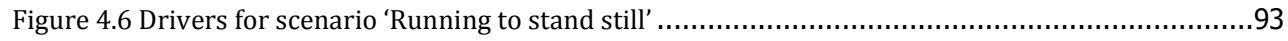

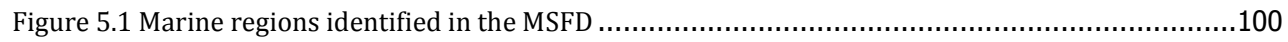

Figure 5.2 Representation of the sectors in the survey results .................................................108

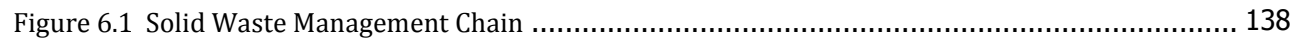




\section{List of tables}

Table 2.1 Participatory Sanitation Planning Tools with Multiple Stakeholder Involvement.....

Table 2.2 Phases and Stakeholder Participation in Proact.

Table 2.3 Phases and Stakeholder Participation in Environmental Multi Criteria Decision Making

Processes

Table 2.4 Phases and Stakeholder Participation in Proact 2.0

Table 2.5 Background Variables Participants Katanga Workshop .....

Table 2.6 End User Criteria for Selecting Feasible Options for Sanitation Improvements

Table 3.1 Assessing the ODEMM approach by comparing it to Reed's best practices of stakeholder involvement (2008).

Table 4.1 Level of institutional ambiguity for each regional sea associated with implementation of the MSFD (taken with permission from Van Leeuwen et al. 2012)

Table 5.1 The type of involvement for each stakeholder group in the implementation process of the MSFD

(\% per sector.

Table 5.2 Stakeholder answers about the six drivers of good governance to achieve Good environmental Status for the MSFD. Negative percentages correspond to the disagreements and the positive to the agreements. The neutral answers are centered on zero. The missing answers (boxes non-applicable and do not know) are expressed in percentage of the total answers to each statement but are not included in the bars

Table 5.3 Baltic Sea sector perspectives about the current, foreseen and ideal situation for regional cooperation for MSFD implementation based on governance drivers

Table 5.4 The ranking of drivers into current, foreseen and ideal situations by survey respondents disaggregated by stakeholder group for the Black Sea

Table 5.5 Mediterranean Sea perspectives about the current, foreseen and ideal situation .....

Table 5.6 North East Atlantic Ocean sectors perspectives about the current, foreseen and the ideal situation

Table 5.7 Baltic Sea respondents' foreseen and the ideal scenarios of regional cooperation in $2020 \ldots . . .121$

Table 5.8 Black Sea respondents' foreseen and the ideal scenarios of regional cooperation in $2020 \ldots \ldots 121$

Table 5.9 Mediterranean Sea respondents' foreseen and the ideal scenarios of regional cooperation in 2020 
Table 5.10 North East Atlantic Sea respondents' foreseen and the ideal scenarios of regional cooperationin 2020

Table 6.1 Phases in participatory decision making processes on sustainability issues 


\section{List of boxes}

Box 1.1 The Aarhus Convention ..................................................................................... 3

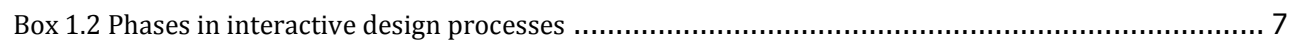

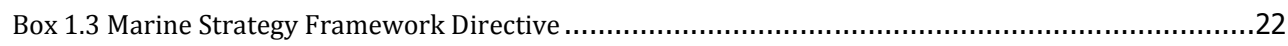

Box 3.1 Best Practices of stakeholder participation. Source: Reed 2008.......................................62

Box 5.1 The five proposed future governance scenarios presented to survey respondents in the online

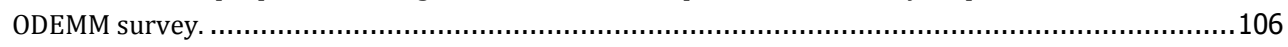

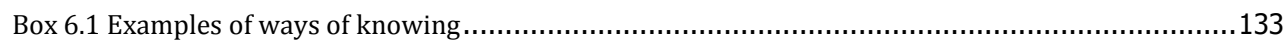




\section{Abbreviations}

CBO Community Based Organisation

CFP Common Fisheries Policy

DG MARE Directorate-General for Maritime Affairs and Fisheries

Eco-san Ecological Sanitation

EBM Ecosystem-Based Management

EEZ Exclusive Economic Zone

eNGO Environmental Non-Governmental Organisation

EU European Union

EU FP7 Seventh framework programme of the European Union

GES Good Environmental Status

INREF Interdisciplinary Research and Education Fund of Wageningen University

IPCC Intergovernmental Platform on Climate Change

MARE Centre for Maritime Research

MCDA Multi Criteria Decision Analysis

MDG Millennium Development Goals

MS Member State

MSs Member States

MSFD Marine Strategy Framework Directive

NEAO North East Atlantic Ocean 
NGO Non-Governmental Organisation

O\&T Opportunities \& Threats

ODEMM Options for Delivering Ecosystem-Based Marine Management

PHAST Participatory Hygiene and Sanitation Transformation

PROACT Problem analysis, Objectives, Alternatives, Consequences, Trade-off

PROVIDE Partnership for Research on Viable Environmental Infrastructure Development in East Africa

RACs Regional Advisory Councils

RSA Regional Sea Assembly

RSC $+\quad$ Regional Sea Convention Plus

SWOT Strength-Weaknesses-Opportunities-Threats

UN United Nations 



\section{Introduction}

\subsection{A Stakeholder Dialogue on Sustainability}

Over the past few decades environmental risks such as climate change, loss of biodiversity, drinking water contamination and air pollution have become more complex and uncertain. Nowadays environmental dangers, such as plastic pollution in marine environments have proven to give rise to worldwide consequences that are difficult to control. Beck (2007: 3-4) stated that "many decisions over major environmental risks do not involve a choice between safe and risky alternatives, but one between different risky alternatives, and often a choice between alternatives whose risks concern qualitatively different dimensions which are barely mutual measurable." As a result, environmental risks are affecting the traditional relations between science, policy-making, private sectors and society. Science, for a long time the reliable source of knowledge production, has been questioned by public and private actors when it comes to the understanding and management of environmental issues. Meanwhile, environmental policy-making processes have been considered inadequate in the absence of a dialogue between all relevant stakeholder groups. Implementation of new policies failed because decisions proved not to be tailored to society's needs, constraints and challenges (Reed 2008; Van Buuren and Hendriksen 2010). Given these challenges, the search for sustainable solutions for environmental risks implies dealing with complexity and uncertainty, calls for new roles for and new relationships between scientists, policy-makers, private sectors and civil society and asks for innovative decision making and implementation strategies. Consequently, the idea of involvement of various stakeholder groups in environmental decision making has become more and more popular.

Looking backwards, participatory decision making became indisputable since the Brundtland Commission published its report 'Our Common Future' (World Commission on Environment and Development 1987) and the concept of sustainable development became widely supported. The Commission defined sustainable development as "development which meets the needs of current generations without compromising the 
ability of future generations to meet their own needs" (World Commission on Environment and Development 1987: 15). This concept became popular around the globe and found an eager audience at the United Nations Conference on Environment and Development in Rio de Janeiro (1992), which resulted in the Rio Declaration and in Local Agenda 21. Bearing in mind several key messages in the Rio Declaration such as "environmental issues are best handled with the participation of all concerned citizens" or "sustainable development requires better scientific understanding of the problems and therefore nations should share knowledge and technologies to achieve the goal of sustainability", the debate on what role scientists, policy-makers, private sectors and society should play in decision making around sustainable development became an urgent and imminent one. This debate is enhanced by Local Agenda 21, simultaneously adopted with the Rio Declaration and contains an appeal to local authorities to engage in a dialogue for sustainable development. Local Agenda 21 stresses, amongst others, the need of individuals, groups and organizations to participate in environmental impact assessment procedures. Since then sustainability and stakeholder participation seem to be connected, especially since a broad range of stakeholders embraced the concept as a way to create societal change while often not having a complete overview of the consequences. A transition towards a sustainable society implies that stakeholders give up certain (world)views, principles and positions; institutions to change their modus operandi; (non) expert knowledge and values to be shared and disseminated; and vested interests to transform their routine practices and behaviour.

Quite some academic, administrative and political effort has been put into trying to find a more precise and equally widely supported definition of sustainable development than the one put forward by the Brundtland Commission, but to no avail. As 'sustainability' in itself does not provide guidelines for operationalisation most stakeholder groups invent their own operationalisation and meaning for this concept. This is where the consensus on 'sustainable development' has started to become fragmented and turned into a tense debate (Bruyninckx 2005; UNECE Aarhus Convention 2001; UNCTED 1992).

After the Earth Summit in Rio, in 2001 the Aarhus Convention established a number of rights of citizens and stakeholders with regard to decision making on sustainability issues. Access to environmental information and participative decision making are at the core of 
this convention (see Box 1.1). The vision behind the Aarhus

Convention is that accurate and easy-to-find environmental information empowers policy and society to take informed decisions that have an impact on the environment. The strength of the Aarhus Convention lies in its binding obligations on public authorities to ensure proper access to environmental information and public participation in decision making procedures within a transparent framework. Similarly, the World Summit on Sustainable Development in South Africa (2002) supported sustainable development as principal guideline for international policy-making. Increasingly, it became clear that decision making on sustainable development deals with the public space of policy-making as well as with the private space of business and personal lifestyles and values. The interaction between those spheres is highly relevant when trying to set up a dialogue on sustainability and to foster participatory decision making.

Participatory decision making is widely seen as a valuable contribution to good governance and successful policy implementation and it may empower local communities (Rondinella et al. 2017). More stakeholder participation is believed to result in better policy-making and especially policy implementation as stakeholders that have been involved are expected to accept the proposed solutions more easily and support the required behavioural changes. This may reverse the widely reported failures in the implementation of policies on complex societal problems, such as those related to sustainability, into successful achievements (Acevedo Guerrero 2018; Howes et al. 2017; Geissel 2009).

While stakeholder participation in decision making on sustainability issues seems to be supported today by many researchers and policy-makers and is no longer ignored in the
The Aarhus Convention (2001) establishes a number of human rights with regard to the environment. On that account the Convention provides for: (1) the right of information that is held by public authorities. (2) the right to participate in environmental decision making. (3) the right to review procedures to challenge public decisions that have been made without respecting the rights about access to environmental information and participative decision making or environmental law in general' (United Nations Economic Commission for Europe, Aarhus Convention, 2001). everyone to receive environmental 
academic literature, it does not mean that it is standard practice around the globe. Moreover, how to involve stakeholders meaningfully in decision making processes is widely disputed. Based on the understanding that stakeholder involvement will be regarded as a prerequisite for decision making on sustainability issues, it remains unclear how preferred options, based on ideas, preferences, values and knowledge from stakeholder groups involved, could be combined and integrated in such decision making processes. Furthermore, it is also not clear what the consequences of participatory decision making are for the positions of science, policy-making, society and the private sector. Meaningful stakeholder involvement needs to deal with the complexity and uncertainty of environmental risks and should find a way to balance these various sources of input in aiming for a sustainable dialogue. Complicating factors are that as a rule decisions on sustainability issues are meant for the longer term, that environmental policy implementations often are costly, that environmental solutions cannot easily be changed and that solutions have severe consequences for multiple stakeholder groups involved. The purpose of this thesis focuses exactly around these questions and dilemmas, and aims to analyse and discuss the challenges and potential of meaningful stakeholder involvement in decision making on sustainability questions. Before operationalizing more precisely the research questions of this thesis, I will review various approaches in the literature on participatory decision making around sustainability issues.

\subsection{Stakeholder Positions in the Field of Decision Making on Sustainability Issues}

Freeman (1984: 4) in his now classic text, defines stakeholders as "any group or individual who can affect or is affected by the achievement of the organization's objectives". When applied to environmental risks and problems this broad definition would mean that anybody can be a stakeholder anytime (Meffe et al. 2002). Identifying stakeholders is usually an iterative process where stakeholders are added as the analysis continues, for example, using expert opinions, focus groups, snowball sampling or a combination of these methods (Reed 2008). Stakeholder identification may be important as a first step in involving stakeholders in decision making on sustainability 
issues, a real challenge appears to be how to organize and assure meaningful participative decision making.

Nowadays, as many argue, environmental knowledge is supposed to be uncertain by definition and policy-making is not an entirely rational process of identifying problems and choosing optimal solutions. More and more, complicated environmental questions are challenging the way scientific knowledge is conducted and disseminated. As a consequence, scientists are often not able to avoid value-laden assumptions and extrapolations in the face of highly uncertain data to answer questions posed by policymakers. Especially in the environmental field there is an increase in public and private resistance about the classical way decision making is organised, principally because environmental issues not only touch on technical components but often as well on a wide range of social, cultural and economic components offering people multiple choices for various levels of (non) collaboration or for (not) using final project outcomes. As a result, environmental knowledge creates space for all stakeholder groups involved to disseminate their views, values, opinions and knowledge about environmental issues constantly (Mielke 2016; Karl et al. 2007; Beck 1992).

The search for meaningful participatory decision making in the complex and uncertain field of environmental risks has identified several classifications for stakeholder involvement (Benn et al. 2009; Reed 2008; Bulkeley and Mol 2003). I elaborate on three partially competing normative schools of thought for stakeholder participation, offering different motives for the inclusion and representation of various stakeholder groups: functionalism, neo-corporatism and democratic pluralism (Nasiritousi et al. 2016; Willetts 2006).

\section{Functionalism}

Functionalism appeals to the rational use of expertise in decision making, hence this school of thought is dominated by the scientific research process. The role of stakeholders is to provide issue-specific, objective and falsifiable information and thus broaden the extent of available information. If non-experts are involved in the decision making process, they are considered a source of data and therefore their role is limited (Mielke et al. 2016). This school of thought seems quick and simple at first sight. Experts 
can use their expertise to come up with independent, result-focused, evidence-based solutions and the structures these experts work within ensure that decisions are reached and implementation is followed even if not everyone agrees with them. Interactive private or public participation is viewed as unnecessary roadblocks to technical progress (Parkins and Mitchell 2005). For a long time this functional expertdriven approach was not brought up for discussion, either in the belief that technical experts are professionals and therefore best placed to communicate the generated knowledge to policy-makers and because politicians believed that they best represent stakeholder interests (Cascetta and Pagliara 2013). Welp et al. (2006) supported the idea that even though science has a critical role to play in meeting the needs of the current and future generations while maintaining the planet's life-support systems in a sustainable way, it may remain a purely academic endeavour with little relevance for society if there is no connection between science, policy-making and the 'real world'. According to Cornell et al. (2013), real-world situations such as climate change, unbalanced ecosystems and overexploitation of natural resources call for a great variety of participatory designs of decision making. This challenges the way science is conducted and how methods and theories are used in scientific knowledge generation, application and dissemination (Mielke et al. 2016; NOAA 2015; Reed 2008). Yet, according to Cornell et al. (2013), to a large extent a school of thought like functionalism, in which science is the main producer of knowledge, is still being deployed for many emerging environmental challenges. Likewise, Brugnach and Ingram (2012) stated that commonly, policy choices hardly reflect the diversity of meaning and interpretations that the inclusion of multiple stakeholder groups could bring and decisions made do often not reflect local conditions and preferences. This hinders the legitimacy and with that the implementation of sustainable solutions.

\section{Neo-Corporatism}

Neo-corporatism differs markedly from functionalism in acknowledging that different interests may be in conflict with each other which has consequences for the role of knowledge, information and distinct perspectives in decision making processes. As a result the focus in neo-corporatist decision making processes is on processes such as multi-stakeholder dialogues and public private partnerships (Willetts 2006). The main 
goal, according to followers of neo-corporatism is to engage stakeholders in a constructive discussion, making use of each other's knowledge, experiences and viewpoints.

Box 1.2 Phases in interactive design processes

Both settings, multi-stakeholder dialogues as well as public private partnerships, facilitate solution-oriented social interaction processes in which various stakeholder groups from private and public sectors are participating. The main difference between multistakeholder dialogues and public private partnerships is that the former focuses on exchange of knowledge and the latter focuses more on implementation following decision making processes. Increasingly, multi-stakeholder dialogues and public private partnerships are being used in decision making strategies because of their potential for Phases in interactive design processes The success of multi-stakeholder dialogues and public private partnerships depends on how exchange and implementation measures among stakeholder groups are designed. Four phases in design processes can be distinguished:

1. Exploring: engaging and understanding the context;

2. Building: clarifying common goals and resources, consolidate agreements, establish structures and plan the future together;

3. Implementing: monitoring, ensure transparency and communication, establish learning mechanisms, create results and celebrate success;

4. Developing further: establishing learning systems and institutionalising.

(Kuenkel, 2019)

effective consensus-building, knowledge-sharing and including different represented interests. During the different phases of these interactive processes (see Box 1.2), the role of interest groups is perceived to represent particular issues/interests that have an important stake in decisions. Therefore it is not only important that conflicts of interests are addressed through procedures that are considered fair by all participating stakeholders, also special attention should be paid to the selection and representation of stakeholder groups, a balance across stakeholder groups, the distribution of tasks 
among various stakeholder groups in the decision making process and the differences in experiences, opinions, values and knowledge of stakeholder groups involved in the decision making processes. Karl et al. (2007) noticed that often decisions are based on a range of values along with the interests of many stakeholder groups. Current institutional frameworks seem to be inadequate to achieve such an integration. Each side seeks to gain an advantage by exploiting whatever scientific and technical uncertainty exists. Therefore, according to Rühli et al. (2017), a monitoring framework should be part of multi-stakeholder dialogues to assess how value is established and distributed among all involved stakeholders. Such a monitoring framework can also provide insight about stakeholder awareness and acceptance of their responsibility for the consequences of their contributions. Lindeboom et al. (2015) add that monitoring can provide significant knowledge on positive and negative impact in the long term. The level of mutual trust, joint decision making and shared responsibility and accountability are seen as key factors that influence the performance of multi-stakeholder dialogues and public private partnerships. (Hueskes et al. 2017; Verweij et al. 2017; Rühli et al. 2017; Stadler 2016; De Schepper et al. 2014).

\section{Democratic Pluralism}

Democratic pluralism, as a school of thought, wants to enhance the representation and empowerment of marginalised societal groups, enabling the inclusion of opinions that would otherwise risk to remain unheard. Therefore a key component of democratic pluralism is to facilitate public dialogues between agencies of private or public governance and those affected by decisions. The broad concept of governance tries to give insight how society organises their decision making processes: who has a voice in making decisions and whose voices are not heard; how are decisions being made; and who is accountable? Democratic pluralism overlaps significantly with participatory and deliberative democracy (Nasiritousi et al. 2016). Public decision making has the ability to become more deliberative when it reflects the results of an equal and open communication process in which participants appeal to reasons that others can accept, rather than money or status (Fung 2006). Deliberation, according to Habermas (1984), builds relationships through dialogue, influences people's choices and decisions towards positive social change and is based on rational arguments in an ideal speech situation. 
However, it is not easy to create an ideal environment in which stakeholders are at the table and feel safe to expose their experiences and viewpoints in the search for the 'best' decision for society. One of the main issues to overcome for followers of democratic pluralism is how to provide access to and inclusion in decision making processes for societal groups, who are usually excluded in these decision making processes. Even when decision making processes are open to the whole community, many participatory structures are exclusive or selective in one way. Besides, social deprivation, lack of information and absence of procedural knowledge and know-how can be important reasons that discourage and disable communities to participate. What are meaningful reasons to try to include the viewpoints of marginalised societal groups? Nasiritousi et al. (2016) mention that these groups have the ability to give a voice to public interest, serve as watchdogs, keep governments accountable and translate complex text of negotiators to understandable perspectives for ordinary people. A common misunderstanding is that grassroots involvement is always progressive, that participation is synonymous with empowerment and leads to a redistribution of social justice. Power inequalities between participants remain and getting to the table is often not enough. The main critique of promoting participation in deliberative decision making and governance is that it serves to hide inevitable inequalities, exclusion and conflict. Even when forums are open to the public and traditionally excluded groups have access to deliberation and decision making, their voices may not be influential because of lacking time, resources, skills, a different style of expression and social capital (Silver et al. 2010).

Functionalism, neo-corporatism and democratic pluralism are offering different perspectives on the inclusion or exclusion of various stakeholder groups in decision making processes on sustainability issues. Access, representation, roles, knowledge and legitimacy of stakeholder groups vary considerably in the approaches of the above mentioned schools of thought. 


\subsection{Dilemmas of Stakeholder Participation in Decision Making Processes on Sustainability Issues}

The ladder of participation (Arnstein 1969), showing the different modes and degrees of stakeholder participation exposes that the extent of stakeholder influence during decision making processes is a crucial factor to the commitment and approval of decisions on sustainability issues by different stakeholder groups. Despite the many claims in favour of stakeholder participation there have been few efforts to monitor and evaluate the impact of stakeholder engagement in (searching for and deciding upon) sustainable solutions. Moreover, reviewing the numerous discussions about stakeholder participation, it can be noticed that there is a great variety of insights in what experts consider as meaningful stakeholder participation (Cottrell et al. 2015; Reed 2008; Fung 2006; Irvin and Stansbury 2004; Alsop and Farrington 1998).

In this research pparticipation is not considered as just an end in itself, but as a means towards sustainable solutions that are perceived as legitimate and thus will be successfully implemented. Hence, a distinction needs to be made between stakeholder participation where different stakeholder groups are provided formal access to decision making processes, and meaningful participation where participation moves beyond formal access and comes with stakeholder inclusion. Inclusion allows stakeholders to jointly generate knowledge and exert influence in phases of the decision making process where different stakeholder groups have relevance. Meaningful participation adds value to the participation of stakeholder groups involved as well as to the quality, legitimacy and output of the decision making process.

Even though many benefits have been claimed regarding stakeholder involvement in decision making on sustainability issues, increased levels of participation are subject to various governance debates. Four stakeholder groups, respectively representing science, policy-making, private sectors and society, are intervening actively in these discussions, and at the same time holding decisive positions in the field of decision making on sustainability issues (Nasiritousi et al. 2016; Silver et al. 2010; Reed 2008; Willetts 2006). Meanwhile it becomes clear that the complexity and uncertainty of environmental challenges require a meaningful stakeholder dialogue in decision making on sustainability issues. 
A number of challenges have been touched upon in the search for meaningful and participatory decision making (Reed 2008; Fung 2006). I elaborate on three challenges described in the literature, which are expected to have a major influence on meaningful stakeholder involvement in decision making processes on sustainability issues. First, often mentioned in debates on participatory governance is that involvement of various groups of stakeholders in decision making on sustainability issues can have considerable complications as their knowledge, experiences, viewpoints and preferences do not automatically synchronize with the most optimal technological and economic solutions from an scientific expert-based point of view. Most stakeholder groups do not have the expertise or complete overview to judge which sustainable innovations in the complex and uncertain field of environmental issues are technologically feasible and/or cost effective for their community. There is often not one single best solution that fits all stakeholder group interests and perspectives equally, as different stakeholder groups vary in resources, preferences and social-cultural practices. However, it does mean that the established procedures with reference to the positions of various stakeholder groups in decision making on sustainability issues need to be carefully reconsidered to give all stakeholder groups involved a meaningful place in the process of knowledge generation and decision making. Therefore, decision making processes on complex environmental issues not only require just more stakeholder involvement, but also new environmental governance practices, strategies and institutional designs to enable meaningful involvements of stakeholders (Mol 2006; Bulkeley and Mol 2003). Hence we are in need of methodologies that give stakeholder groups a justified, meaningful role and position in decision making on sustainability issues. As a consequence, searching for sustainable environmental solutions calls for clear roles for science, policy-making, private sectors and society (Van Buuren and Hendriksen 2010; Reed 2008), and these roles might differ in different stages or phases of a decision making process.

Second, to move knowledge generation from an external source to a source internal to the governance processes -while reflecting the needs of the different stakeholder groups- is critical. Shared knowledge generation between groups of stakeholder representatives is often complicated, fragmented and non-transparent (Pennington 2016; Brugnach and Ingram 2012; Edelenbos et al. 2011). It is worthwhile to examine how during decision making processes knowledge can be generated by a wide group of 
stakeholders and thus becomes a shared knowledge base. According to Hordijk and Baud (2006) amongst others, joint knowledge generation has various advantages. If for example all stakeholder groups involved are considered as co-producers of knowledge, they all have the ability to influence the decisions, which lead to meaningful participation. Knowledge producers will no longer only be seen as outsiders who advise or evaluate complex problems but also as actors who can contribute by providing relevant findings throughout the distinct phases of the decision making process. Another advantage of jointly generating knowledge can be the building of cross-sectoral social relations and the development of boundary-crossing skills, such as the ability to change perspective, to cope with complexity and to synthesize knowledge in a critical and creative way (Hordijk and Baud 2006). Others refer to this as the construction of new knowledge coalitions, sometimes out of classical - and often opposing - knowledge coalitions (Brugnach et al. 2017; Brugnach \& Ingram, 2012; Edelenbos et al. 2011; Feldman et al. 2006; Van Buuren and Edelenbos 2004).

Third, through the active involvement of a diverse group of stakeholders in decision making processes, the traditional emphasis on expert knowledge is now faced with competition from non-expert knowledge. This can easily lead to problems and conflicts of legitimacy in the generation of knowledge that is to be used in policy-making in the complex and uncertain field of sustainability issues (Edelenbos et al. 2011). Legitimacy refers to the acceptance and justification of (shared) decisions by all stakeholder groups involved. A three-dimensional interpretation of legitimacy is adopted: input, throughput and output legitimacy. Input legitimacy concerns whether the decision making process conforms to procedural demands by the people, such as representation of relevant stakeholders meaning to what extent are various stakeholder interests included. Throughput legitimacy consists of governance processes with the people, analysed in terms of process efficacy, accountability which refers to the relationships between different stakeholders involved, transparency, inclusiveness and openness of the decision making processes. Output legitimacy revolves around a degree of effectiveness in achieving goals or the problem solving capacity of a governance system for the people. Input, throughput and output legitimacy are mutually dependent (Schmidt 2013; Bäckstrand et al. 2006; Scharpf 1997). According to Purdy (2012) the legal foundation for collaborative processes is incomplete and raises several questions around input-, 
throughput- and output legitimacy. There is a risk that critical interests may not be represented (input legitimacy), collaborative decision making processes may bias decisions towards participants with greater resources (throughput legitimacy) and decisions made may not be accepted by diverse groups of stakeholders (output legitimacy). As a consequence, legitimacy of participatory decision making processes is under strain.

Hence, meaningful stakeholder participation in decision making on environmental risks is closely connected to the following three dilemmas: (1) the extent of access, representation and inclusion; (2) the ability of joint knowledge generation by various stakeholder groups; and (3) the legitimacy of sustainable solutions. I elaborate on the above mentioned dilemmas in meaningful stakeholder involvement in decision making on sustainability issues.

\section{Dilemma 1: Access to and inclusion in participatory decision making processes}

Once the participatory decision making process has been initiated, several questions emerge how multiple perspectives, expertise and interests from selected stakeholder groups are used, how these different viewpoints are assembled and what the limitations and contributions of each stakeholder group involved are in order to establish a meaningful dialogue. But who is sufficiently equipped to participate in decision making on sustainability issues and to which purpose? Who decides on that and organizes participation? Accessibility to and inclusion in the decision making process is the key issue here. Self-selection through voluntary participation often results in homogeneous groups, represented by participants whose livelihoods or values are strongly affected by the decisions being made, or results in a group of participants who live comfortably enough and often have a high social-economic status and high level of education to allow them to participate regularly, excluding stakeholder groups with less time, money, knowledge resources and information (Silver et al. 2010; Irvin and Stansbury 2004). Especially, since many environmental options can only be implemented successfully if these options are accepted by the majority of stakeholder groups involved and affected, it might be important to entangle a more diverse group of stakeholders in the decision 
making process. Still, the question remains whether it is advisable that everyone has an equal chance to sit at the table at any stage of the decision making process. According to Silver et al. (2010) when searching for sustainable solutions should be seen as a process in which different groups of stakeholders participate, certainly there will be stages in the process in which marginalised groups should have a say in the discussions. But how to make sure that these voices are heard, have an influence and thus become meaningful? Dewulf and Elbers (2018) stated that unbalances in power between different stakeholder groups can result in a range of undesirable consequences in decision making processes as low-power stakeholders may be ignored or over-ruled by more powerful stakeholders. Ounanian et al. (2012) revealed how unequally prepared different stakeholder groups have been when participating in decision making on sustainability issues. There are critical differences in organizational capacity, available resources access to information or power, leading to unequal footing in terms of capacity and capability to participate in and influence decision making.

Several questions emerge regarding to who is in charge to define and decide what a stakeholder or a stake is? Who should get access and be invited to sit at the table and what if 'representatives' sitting at the table do not represent all stakeholders? What if power unbalances are not managed? Who should count as 'legitimately concerned' and who should be able to influence the final decision on that?

\section{Dilemma 2: Joint knowledge generation in decision making processes}

As environmental risks are becoming more complex and uncertain the role of stakeholder groups represented in decision making on sustainability issues is changing as well. There is a wide consensus that expert knowledge is increasingly needed to address today's wicked environmental problems while at the same time the old (functionalist) view of science as the only producer of (valued) knowledge seems to be holding back the successful implementation of sustainable solutions. Observing the ladder of citizen participation (Arnstein 1969) it seems that up to now stakeholder dialogues in both policy decision making and scientific debates mostly resemble the 'informing' and 'consultation' steps of the ladder. Involvement often happens in a one- 
dimensional way in which scientists and policy-makers consider other stakeholder groups as receivers of information with few options provided for feedback and little power for negotiation. Among the most frequently used methods for consulting stakeholders are questionnaires. When the input of citizens' ideas is solely restricted to generating data from questionnaires, stakeholders are perceived as statistical abstractions and participation is measured by how many respondents answered the questionnaire. What stakeholders achieve in all this activity is that they have 'participated in participation' (Bär et al. 2016).

Cottrell et al. (2015) stress that the suggestion 'the more stakeholder involvement the better' should be replaced by creating specific roles for stakeholder groups at different stages in the decision making processes, rather than simply engaging a broad range of stakeholders in all phases of decision making as 'insurance' or in response to programmatic requirements. Since stakeholders are no longer involved in every phase of the decision making process, this means that when multiple stakeholder groups, -all with their different institutional, personal and professional backgrounds, experiences and perspectives- are involved, information and knowledge flows should be transparent, accessible and shared with all relevant stakeholders to support decision making on sustainability issues. However, it is not common practice for scientists to disseminate their findings understandable to the outside world as scientists publish papers that do not reach non-scientists for a number of well-known reasons. Sharing knowledge can be very complicated in participatory decision making processes as a result of unequal footing in terms of accessibility, resources and organizational embedding.

According to Edelenbos et al. (2011) the worlds of decisive stakeholder groups in decision making on sustainability issues are rather different and these differences in perspectives, values and experiences may hinder the knowledge co-production processes. Joint knowledge generation is regarded as an interaction process between different stakeholder groups such as, societal actors, private sectors, policy-makers and (scientific) experts resulting in a common knowledge base, which gives meaning to- and legitimizes decisions taken. Van Buuren and Edelenbos (2004) assume that the main problem of joint knowledge generation is the existence of different and conflicting knowledge networks simultaneously: “Today's knowledge production in complex multi- 
actor settings takes place in separate and closed actor coalitions that declare war on each other: a knowledge management strategy is needed to prevent these knowledge battles." Feldman et al. (2006) introduce the ways of knowing model to understand the structuring of knowledge that is associated with policy issues. They argue that if people from different perspectives get the opportunity to work together and as a result start to appreciate each other's perspectives, the design and implementation of policy improves. In this way, inclusion facilitates deliberation and involves different ways of knowing in the continuous process of problem solving. Van Buuren and Edelenbos (2004) amongst others, propose three conditions to restructure the relationships among knowledge coalitions by (1) composing a new knowledge coalition in which different actors of different knowledge coalitions participate, design and mutually agree on the research agenda; (2) developing a research strategy, guiding principles and common assumptions in mutual interaction and testing the results by all stakeholder groups involved together; (3) starting with an open problem definition and an open policy agenda in order to reach collective agreement about policy options and the underlying argumentation and with that new governance strategies (Brugnach and Ingram, 2012; Edelenbos et al. 2011; Feldman et al. 2006).

Taking into account that decision making on sustainability issues should be dispersed among various stakeholders involved, questions arise such as who decides what happens after the diversity of perspectives have been discussed, recognized and taken into account. Who divides and decides on the different roles and responsibilities that stakeholders play in the distinct stages of a decision making process? Who takes the lead in and enables the formation of a new knowledge coalition where knowledge is jointly constructed? What if stakeholder groups are missing competences that enhance collaboration on joint knowledge generation? To put it more generally, to ensure participatory and meaningful decision making processes, joint knowledge generation is an important condition.

\section{Dilemma 3: Legitimacy of decisions on sustainability issues}

Input-, throughput- and output legitimacy of meaningful and participatory decision making processes are mutual dependent and increasingly under strain. Input legitimacy 
refers to the participatory quality in knowledge coalitions. The main issue is in creating a balanced relationship, in which the voices of those most affected by a decision are not overshadowed by the interests of the most powerful (Blagescu et al. 2005). Often it is implicitly presumed that the way participants exchange information and make decisions during stakeholder dialogues should approximate some deliberative ideal, like participants engaging with one another directly as equals who reason together about public problems (Fung 2006). This means that involving stakeholders in decision making on sustainability issues will be consensus-oriented and closely linked to the acceptance of jointly agreed decisions. As a result meaningful stakeholder participation would increase the legitimacy of decisions taken, reduce the level of conflict and thus would facilitate action and implementation. Yet, when a decision making process starts, resources and power of different stakeholder groups are almost never in balance and unequal footing can be perceived as a real risk. Incentives for stakeholders to participate and collaborate differ and often increase when stakeholders see a direct relationship between their input and tangible results or are interdependent from other stakeholder groups to reach their goals. Whether stakeholders want to cooperate also depends on previous experiences among different stakeholder groups involved (Ansell and Gash 2012). Throughput legitimacy is concerned with the process of decision making. Shirk et al. (2012) suggests that regardless of the context, decisions are influenced by the degree of public participation and by the quality of public participation as negotiated during the process. Therefore, improvement of the quality of decisions on sustainability issues seems to be strongly dependent on - but of course not limited to - the quality of the process that leads to it. Output legitimacy is concerned with the acceptance and justification of decisions made. Hence, the legitimization of environmental solutions is closely connected to the transparency and efficiency of the problem solving capacity of the decision making process. When it comes to the case of decision making on sustainability issues, each individual stakeholder becomes at a certain level a decisionmaker about environmental choices, for instance on waste separation, water and energy use at home or commuting. Concurrently, decision-makers responsible for planning and policy-making need to be well informed to be able to develop strategies adapted to the needs of all stakeholder groups involved. Equally important is that decision-makers justify, explain and communicate their proposed measures already during the process of 
participative decision making to all stakeholders. Reed (2008) noticed that more and more disillusionment has grown amongst stakeholder groups who have felt let down when their claims are not realized. Building trust, accountability and legitimacy are decisive criteria for meaningful and participatory decision making on sustainability issues. But how to ensure scientific accuracy, political legitimacy and meaningful input of all relevant stakeholder groups at the same time?

\subsection{Research Objective and Methodology}

\subsubsection{Research Objective and Questions}

This thesis analyses and discusses the challenges and potentials of meaningful stakeholder participation in decision making on sustainability issues. Searching for sustainable solutions implies dealing with complexity and uncertainty and calls for innovative and meaningful participatory decision making methodologies. Hence we are in need of methodologies that give stakeholder groups involved a justified and meaningful role and position in the process of decision making on sustainability issues. The objective of this research is therefore formulated as follows: "To design, test and evaluate a methodology for participatory and meaningful decision making processes on sustainability issues?"

Three research questions guided the research:

> How to ensure access to and inclusion in participatory decision making on sustainability issues?

> What enables stakeholder groups to jointly generate knowledge in decision making on sustainability issues?

> How can stakeholder involvement contribute to improved legitimacy of sustainability decisions?

\subsubsection{Research Context}

In the search for meaningful stakeholder involvement in decision making on sustainability issues, this thesis strives for analysing and discussing how the preferences from stakeholder groups involved, based on their ideas, values, experiences and knowledge, could be integrated in decision making processes. In this research 
inclusiveness, joint knowledge generation, the changing roles of science, policy-making, public- and private sectors and society and with that the legitimization of decisions made will be explored in relation to participatory decision making processes on sustainability issues.

Two research programmes, in which participatory decision making on sustainability issues has been investigated, designed, tested and evaluated, are the basis of this thesis: (1) the 'Partnership for Research on Viable Environmental Infrastructure Development in East Africa' (PROVIDE) programme; (2) the 'Options for Delivering Ecosystem-Based Marine Management' (ODEMM) in European Seas programme. In both research programmes major shifts in participatory decision making strategies were designed and subsequently investigated.

\section{Partnership for Research on Viable Environmental Infrastructure Development in East Africa (PROVIDE)}

Rapidly growing cities in East Africa face the problem of inadequate sanitation and waste management services. This situation is responsible for frequent incidents of epidemics, adverse environmental loads on natural resources and loss of precious nutrients. These consequences are especially felt by the low-income communities and informal settlements that often comprise more than half of these municipalities. The global significance of this problem prompted the United Nations to include these challenges as one of the Millennium Development Goals. Within the framework of this problem, the 'Partnership for Research on Viable Environmental Infrastructure Development in East Africa' (PROVIDE) programme focused on and contributed to the understanding and improvement of sanitation and solid waste management in informal settlements of municipalities in Kenya, Uganda and Tanzania, with an emphasis on the Lake Victoria Region.

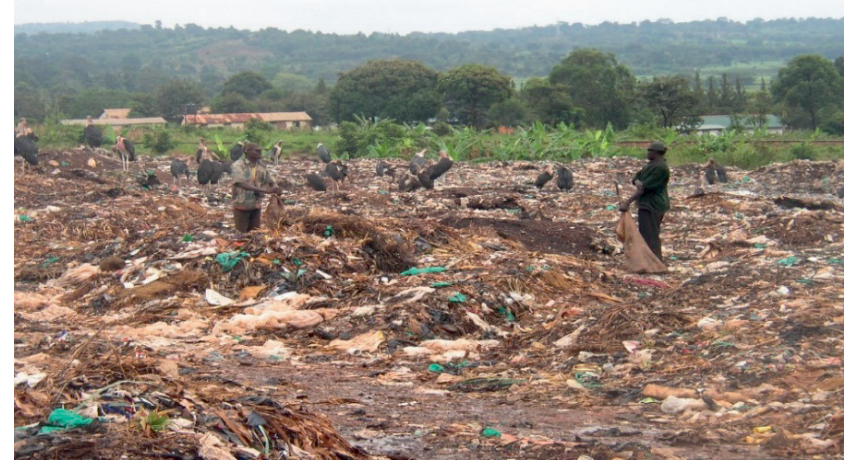

Waste Management Uganda, Photographer Bas van Vliet (2014) 
This academic research programme has been a collaboration between Wageningen University and three universities in East Africa: ARDHI University in Dar es Salaam, Tanzania; Kenyatta University in Nairobi, Kenya; and Makerere University in Kampala, Uganda. The PROVIDE programme brought together international scientists in the fields of environmental policy, development economics, environmental systems analysis and environmental technology. It aimed to develop the knowledge base and the relevant networks for designing and applying an integrated approach for urban waste and sanitation infrastructure challenges, labeled modernized mixtures approach (see Figure $1.1)$.

The modernized mixtures approach (Van Vliet et al. 2010) offers an integrated approach for identifying adequate solutions to environmental problems, such as clean water, environmentally healthy sanitation and waste management that deviates from the largescale, technology intensive, centralized designs on the one hand and from the smallscale, low-tech, decentralized technologies corresponding to the local requirements on the other hand. It combines centralized and decentralized paradigms of infrastructure provision while taking into account the economic, social, governance and technological dimensions of new infrastructures simultaneously developed at different scales in a local context. The aim of developing such an integrated approach is to establish sustainable connections between possible technological solutions and the local context where they are applied.
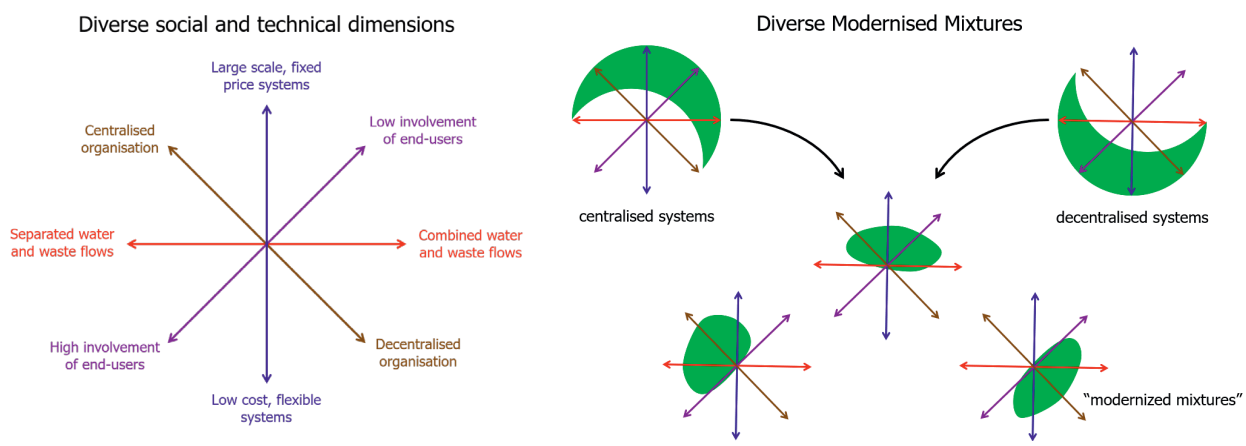

Figure 1.1 Modernized Mixtures Approach 
In order to establish sustainable connections, the modernized mixtures approach has to be complemented by a methodology for bringing, especially, social and cultural dimensions into the design and implementation process as well. Many of these social and cultural characteristics are only to be found among the various specific stakeholder groups related to new sanitation and waste management systems and cannot be standardized. Hence, assessing different socio-technological solutions to sanitation problems on multiple characteristics should allow for a strong stakeholder involvement. Within the framework of the PROVIDE programme, the focus is on the roles of stakeholder groups that design and implement urban sanitation facilities. Accordingly various stakeholders at multiple levels in urban sanitation were the main study objects. Therefore the PROVIDE programme has been closely linked to a wide network of international agencies, national policy-makers, local municipalities, households, NGOs, CBOs and private enterprises.To put it more specifically, how can potential users of sanitation facilities living in urban slum areas be involved in the design and decision making process to realize sustainable sanitation facilities that are of good technical quality and will also be accepted by them because these facilities fit their specific socialeconomic and cultural situation?

\section{Options for Delivering Ecosystem-Based Marine Management (ODEMM)}

Although it is well known that human activities can have a severe impact on marine ecosystems, management of these activities is often fragmented and approaches vary across countries and institutions. In the European Commission funded project Options for Delivering Ecosystem-Based Marine Management (ODEMM) the development of options for alternative governance settings for implementing the Marine Strategy Framework Directive was one of the main questions (see Box 1.3). With regards to stakeholder participation, the ODEMM project focused on: (i) the identification of stakeholder opinions and attitudes when it comes to the creation of governance structures directed towards implementation of the ecosystem approach at the regional level between Member States and within marine eco-regions; (ii) the identification of alternative governance or institutional settings and management options from diverse stakeholder perspectives; (iii) the investigation of legal constraints and opportunities at 
the EU level and within the

Member States for

adaptation of the Marine

Strategy Framework

Directive at the regional

level; (iv) the elaboration of

different scenarios for

changing governance

structures and legislation to

facilitate a gradual transition

from the current fragmented

management approach

towards fully integrated

ecosystem-based

management; and (v) the

assessment of the

acceptability of the proposed

management scenarios and

governance options among

key stakeholder groups.
The Marine Strategy Framework Directive (Directive 2008/56/EC) set out a common framework based on cooperation between European Member States to ensure the sustainable use of marine goods and services by current and future generations. The overall goal of the Marine Strategy Framework Directive has been to promote sustainable use of the four European Seas: the Baltic Sea, the Black Sea, the Mediterranean and the North-East Atlantic Ocean, and to conserve marine ecosystems. It was also stated that each Member State must achieve or maintain Good Environmental Status in the marine environment by 2020 and that the capacity of marine ecosystems to respond to human-induced changes was not compromised on sustainability. Good Environmental Status is defined as: "Environmental status of marine waters where these provide ecologically diverse and dynamic oceans which are clean, healthy and productive within their intrinsic conditions, and the use of the marine environment is at a level that is sustainable, thus safeguarding the potential for uses and activities by current and future generations" (European Commission Marine Strategy Framework Directive, 2008).

Although European Union Member States sharing a marine region should cooperate and coordinate their activities, such as through the use of existing regional institutional cooperation structures, the Marine Strategy Framework Directive itself does not provide any specific legal framework nor specifies governing structures to ensure this. To address this challenge a step-by-step decision making methodology is developed that supports participatory decision making structures for ecosystem-based management in the European seas (Baltic Sea, North Sea, Mediterranean Sea, Black Sea). For this 
purpose, a governance system for ecosystem-based marine management in European seas (ODEMM approach) has been developed that identified key human activities or sectors, ecological components and ecosystem services and the linkages between them, in order to identify the main threats and opportunities to reaching good environmental status (see Figure 1.2).
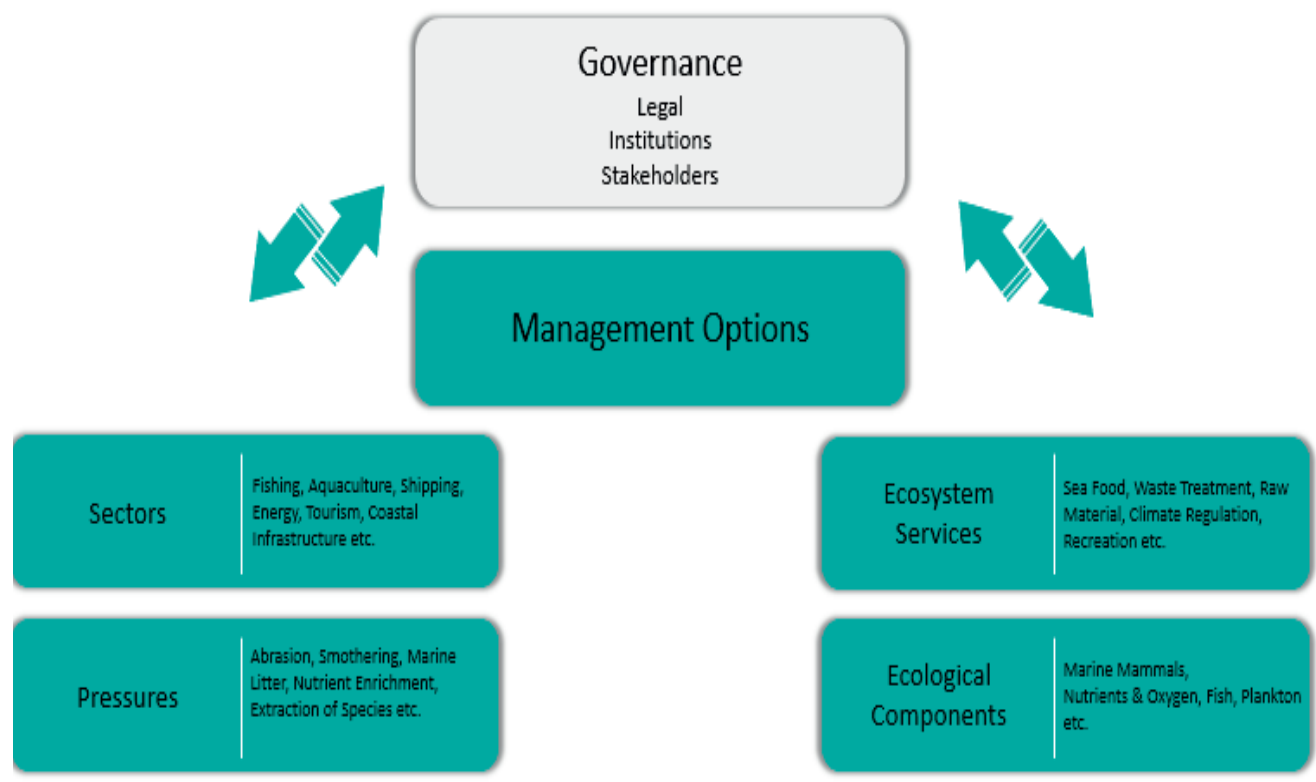

Objectives Biodiversity, Food webs, Seafloor Integrity etc.

Figure 1.2 The ODEMM Approach

Within the ODEMM programme, this thesis contributes especially to the design, analysis and testing of alternative governance models in order to facilitate thinking about the 
options and challenges of stakeholder involvement in decision making processes for the implementation of the Marine Strategy Framework Directive.

\subsubsection{Research Methodology}

\section{Case study research methodology}

This thesis strives to analyse and discuss the challenges and potentials of meaningful stakeholder participation in decision making on sustainability issues in both research programmes PROVIDE and ODEMM in a multiple case study research methodology. This multiple case study analysis is applied to answer the research questions. Yin (2009: 18) defines the case study research methodology as "an empirical inquiry that investigates a contemporary phenomenon within its real-life context, especially when the boundaries between phenomenon and context are not clearly evident and in which multiple sources of evidence are used." Examining meaningful stakeholder involvement in decision making on sustainability issues in the PROVIDE and ODEMM programmes is promising in fulfilling the criteria of a case study research methodology. The cases in the PROVIDE and the ODEMM programmes focus on real-life cases, consist of multiple levels and components of stakeholder involvement in decision making on sustainability issues and gain credibility by thoroughly triangulating the descriptions and interpretations, not just in a single step but continuously throughout the period of study.

\section{Case selection}

Three characteristics were vital for the selection of the case studies in the PROVIDE and ODEMM programmes: (1) the focus should be on sustainable solutions designed in a decision making process with the intention to have meaningful stakeholder participation; (2) access to decisive stakeholder groups involved, throughout a whole decision making process on sustainability issues should be possible; (3) the possibility of data triangulation should be ensured. The selected cases in the PROVIDE programme and in the ODEMM programme have met the above mentioned characteristics.

The ODEMM programme covers four comparative cases in marine management. Each case represents a regional European Sea: the Baltic Sea, the Black Sea, the Mediterranean Sea and the North-East-Atlantic Ocean. Every regional sea needs to 
implement the Marine Strategy Framework Directive, based on the specific needs and challenges identified for its own waters. All case studies followed similar field procedures and general rules, data collection and analysis protocols. A step by step methodology is designed, tailored to the decision making context, considering the objectives, type of participation and appropriate level of engagement for all four cases.

The PROVIDE programme includes the case of Katanga village, one of the major informal settlements in Kampala, Uganda where the majority of the urban poor is accommodated. Among the multiple problems related to poverty, sanitation is one of the most prevalent ones. Previous efforts to improve the sanitation situation in Katanga village have not resulted in sustainable solutions. Although the case itself is not comparable with the ODEMM cases, the case study protocol is largely similar. For the Katanga case too, a participatory decision making methodology is designed, tailored to the decision making context and combining technical and social dimensions that fit the local context.

The five cases provide the empirical testing ground to answer the research questions. Conclusions are based on the results of the cases. The objective of this research: To design, test and evaluate a methodology for participatory and meaningful decision making process on sustainability issues?" is at the core of each case study. The research is guided by three sub-questions. To answer these sub-research questions in-depth analyses for each case have been carried out and with that strengthen the internal validity (section 1.4.5). A schematic representation of the case study research design is provided in Figure 1.3. 


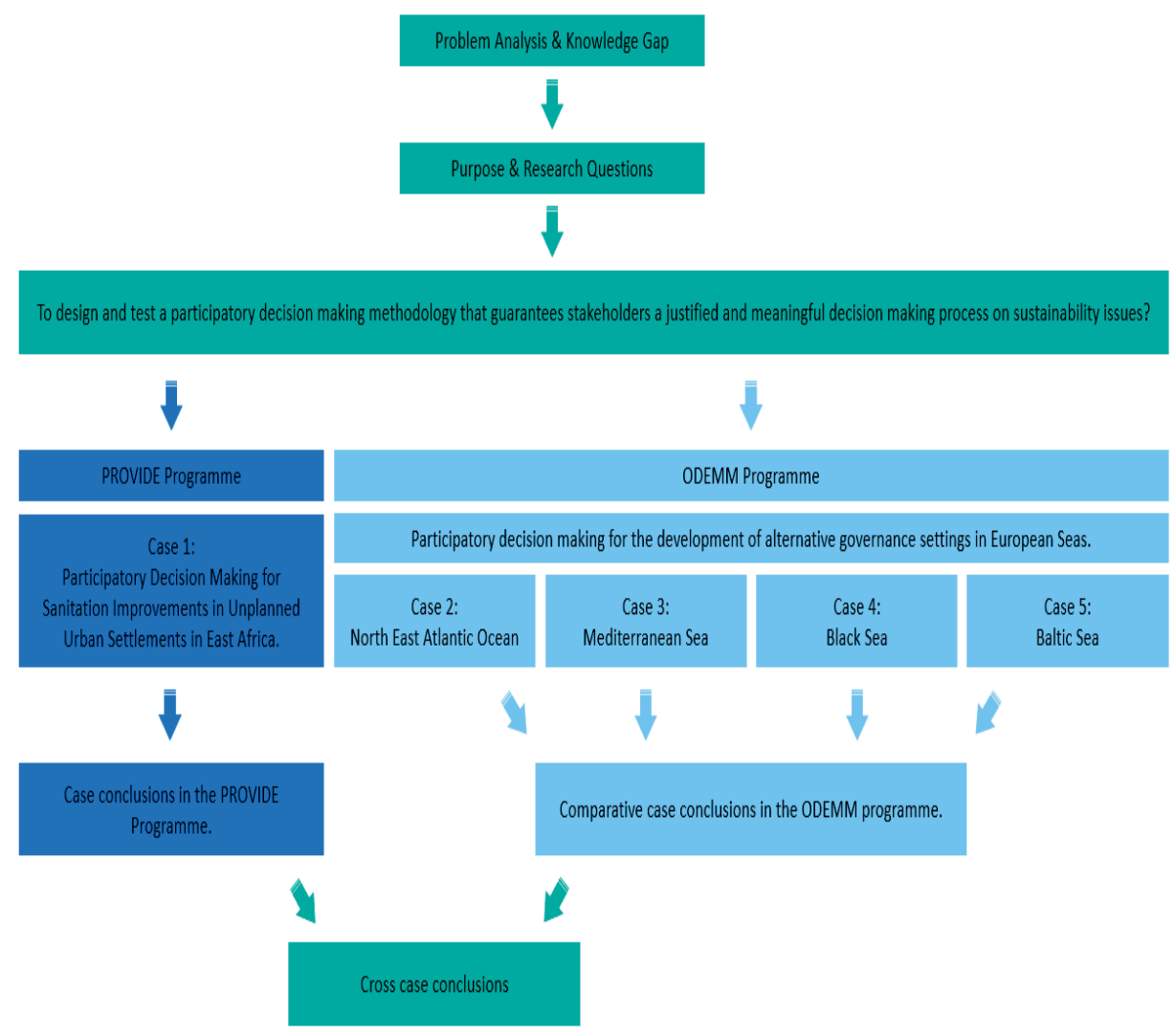

Figure 1.3 Research design of the thesis

\subsubsection{Data Collection}

Case study research seeks to achieve complex and full explanations of phenomena. As the object of study in this research is the participatory decision making process on sustainability issues, the case study aims to understand participatory decision making as a whole, examining amongst others the process by which the decisions were made, the selection and the roles of stakeholders involved and the legitimization of the decisions. In this thesis along with a literature and document review, quantitative and qualitative methods of data collection are selected and tailored to the participatory decision making context. This fits the case study approach as understanding a case often requires going beyond countable aspects and trends, combine data sources and apply data triangulation. Figure 1.4 gives an overview of the different methods of data collection in the PROVIDE case and in the ODEMM cases. 
Methods of data collection in the PROVIDE programme

Literature and document review to identify various stakeholder groups living in urban slums in East Africa.

Multi-Criteria-Decision-Analysis with a group of 50 inhabitants of Katanga slum, to set criteria for decision-making on alternative sanitary solutions by all stakeholders involved. In the final stage of the decision-making process, the scores on the criteria are combined for each alternative to derive their overall value and with that the best alternative can be determined.

12 semi-structured expert interviews to gain knowledge from various experts for feasible sanitary options in a specific context.

Participant observations during meetings with various groups of stakeholders in different phases of the decision-making process are part of the research in each case-study.

Focus groups, where all representatives are invited to formulate the problem analysis and assess the consequences of various options thoroughly resulting in sanitation improvements.
Methods of data collection in the ODEMM programme

Literature and document review to identify the institutional setting of the Marine Strategy Framework Directive.

650 Questionnaires, across 18 European and 5 non-European countries that surrounded the Baltic Sea, Black Sea, Mediterranean Sea and the North East Atlantic Ocean have been sent to obtain an overview of opinions and views from the main marine sectors.

(see Appendix 1)

5 explorative scenarios are developed and tested in the questionnaire (See Appendix 1). The testing of possible and feasible future options for cooperation at the different European regional seas from a stakeholder's point of view was useful to elaborate on alternative future governance models.

(see Appendix 2)

50 semi-structured expert interviews to gain knowledge from various experts for driving forces with an impact on regional cooperation in implementing the Marine Strategy Framework Directive.

Participant observations during meetings with various groups of stakeholders in different phases of the decision-making process are part of the research in each case-study.

Focus groups, where all representatives are invited to assess various options thoroughly and come up with new ideas resulting in alternative governance options.

Figure 1.4 Overview of data collection methods 


\subsubsection{Validity and Reliability}

\section{Validity}

In this research, an answer to the research questions is obtained by designing a multiple case study research strategy. Internal validity is the extent to which the structure of a research design enables us to draw unambiguous conclusions from our results. External validity refers to the extent to which results from a study can be generalised beyond the particular study. In a case study design internal validity is crucial and key concepts are triangulation and credibility. Triangulation of data collection methods, such as expert interviews, questionnaires, participative observation, focus groups, round table discussions and document analysis, are required to obtain valid data in a case study design and have for this reason been part of this research. The same processes could be analysed and understood from different sources (Denzin and Lincoln 2005).

Both the PROVIDE and the ODEMM case studies consist of different stages. Every stage is built on data collection and analysis of the previous stage and after every round of data collection workshops have been organised for the different stakeholder groups involved to disseminate and validate the acquired knowledge. To assure internal validity, triangulation of data and triangulation of researchers have been applied. The results of the data analysis have been shared and validated with various stakeholder groups involved during the decision making process on sustainability issues. The preliminary findings have been presented to scientific audiences during PROVIDE ${ }^{1}$, INREF², ODEMM and MARE workshops and conferences. The four empirical chapters have been published in international peer reviewed journals.

While internal validity in case study design is essential, external validity is often complicated and limited. External validity refers to the degree to which the results can

\footnotetext{
1 Presentation PROACT in PROVIDE workshop, Kampala, Uganda 2008: 7-8 July; 2009: 22-24 June. Presentation PROACT in PROVIDE workshop Arusha, Tanzania 2008: 6-9 October.

2 Workshop PROACT on sanitation and solid waste management, Ho Chi Minh City, Vietnam, 2007: 11-12 September. Presentation PROACT, INREF conference, Wageningen, The Netherlands, 2012: 23 April. Presentation PROACT, International Conference: Technological and Management Solutions for Climate Change Adaptation. Opportunities and Challenges to Asian Countries, Van Lang University, Ho Chi Minh City, Vietnam, 2015: 24 April.
} 
be statistically and theoretically generalised or transferred to other contexts or settings. The critical question is whether the results are likely to apply more widely (Denzin and Lincoln 2005). De Vaus (2009) stated that collecting and analysing data from case studies must have a theoretical dimension to add value for wider generalisation. One way of using theory in designing case studies is the theory building approach. In this approach, the research starts with questioning real life cases and ending up with a first step to theoretical dimensions or a set of propositions as a result of examining actual cases. Based on the search for meaningful participatory decision making in the complex and uncertain field of environmental risks, a multiple and comparative case study has been carried out with the aim to formulate a set of substantiated requirements for a participatory decision making methodology that guarantees stakeholders a justified and meaningful decision making process on sustainability issues. In the concluding chapter of this thesis I will argue under what circumstances the case study results can be applied to other decision making processes on sustainability issues as well.

\section{Reliability}

Reliability refers to the degree to which the findings of a study are independent of accidental circumstances of their production. According to Silverman (2009) reliability deals with replicability, the question of whether or not future researchers could repeat the research and come up with the same results, interpretations and claims. Denzin and Lincoln (2005) added that reliability is concerned with whether the same results, if investigated the same thing twice, would be obtained. During all phases of this research extensive, transparent and detailed records such as interview transcripts, driving forces for scenarios, questionnaire set up, potential governance models and round table discussion formats, have been saved and shared with the wider audience within and beyond both research programmes PROVIDE and ODEMM. In this way, in this research I ensured reliability of the research results.

\subsection{Thesis Outline}

This thesis consists of six chapters and is presented in a publication-based format which means that the chapters $2,3,4$ and 5 are separately written as scientific papers, all four published in international scientific peer reviewed journals. Besides, the concept of 
meaningful stakeholder participation in decision making on sustainability issues as well as the purpose, research questions, research design and research strategy have been explored in this introduction chapter. The final chapter draws conclusions on the research questions.

Chapter 2 intends to contribute to substantial improvements in participatory decision making on sustainability issues in the field of sanitation in unplanned settlements in East Africa. Solving the problems of inadequate access to sanitation in these urban slums needs a decision making framework that connects knowledge, values, experiences and preferences from experts and policy-makers with those of the end users. To put it more specifically, how can potential users of sanitation facilities living in urban slums be involved in the design and decision making process to realize sanitation facilities that will be accepted by all stakeholders involved because these facilities fit the specific technical, social-economic and cultural situation. This chapter studies the design and testing of a participatory sustainable decision making framework that provides all stakeholders with a justified role and position in planning and decision making on sanitation.

Chapter 3, 4 and 5 are expanding on the search for meaningful stakeholder involvement in decision making on sustainability issues by examining new roles and relationships for stakeholder involvement in marine governance. To address this challenge, alternative governance models are developed to facilitate thinking about the options of stakeholder involvement and regional collaboration for the implementation of the Marine Strategy Framework Directive. The following chapters study the development and assessment of these alternative governance models.

Chapter 3 examines a layered methodology, including literature and document analysis, expert interviews, questionnaires, scenario building and testing, focus groups and roundtable discussions, to develop alternative governance settings for future ecosystem-based models at the regional seas.

Chapter 4 makes a more profound attempt to support stakeholders in the decision making process to explore the full range of possibilities that exists for the development of these alternative governance models. 
Chapter 5 presents the results of a survey covering four European Regional Seas aimed to collect stakeholders' views and preferences for future alternative governance structures implemented under the Marine Strategy Framework Directive.

The final chapter answers the research questions, synthesises the overall findings and reflects on the contribution of this research. 


\section{Participatory Decision Making for Sanitation Improvements in Unplanned Urban Settlements in East Africa ${ }^{3}$}

\subsection{Abstract}

Solving the problem of inadequate access to sanitation in unplanned settlements in East Africa needs to combine social and technical dimensions in such a manner that they fit the local context. The modernized mixtures approach offers an analytical framework for identifying such solutions, but this approach requires effective methods for participatory decision making. This article intends to contribute to filling this gap by identifying and further elaborating an appropriate multi criteria decision analysis tool. The multi criteria decision analysis methodology, Proact 2.0, offers an adequate solution as it creates the possibility to connect knowledge, experiences, and preferences from scientists, experts, and policy-makers with those of the end users. We show in particular that users not always prefer the most optimal sanitation system, defined from an 'expert' point of view. This article concludes that using Proact 2.0 can lead to substantial improvements in decision making in the field of sanitation in unplanned settlements in East Africa.

\subsection{Introduction}

The United Nations declared 2008 to be the international year of sanitation by explaining,

\footnotetext{
3 This chapter has been published as: Hendriksen, A., T.J. Tukahirwa, P.J.M. Oosterveer, A.P.J. Mol (2012). Participatory Decision Making for Sanitation Improvements in Unplanned Urban Settlements in East Africa. Journal of Environment \& Development 21(1) 98-119.
} 
"Improving sanitation represents one of the best options to really accelerate health, social, and economic development. Sanitation is not the topic of the Millennium Development Goals (MDG) or of the International Year of Sanitation because it is a problem, but because it is a solution and yet sustainable solutions for dense urban slums remain elusive. (United Nations, 2008).”

Today more than 2.6 billion people still lack access to adequate sanitation facilities. At current rates of progress, the world will not achieve the Millennium Development Goal sanitation target: "Halve, by 2015, the proportion of people without sustainable access to safe drinking water and basic sanitation," which equals a reduction by almost 1.4 billion people. However, realizing this MDG does not mean the end of the sanitation challenge. Even then some 1.4 billion people will still not have access to improved sanitation facilities (WHO/UNICEF 2010). Moreover, in less than 30 years, these numbers are set to double because of the rapid urbanization (United Nations 2005).

Poor sanitation and solid waste management are among the key factors not only affecting the health of urban dwellers but also contributing to high poverty levels in developing countries. The worldwide focus on sanitation generated by the UN's year of sanitation has definitely led to increased attention for making sanitation facilities available to the urban poor. However, the challenge does not merely lie in the quantitative expansion of sanitation facilities in slum areas. It does also lie in ensuring that these facilities fit the conditions of the slums. In the past, too often newly constructed sanitation facilities were ignored by the urban poor, the potential users, because they did not fit their daily lifestyles, their religious beliefs, their cultural habits or their economic capacity. Filling the sanitation gap is therefore not only a matter of constructing more toilets, water points, and sewerage systems but also to make sure these infrastructures fit with the practices, concerns and capacities of their users (Black and Fawcett 2008; Isunju, Schwartz, Schouten, Johnson and van Dijk 2011; Schouten and Mathenge 2010; Lenton, Wright and Lewis 2005).

Hence, both the technical and the socio-economic dimensions of sanitation solutions need to fit the local context. The modernized mixtures approach (Oosterveer and Spaargaren 2010; Scheinberg and Mol 2010; Spaargaren, Oosterveer, van Buuren and Mol 2006; Scheinberg, Spies, Simpson and Mol 2011) offers an analytical framework for 
identifying and designing infrastructure solutions (among which sanitation) that are adapted to the specific local contexts, through more flexible combinations of sociotechnical system elements at multiple levels of scale. It is not the characteristics of the technical (sanitation) system that are the starting point; the characteristics of both the social contexts and technical systems themselves are combined in an optimal way. This is why the modernized mixtures approach differs from the modern, grid-based centralized systems in the developed world as well as from decentralized on-site systems that are common in developing countries. Hence, the modernized mixtures approach represents a new paradigm that helps us to overcome conventional dichotomies in system design, such as those between large- and small-scale systems, advanced and low technological systems, centralized and decentralized systems, and consumer exclusion and involvement (Spaargaren et al. 2006). This is attractive when designing a sanitary system in unplanned settlements (van Buuren 2010), where sanitation systems have to be adapted and designed to fit specific local circumstances and context, instead of implementing existing ill-fitting turnkey systems. To do so, however, the modernized mixture framework has to be complemented by approaches and tools for bringing, especially, social characteristics and dimensions into the design and implementation process as well. Many of these characteristics are only to be found among the multiple specific stakeholders related to new sanitation systems and cannot be standardized. Hence, assessing different socio-technological solutions to sanitation problems on multiple criteria should allow for the active involvement of different stakeholders.

This article therefore aims to contribute to the further operationalization of the modernized mixtures approach by developing and testing a multi criteria decision analysis method with a strong user involvement to close the gap between technological innovation and user acceptance. To put it more specifically, how can potential users of sanitation facilities living in urban slum areas be involved in the design and decision making process to realize sanitation facilities that are of good technical quality and will also be accepted by them because these facilities fit their specific social-economic and cultural situation? 
With this objective, this article starts by further developing the argument that user acceptance of sanitation facilities is fundamental to achieve a sustainable impact, which makes a participatory decision making methodology an essential component of the system of design and implementation. The section on participatory decision making methods reviews different participatory multi criteria decision making methods and then identifies and, furthermore, revises a method that may be expected to offer promising perspectives for concrete application. The next section reports on the testing of this method, Proact 2.0, in the practical conditions of Katanga, a slum area in Kampala, the capital of Uganda. Finally, we conclude on the perspectives of Proact 2.0 as a participatory multi criteria decision making tool to identify sustainable sanitation facilities that bridge the gap between technological optimization, financial limitations, environmental conditions, and user acceptance.

\subsection{Stakeholder Involvement in the Modernized Mixtures Approach}

Lack of sanitation is among the main causes of health problems among urban dwellers in African cities and is widely considered to contribute to poverty (Tukahirwa, Mol, and Oosterveer 2010, 2011). Hence, for many years, initiatives from a variety of local, national, and global actors have been taken to increase levels of access to sanitation in the poorer urban communities in African cities. In recent years, following the emphasis on sustainability, a number of innovative sanitation alternatives, the eco-san toilet being the most recent one, have been installed by technological experts, often following initiatives from NGOs and CBOs. Yet increasingly there are indications that the urban poor tend to ignore these innovative sanitation systems, blaming NGOs and CBOs and other sanitation promoters for being led by their own ideas and agendas instead of solving the concrete problems of the urban poor. This resulted in many failed initiatives aimed at the introduction of eco-san toilet systems (see Kaggwa, Kiwanuka, Okurut Okia, Bagambe and Kanyesigye 2003). Such results reflect a broader tradition, where sanitation facilities were identified and implemented on the basis of expert assessments, ignoring the users' perspectives and the local social conditions (Pahl-Wostl 2002). Such 'expert-based' or 'expert-led' approaches stress the importance of sanitation optimization from a technological and/or economic point of view and result in a one- 
directional flow of recommendations from experts to governmental and NGO/CBO decision-makers. Hence, sanitation solutions are often defined by experts and imposed on local communities, although these communities may not necessarily perceive the solutions as beneficial as the experts for social, cultural, or even economic reasons. It has been widely recognized, but not yet widely applied in practice, that decision making on sanitation improvements for the urban poor should involve community members; that is, households that are the ultimate users of proposed sanitation solutions. The consequence of this is quite radical: Recognizing the importance of user and stakeholder involvement means that technological optimization can no longer be the dominant criterion in decision making and a trade-off between public acceptance and technical quality (Beierle 2002) may be necessary. Hence, more varied and flexible responses to the present sanitation challenges are required, particularly in the context of African cities where financial resources are limited and the pressure for finding rapid solutions are high.

The modernized mixtures approach (Oosterveer and Spaargaren 2010; Spaargaren et al. 2006; Scheinberg and Mol 2010) offers a conceptual framework for identifying more adequate solutions to the current sanitation problems in the context of urban Africa. This approach is developed to identify sustainable urban environmental infrastructures by combining various levels of scale with different degrees of involvement of end users, of separation or mixture of water and waste flows, of level of technological advancement, and of centralization of infrastructure and decision making, all to establish better connections between the possible infrastructural solutions and the social-economic context where they are applied (Oosterveer and Spaargaren 2010). For this, the modernized mixtures approach argues for the inclusion and integration of technical and social scientific knowledge when designing sanitary solutions in specific settings. Hence, views and contributions from experts, decision-makers, and end users need to be included and combined into (hybrid) solutions. The rationale behind this approach is the need for creating a 'fit' between different potential sanitation options and the prevailing (perceived) socio-economic, ecological, and technological circumstances. Involved users are invited to identify preferred sanitation solutions among those that are realistically (i.e., technologically and economically) feasible in their particular user-context. This implies that each community may identify a specific 
sanitation solution, as the specific user-context may differ. Using this modernized mixtures framework means, therefore, promoting a modular approach to sanitation problems rather than aiming for a one-size-fits-all solution.

The modernized mixtures approach has determined three key criteria to design and assess adequate sanitation solutions, including ecological sustainability, accessibility (particularly of the poor), and technological flexibility (Van Vliet, Spaargaren and Oosterveer 2010). Ecological sustainability refers to the environmental profile of sanitation solutions, in terms of minimizing pollution (e.g., waste), minimizing natural resource use (e.g., water), and reusing valuable resources (nutrients). Accessibility relates to the extent to which all households in poor communities can make use of sanitary infrastructures and are not prevented from doing so for financial, physical, or socio-cultural reasons. Technological flexibility points at how sanitation systems function and 'behave' in times of economic, political, and climatic variability, extremes, and instability. Although entailing a promise for designing more sustainable sanitation systems, the modernized mixtures approach is in need of further elaboration particularly on how stakeholders can participate in designing and assessing sanitation options and systems in concrete situations. Hence, we need to extent this modernized mixtures framework with a methodology of participatory decision making on sanitation.

\subsection{Participatory Decision Making Methods}

Nowadays, stakeholder support is recognized as essential for successful implementation of many (environmental) policies and programs. Since Arnstein described the 'ladder of participation' in 1969, it is known that significant degrees exist in stakeholder involvement and participation and that the extent of their influence during decision making processes is a crucial factor in determining their future stakeholder (Arnstein 1969, Beierle 2002; Jonsson, Andersson, Alkan-Olsson and Arnheimer 2007; Kasemir, Jäger, Jaeger and Gardner 2003). This general argument is not different for sanitation policies and programs. Also in sanitation knowledge, experiences and ideas of specialists and official decision-makers should be coalesced with those of the community, the users, who are affected by sanitation system (Addo-Yobo and Njiru 2006; Irvin and Stansbury 2004; Jonsson 2005; Kasemir et al. 2003). This means that the focus of experts in 
sanitation policy-making has to change from a pre-occupation with only scientific expertise to one with wider contributions to accommodate the needs and demands of different stakeholder groups. At the same time, involving local community members in sanitation planning need further elaboration. The main problem is that involvement of end users in decision making processes can add considerable complications, as their knowledge experiences and preferences do not automatically synchronize with the most optimal sanitation solution(s) from an 'expert-based' (technological-economic) view. Most users do not have the expertise to judge which innovations in sanitation are technologically feasible for their community. In addition, there is not one single best sanitation solution that fits all stakeholder groups equally, as they often differ in economic means, social preferences, and cultural practices. Hence, end users are often portrayed as incapable of overseeing the full complexity of technical innovations and as providing their input only on the basis of private interests (Devas and Grant 2003; Williams et al. 2001). Recognizing the importance of incorporating an end user perspective in decision making on sanitary infrastructures should not make us naive regarding the capacity and capabilities of end user to (co-)decide in such processes. However, it does mean that the established procedures need to be carefully reconsidered to give end users a place in the process of planning and decision making.

Hence, we are in need of methodologies that give experts and local stakeholders a justified role and position in planning and decision making on sanitation.

\subsection{Participatory Sanitation Planning Tools}

Over the last decades, many participatory decision making tools have been developed, some specifically for sanitation policy but many others destined for more general use in environmental decision making. Netssaf (2008) provides the most encompassing recent overview of various frameworks for participatory planning tools in the domain of sanitation. Table 2.1 presents the summary of this inventory and shows that these tools all divide the planning process in a different number of phases. 
Participatory Sanitation Planning Tools

\begin{tabular}{|c|c|c|c|c|}
\hline PHAST & $\begin{array}{l}\text { Open planning of } \\
\text { sanitation systems }\end{array}$ & $\begin{array}{l}\text { Household centered } \\
\text { environmental } \\
\text { sanitation planning } \\
\text { approach }\end{array}$ & Sanitation 2I & $\begin{array}{c}\text { Multi criteria } \\
\text { decision analysis } \\
\text { systems }\end{array}$ \\
\hline \multicolumn{5}{|l|}{ Phases } \\
\hline $\begin{array}{l}\text { Problem } \\
\text { identification }\end{array}$ & $\begin{array}{l}\text { Problem } \\
\text { identification }\end{array}$ & $\begin{array}{l}\text { Request for } \\
\text { assistance }\end{array}$ & $\begin{array}{l}\text { Institutional } \\
\text { mapping }\end{array}$ & $\begin{array}{l}\text { Problem definition, } \\
\text { goals and } \\
\text { objectives }\end{array}$ \\
\hline Problem analysis & $\begin{array}{l}\text { Identification } \\
\text { of boundary } \\
\text { conditions }\end{array}$ & $\begin{array}{l}\text { Launch of the } \\
\text { planning and } \\
\text { consultancy } \\
\text { process }\end{array}$ & $\begin{array}{l}\text { Interests/ } \\
\text { objectives }\end{array}$ & $\begin{array}{l}\text { Definition of } \\
\text { criteria }\end{array}$ \\
\hline $\begin{array}{l}\text { Planning for } \\
\text { solutions }\end{array}$ & $\begin{array}{l}\text { Terms of } \\
\text { requirement }\end{array}$ & $\begin{array}{l}\text { Assessment of the } \\
\text { current status }\end{array}$ & $\begin{array}{l}\text { External } \\
\text { factors }\end{array}$ & $\begin{array}{l}\text { Definition of } \\
\text { alternatives }\end{array}$ \\
\hline Selecting options & $\begin{array}{l}\text { Analysis of possible } \\
\text { solutions }\end{array}$ & $\begin{array}{l}\text { Assessment of user } \\
\text { priorities }\end{array}$ & Capacity & $\begin{array}{l}\text { Definition of } \\
\text { preferences }\end{array}$ \\
\hline $\begin{array}{l}\text { Planning for new } \\
\text { facilities and } \\
\text { behavior change }\end{array}$ & $\begin{array}{l}\text { Choice of the most } \\
\text { appropriate } \\
\text { solution }\end{array}$ & $\begin{array}{l}\text { Identification of } \\
\text { options }\end{array}$ & $\begin{array}{l}\text { Sanitation } \\
\text { elements }\end{array}$ & Decision making \\
\hline $\begin{array}{l}\text { Planning for } \\
\text { monitor and } \\
\text { evaluation }\end{array}$ & & $\begin{array}{l}\text { Evaluation of } \\
\text { feasible service } \\
\text { combinations }\end{array}$ & Management & \\
\hline \multirow[t]{4}{*}{$\begin{array}{c}\text { Participatory } \\
\text { evaluation }\end{array}$} & & $\begin{array}{l}\text { Consolidated plans } \\
\text { for study area }\end{array}$ & evaluation & \\
\hline & & $\begin{array}{l}\text { Finalizing of } \mid \\
\quad \text { consolidated plans }\end{array}$ & & \\
\hline & & $\begin{array}{l}\text { Monitoring, } \\
\text { evaluation, and } \\
\text { feedback }\end{array}$ & & \\
\hline & & Implementation & & \\
\hline
\end{tabular}

Source: Netssaf (2008).

Note: PHAST $=$ participatory hygiene and sanitation transformation.

The different participatory sanitation planning tools with multiple stakeholder involvement as presented in Table 1 all have their specific characteristics and focus. The Participatory Hygiene and Sanitation Transformation (PHAST) approach is designed to promote hygienic behavior, sanitation improvements, and community management of water and sanitation facilities, building on people's ability to address and resolve their own problems. Decision making with PHAST is, among other things, based on the 
principles that "those who create decisions will be committed to follow them through" and "every community understands its own situation best." Community involvement is believed to result in higher levels of effectiveness and sustainability than could be expected from externally imposed solutions (WHO and UNDP/World bank Water and Sanitation Program 2000). The PHAST approach relies heavily on extension workers, who organize workshops for the community and guide community members through the different steps of the sanitation planning process. Although the focus is on hygienic behavioral change, this approach also stimulates improvements in the sanitary conditions of these communities by encouraging them to set up their own systems for monitoring community behavior based on the criteria they identified themselves.

What the PHAST approach has in common with the open planning of sanitation systems and the household-centered environmental sanitation planning approach is a stakeholder analysis, which is included in the first phase of problem identification. All three approaches emphasize that the probability of success will increase if the users are seen as participants in the planning process and therefore they need to be involved right from the start. All three approaches claim that involving the users of sanitation facilities in every step of the planning process is essential for a successful end result. During the Terms of Requirements phase in the Open Planning of Sanitation Systems approach, a distinction is made between primary and practical functions. Primary functions can be environmental protection or resource conservation and practical functions can relate to reliability and affordability. After identifying the criteria for these two functions, at least three alternative solutions should be compared before a final choice for a particular sanitation system can be made by all stakeholders (Schönning and Stenström 2004). The household-centered environmental sanitation planning approach combines PHAST and the Open Planning Sanitation Systems in a 10-step planning process.

Sanitation 21 aims at closing the gap between households and urban sanitation systems. The focus of this decision making tool is an analysis of the different technical options that are relevant within a sanitation system that covers all levels of the urbanized area, including households, neighborhoods, districts, the city, and beyond. Multi criteria decision analysis (MCDA) constitutes an approach that is nowadays used in environmental projects to support multiple stakeholder involvement. It provides an 
ordering of alternatives -from the most preferred to the least preferred ones- based on different technological, economic, social, and ecological criteria. The involvement of multiple stakeholders is crucial in MCDA, but it can be organized in different ways, such as focus group meetings, workshops, interviews, or surveys. This methodology is widely applied during participatory decision making processes on complex problems (Chowdhury and Rahman 2008). MCDA methods aim at supporting complex decision making processes by providing a framework for collecting, storing, and processing all relevant information from experts and end users. The core of the MCDA method is a decision making model, which is a formal specification of how to combine different kinds of information to reach a shared solution (Lahdelma, Salminen and Hokkanen 2000).

A MCDA methodology can be -and has been- used to identify a single most preferred option, to rank different options or to distinguish acceptable options from unacceptable ones (Nigim, Munier and Green 2004). Compared with conventional decision making and different alternative participatory decision making tools, the advantage of using the MCDA methodology is its contribution to increased transparency in judging and deciding on alternatives, to enhanced stakeholder participation, and to better optimized solutions by applying and combining several criteria in the decision making process. The method is also easily adaptable to specific local conditions (Netssaf 2008). Another advantage of the MCDA methodology is the possibility to connect expert-knowledge, knowledge of authorities, and user-knowledge to make a decision that is most likely acceptable for all stakeholders. This is particularly important in the field of sanitation where decisions have substantial consequences: Selected sanitation options remain present for a long term and affect many people, whereas mistakes are not easily remedied because of the costs involved. It is for these reasons that among the different participatory tools for planning on sanitary infrastructures MCDA gains a growing popularity. 


\subsection{Proact: A Multi Criteria Decision Analysis Method for Sanitation Policy}

Proact (Hammond, Keeney and Raiffa 1999) is a MCDA method that matches very well with the goal of initiating a multi-phase stakeholder dialogue to arrive at decisions in the field of urban sanitation. The Proact method consists of five phases: the problem analysis, the setting of objectives, the selection of alternatives, the assessment of the consequences, and the trade-offs between different alternatives. The problem analysis phase focuses on the identification of the problem and on the determination of the decision making context. Scientists, experts, policy-makers, and users need to develop a common understanding of the problem, of the decision that has to be made, and of the criteria by which such decision is to be judged and evaluated. If an issue is not understood or considered to be important by one of the stakeholders, it will be difficult to get this stakeholder involved. By the same token, it is important to engage a wide group of stakeholders as early as possible, particularly in analyzing and defining the problem. The objectives are to be set to reach a common understanding of the problem. Subsequently, the problem definition leads to the formulation and selection of alternative solutions and to a decision on the various criteria to be considered when comparing them. The criteria for decision making on alternative sanitary solutions typically consist of indications for technical feasibility, cost-effectiveness, social impacts, and various environmental impacts. It is important that all stakeholders have the opportunity to actively participate in this phase to allow inclusion of all different perspectives and points of view in the process (Lahdelma et al. 2000). All alternatives are screened by assessing the consequences for each of them. In the trade-off phase, these alternatives are ranked in the order of preference and scored against the criteria that were set in an earlier phase. Each of these criteria has been assigned a particular weight within the final decision making process as a reflection of their relative importance. The weight and the scores on the criteria are combined for each alternative to derive their overall value. Finally, the best alternative can be determined. According to Hammond and colleagues (1999), applying Proact means involving all stakeholder groups throughout the decision making process. Table 2.2 emphasizes that 
Hammond and colleagues do not make any distinction between the roles of different stakeholder groups in the different phases of the process.

Table 2.2 Phases and Stakeholder Participation in Proact

\begin{tabular}{lcccccc}
$\begin{array}{l}\text { Phases in } \\
\text { Proact 2.0 }\end{array}$ & Problem analysis & Objectives & Alternatives & Consequences & Trade-off \\
\hline $\begin{array}{c}\text { All stakeholder } \\
\text { groups }\end{array}$ & $\mathrm{X}$ & $\mathrm{X}$ & $\mathrm{X}$ & $\mathrm{X}$ & $\mathrm{X}$ \\
\hline
\end{tabular}

Source: Hammond et al. (1999).

Note: X participation of this particular stakeholder group is important.

In other models, however, distinctions are made between the roles where different stakeholders can and should play in the various phases of a MCDA: Stakeholder groups are assigned different responsibilities in distinctive phases of the process than others, such as experts, planners, or decision-makers, are. For instance, Lahdelma et al. (2000) make a difference between four stakeholder groups and each of them is involved in two to four of the six different phases (see Table 2.3).

Table 2.3 Phases and Stakeholder Participation in Environmental Multi Criteria Decision Making Processes

\begin{tabular}{|c|c|c|c|c|c|c|}
\hline $\begin{array}{l}\text { Phases in } \\
\text { MCDA } \\
\text { stakeholders }\end{array}$ & $\begin{array}{l}\text { Define } \\
\text { alternatives } \\
\text { and criteria }\end{array}$ & $\begin{array}{c}\text { Make } \\
\text { measurements }\end{array}$ & $\begin{array}{c}\text { Choose } \\
\text { decision aid }\end{array}$ & $\begin{array}{c}\text { Provide } \\
\text { preference } \\
\text { information }\end{array}$ & $\begin{array}{l}\text { Form draft } \\
\text { solutions }\end{array}$ & $\begin{array}{l}\text { Make final } \\
\text { decision }\end{array}$ \\
\hline $\begin{array}{l}\text { Decision } \\
\text { makers }\end{array}$ & $x$ & & $(X)$ & $x$ & & $x$ \\
\hline $\begin{array}{l}\text { Interest } \\
\text { groups }\end{array}$ & $x$ & & & $(X)$ & & \\
\hline Experts & $x$ & $x$ & & & & \\
\hline Planners & $x$ & $(X)$ & $x$ & & $x$ & \\
\hline
\end{tabular}

Source: Lahdelma et al. (2000).

Note: $X=$ participation of this particular stakeholder group is important; $(X)=$ participation is less important. $M C D A=$ multicriteria decision analysis. 
Van Buuren and Hendriksen (2010) follow Lahdelma et al. (2000) by making a distinction between the different stakeholder groups and their contribution in different phases of the planning process on sanitary infrastructures. However, they consider especially the phases of problem analysis and objectives vital in the decision making process, although these phases are absent in the sanitation planning process of Ladehlma et al. (2000) Therefore, van Buuren and Hendriksen designate this multi criteria decision analysis methodology, Proact 2.0, so to underline the continuities and innovations compared with the previous use of this method. Van Buuren and Hendriksen combine the division of the Proact phases (see Table 2.4) according to Hammond et al. (1999) with the division of the stakeholder groups as developed by Ladehlma et al.(2000).

Table 2.4 Phases and Stakeholder Participation in Proact 2.0

\begin{tabular}{lccccc}
$\begin{array}{l}\text { Phases in Proact 2.0 } \\
\text { stakeholders }\end{array}$ & $\begin{array}{c}\text { Problem } \\
\text { analyses }\end{array}$ & Objectives & Alternatives & $\begin{array}{c}\text { Consequences } \\
\text { offs }\end{array}$ & $\begin{array}{c}\text { Trade- } \\
\text { Scientists }\end{array}$ \\
Technological experts & $\mathrm{X}$ & $\mathrm{X}$ & $\mathrm{X}$ & & \\
(Local) policy makers & $\mathrm{X}$ & $\mathrm{X}$ & $\mathrm{X}$ & & $\mathrm{X}$ \\
Users & $\mathrm{X}$ & $\mathrm{X}$ & & $\mathrm{X}$ & \\
\hline
\end{tabular}

Note: $\mathrm{X}=$ participation of this particular stakeholder group is important.

Proact 2.0 considers the involvement of all stakeholder groups important especially in the first phases of the planning and decision making process: problem analysis and the formulation of objectives. In these phases, it is essential that the problem is considered from as many different angles as possible and that all stakeholder groups agree on a number of common objectives. However, in the phase of elaborating alternative solutions, there is no need to involve the end users or the policy-makers or local authorities. During this phase, scientists and experts on sanitation are much better placed and equipped to determine the feasible options in a given context. When all feasible options are identified, end users have to select their personally preferred option among them. For policy-makers, this will lead to a better understanding of the eventual 
positive and negative commitment of end users for certain options, which is important in the final decision making process. Hence, in including stakeholders in decision making processes on improvements in sanitation, adjusting their participation to the different phases in the multi criteria decision analysis process is vital to optimize both the process and the contributions from stakeholders.

The Proact 2.0 method offers practical support in optimizing user involvement to reach feasible and sustainable sanitation improvement. Two phases are particularly important in realizing this: problem analysis and consequences.

Identifying and involving all stakeholders at an early phase of the policy process help to build up mutual trust and allow for a common understanding of what the problem is and how it should be defined, although it also facilitates the joint formulation of objectives against which alternative solutions should be assessed. These objectives should be defined in terms of social needs rather than in the technical solutions to be put in place (Van Vliet 2006). When the consequences of all feasible alternatives are discussed, users are also to be actively involved. As the end users should benefit from the new sanitation improvements, it is crucial that they are involved in discussing all options before deciding on their final preference. This phase of discussing consequences of all feasible alternatives should be based on a deliberative approach to decision making, whereby participants listen to each other's arguments and preferences and generate group choices after due consideration of each possible option. In contemplating on and arguing for what they consider to be the best solution, participants (different groups of end users) ought to try to convince one another by offering arguments that are acceptable by others. Even if this phase of deliberative participation does not result in one clear recommendation, it can still serve as a stage where user values become discernable and identifiable (Forsyth 2007; Fung and Wright 2001).

To evaluate the practical use of the Proact 2.0 methodology developed in this manner, we have applied this method in sanitation upgrading in Katanga slum in Kampala, focusing especially on the phases of problem analysis and consequences. 


\subsection{Testing Proact 2.0 in Katanga Slum, Kampala}

Katanga village is one of the major informal settlements in Kampala. Its growth can be attributed to its location close to the central business district allowing for easy access to informal jobs. It is one of the many informal settlements where the majority of the urban poor in Kampala are accommodated. It is common knowledge that among the multiple problems related to poverty in these areas, sanitation is one of the most prevalent ones (Figure 2.1).
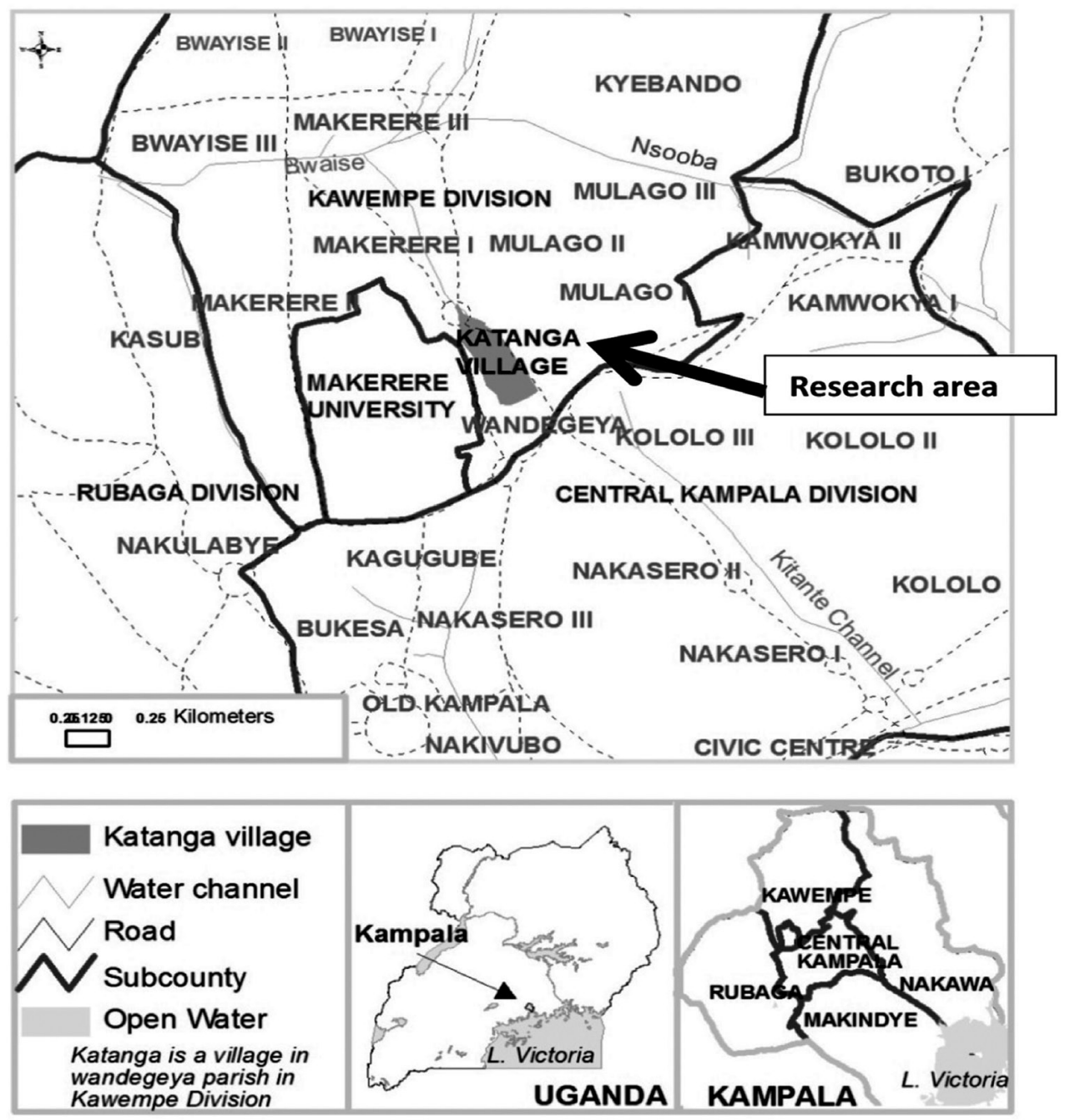

Figure 2.1 Administrative map of Central Kampala, Uganda 
Previous efforts made by local NGOs and CBOs to improve the sanitation situation among the urban poor had not resulted in sustainable solutions (Mabasi 2009; OkotOkumu and Oosterveer 2010). A number of innovative and ecologically sustainable options had been established, such as ecological sanitation (eco-san) toilets and composting plants to improve their health and environmental conditions. For instance, in Katanga, several eco-san toilet blocks had been installed, allowing the separation at source of urine and feces. This separation facilitates the reuse of valuable components from urine and feces and reduces water loss. Hence, it protects public health, prevents pollution, and returns valuable nutrients and humus to the soil. From a technological and environmental sustainability point of view, eco-san toilets are therefore an attractive solution. Yet in Katanga slum, local leaders explained that these eco-san toilets are used by only a very few poor households because the majority of the potential users are convinced that these eco-san toilets are not hygienic. As a result, most human waste is still disposed of indiscriminately, together with solid waste, leading to all the hygienic problems coming along. Here the expert dilemma is felt: knowing solutions without knowing the problem (Van Buuren and Hendriksen 2010). The decision to introduce eco-san toilets was made by technical experts on technical grounds, and its failure underlines the necessity of involving end users in the process of developing and implementing alternative solutions.

To translate this aim in concrete practice, the Proact 2.0 methodology was tested here and two workshops were organized for the different stakeholder groups involved in sanitation upgrading in Katanga. The first workshop was organized with the participation of representatives from all stakeholder groups engaged in sanitation around Katanga. The first workshop was jointly organized by environmental scientists from Makerere University, Kampala, Uganda, and Wageningen University, the Netherlands, who together work on viable options for improving the sanitation situation in Uganda and as such have an overall picture of the different organizations involved in sanitation activities in Katanga slum. Hence, experts were invited from the Uganda Water and Sanitation Network, an umbrella organization working toward achieving universal access to safe water and improved sanitation by coordinating and informing their member nongovernmental and community-based organizations on sanitation. 
Representatives from the Kampala city council which is mandated by the local government act 1997 to provide numerous services including sanitation upgrading attended the workshop. In addition, local policy-makers and local leaders living in Katanga were invited. During this first workshop, 12 stakeholders with a variety of expertise were asked to discuss the present situation to develop a common understanding of the problem. The second workshop was organized to screen the different feasible alternatives for their user preference and acceptance. Hereby, local leaders and inhabitants of Katanga were invited.

\subsubsection{Screening: Selecting Feasible Alternatives for Sanitation Improvement}

During the first workshop, scientists and technological experts gave presentations on sanitation problems and solutions to inform policy-makers and local authorities.

Subsequently, all stakeholder groups interacted to define the problem, to formulate alternative solutions and to identify the various criteria that should be considered when comparing alternatives. Technological, social-cultural, economic, environmental, and health criteria were included. Taking alternative solutions into consideration and comparing them are essential as there are usually several options technologically and economically feasible, but there may also be local conditions that rule out certain options. The process of distinguishing feasible and unfeasible options for sanitation in Katanga was called screening. This screening process was carried out together with a group of diverse technical experts. During the screening phase, these specialists took into consideration the defined set of criteria as well as site-specific conditions of Katanga slum. The implementation of this phase in the decision making process by implying only experts was in line with Proact 2.0: Not all stakeholders have to be involved in all phases of the decision making process. Non-experts in sanitation technology cannot be considered capable of making the complex technological decisions needed for identifying feasible options for sanitation, and expert knowledge is indispensable for making an informed selection in this stage. However, in order not to become trapped or locked in specific technological trajectories, it proved to be essential to have sufficient diversity in this expert group. Too often, individual experts have their own technological preferences based on their specific training, knowledge, institutional 
affiliation, or on other interests. It is vital that screening technological alternatives is an open process among distinct technological experts and expertise.

As a result of this screening process, several feasible alternatives were selected for improving the sanitation situation in Katanga slum. Some of the pro-poor onsite sanitation technologies were not suitable for this context. For instance, as unplanned slum it was not easy accessible for emptying facilities. Field observations in Katanga revealed that pit latrines, often promoted by NGOs, were technically not suited to the local environmental conditions. The areas where these toilets had been constructed were marshy and hence had a high water table. As most of the latrines were constructed without protection from the groundwater, this created a serious health risk. At the same time, conventional pit latrines, an assorted collection of facilities with poorly understood health impacts, were still the main sanitation technologies the urban poor had to rely on. Therefore, despite the serious problems, the pit latrine was included among the feasible options to be investigated by stakeholder.

The other feasible sanitation options identified by experts were the double-pit latrine, the waterless system with the alternating pit, the pour flush sanitary system, and the urine diverting dry toilet (better known as eco-san). The double-pit latrine is an improved version of the single-pit latrine. A second pit is added to allow continued use, while the stored fecal material can settle and later be used as a soil conditioner. The waterless system with alternating pit collects, stores, and treats excreta in the pit itself so the generated compost can be removed and transported for use or be manually disposed of. In pour flush systems, treatment of sludge is on-site but the system can also be connected to an anaerobic biogas reactor where gas can be produced for use when cooking. The last identified feasible option was the urine diverting dry toilet, which separates feces and urine to allow feces to dehydrate and to recover urine for beneficial use.

\subsubsection{User Acceptance}

Many failures of initiatives to improve sanitation conditions in urban slums can be attributed to a large extent to the lack of in-depth understanding of slum life (Isunju et al. 2011; Jenkins and Curtis 2005). Therefore, during the second workshop, the 
stakeholders were invited to further screen the different feasible alternatives on their end users preference and acceptance. Hence, not only the local leaders as the representatives of the Katanga communities, but also inhabitants living in Katanga were invited.

A group of 50 inhabitants of Katanga was invited to participate in a 1-day workshop, and they were challenged to screen the five technical options for sanitation improvement that resulted from the first workshop and the screening process. The participants were selected on diversity and representativeness. Table 2.5 lists some key data on the background of these participants.

Table 2.5 Background Variables Participants Katanga Workshop

\begin{tabular}{lcclcc}
\hline Age in years & Gender & Education & Marital status & $\begin{array}{c}\text { Number of } \\
\text { children }\end{array}$ & Religion \\
\hline$\leq 20=25 \%$ & Male 55\% & $\begin{array}{c}\text { Primary } \\
\text { school 25\% }\end{array}$ & Single 55\% & $0=30 \%$ & Muslim 63\% \\
$21 \leq 40=60 \%$ & Female 45\% & $\begin{array}{c}\text { Secondary } \\
\text { school } 55 \%\end{array}$ & Married 37.5\% & $1-4=50 \%$ & Catholic $18 \%$ \\
$41 \leq 60=15 \%$ & & College 20\% & $\begin{array}{l}\text { Divorced 5\% } \\
\text { Widow(er) 2.5\% }\end{array}$ & $5-10=20 \%$ & $\begin{array}{c}\text { Christian 11\% } \\
\text { Protestant } 8 \%\end{array}$ \\
\hline
\end{tabular}

The participants were split into five diverse subgroups to discuss the feasible sanitation options. Each subgroup was assigned one potential sanitation improvement and was asked to consider this option by doing a SWOT-analysis, without any pregiven criteria for such an assessment. The results from each subgroup were presented to all participants and followed by a plenary discussion on their conclusions. During this part of the workshop, the principle of deliberative decision making was followed, whereby participants were able to listen to each other, invited to exchange and discuss arguments, and encouraged to bring up different points of view.

Discussing the different alternatives during the workshop resulted in an interesting overview of the different criteria used by the participants when assessing options for improving the sanitation situation in Katanga. With regard to the single-pit latrine, 
negative arguments dominated the discussion. Users considered the single-pit latrine a primitive option, not hygienic, a potential danger for infection, not safe for pregnant women, scary for children, without access for emptying when filled up, a dump place for waste, and only suitable as a temporary solution for underdeveloped areas. Most of these negative arguments were also expressed when discussing the double-pit latrine, but some positive considerations were mentioned as well. Both the single- and the double-pit latrines fit into the local conditions and are cheap to build. The double pit is considered less primitive as it does not get blocked, is less polluting because of the process of natural decomposing, and, when used well, is easier to keep clean. An active discussion followed after the presentation of the waterless system with alternating pit. All arguments were nullified by the fact that a waterless sanitation facility is unacceptable for Muslims and this applied to the eco-san option as well. Other arguments against the introduction of eco-san systems were that the construction is expensive, leads to an easy spreading of diseases, produces a bad smell, users need shoes for entering it, and because urine and feces should be diverted, it is impossible for females to make use of such toilets. The discussion about the pour flush toilet system was the most balanced in terms of strengths and weaknesses. It was considered to fit in every place and easy for use by everyone; it saves space, is long lasting and hygienic, and is seen as a dream because every family would like to have its own toilet. Yet it is expensive to build, requires special care to be kept clean, is rapidly blocked, and is not easy to maintain.

The choice to include a SWOT-analysis when asking end users to assess feasible options seems to provide an effective basis for open discussions on their respective advantages and disadvantages and gave extensive insights in the end user expectations, ideas, hopes, and fears. The aim of the SWOT-discussion was not to come to a consensus among users but to bring all considerations, experiences, values, and user behavior patterns to the fore to establish commitment, understanding, and a broader perspective. This was important because during the plenary discussion, the policy-makers and local authorities were also present. This broad exchange of views resulted in better and more complete insights in the diversity of user views and arguments related to the different sanitation alternatives. The plenary discussion constructed a list of criteria that Katanga inhabitants consider relevant when assessing sanitation improvements classified in five main categories (see Table 2.6). 


\begin{tabular}{lllll}
\hline & \multicolumn{4}{c}{ Feasible options sanitation improvement } \\
\cline { 2 - 4 } Criteria & $\begin{array}{c}\text { Single } \\
\text { pit }\end{array}$ & $\begin{array}{c}\text { Double } \\
\text { pit }\end{array}$ & $\begin{array}{c}\text { Waterless system } \\
\text { with alternating pit }\end{array} \quad$ Pour flush & Ecosan \\
\hline Technological & & & & \\
Easy construction & & & \\
Safe & & & \\
Fits in the area & & \\
Economic & & \\
Cheap to build \\
Maintenance costs \\
Water costs \\
Social/cultural/religious \\
Convenient \\
Safe \\
Accessible \\
Environmental \\
Contamination \\
Natural decomposing \\
Little space \\
Health \\
Hygienic \\
Healthy \\
Use of water \\
\hline
\end{tabular}

These main categories, namely, technological, economic, social, cultural, religious, environmental, and health, cover the broad range of social, economic, and technological considerations that end users deem relevant when judging sanitary infrastructures. After consensus was reached on these categories, further refined into 15 specific criteria, all participants were asked to individually rank the different feasible options for sanitation improvement in Katanga in their order of preference. This approached allowed the ranking to be better based on arguments than would have been the case without group discussions, SWOT presentations, exchange of arguments, and criteria construction. After the individual ranking, the option that was identified by the users together as the 'best' was determined and communicated to all participants and also to the other relevant stakeholder groups (see Figure 2.2). 


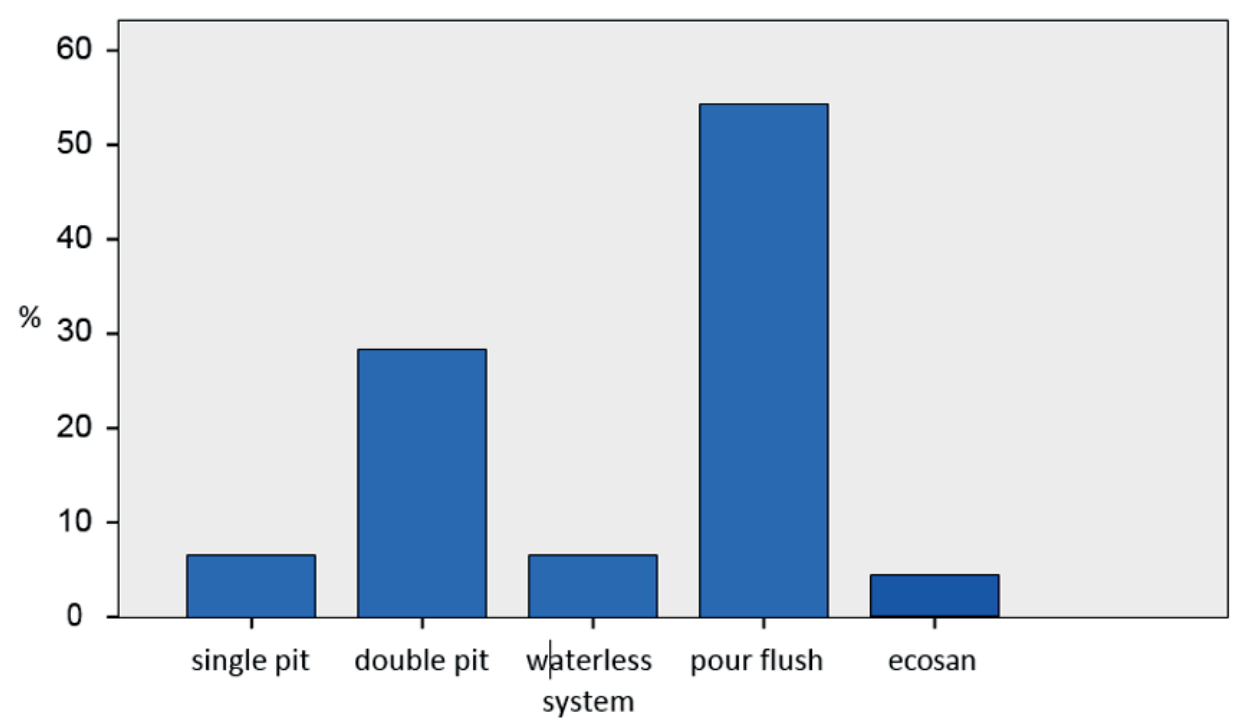

Figure 2.2 Preferred options for sanitation improvement (in percentages)

These results show that most of the users have chosen the pour flush as first, the single pit as second, and the double pit as third preferred option when they applied the technological and economical selection criteria. When they categorized social, cultural, religious criteria, they opted again first for the pour flush, whereas they ranked the single pit together with the double pit and the waterless system as the second preferred option. When applying the environmental and health criteria, the end users preferred the pour flush toilet with the double pit rated as second and the single pit as third preferred option.

\subsubsection{Evaluation: Lessons Learned}

The Proact 2.0 methodology seems to fit extraordinarily well within the framework of the modernized mixtures approach. Where the modernized mixtures approach focuses on the integration of socio-technical systems and the relationship with their users in a specific context, Proact 2.0 seems to be capable of closing the gap between technological innovation and user acceptance by identifying various stakeholder groups and making a distinction between these stakeholder groups and their contribution in the different phases of the planning process on sanitary improvements. 
The Proact 2.0 methodology proved a useful multi criteria decision analysis method for multiple stakeholder involvement in decision making on sanitation improvement in Katanga. Compared with the original Proact method, two major adaptations made the revised, 2.0 version more realistic and feasible. The first major adjustment was the insertion of the screening phase, whereby most stakeholder groups were left out due to their limitations in technical expertise when assessing technological innovations. By relying on qualified, independent experts and ensuring sufficient diversity in technological expertise, a lock-in effect, whereby only few alternatives would be considered, was prevented.

The second major adjustment was introduction of the SWOT analysis of the feasible options by the end users only. Considering the consequences of these feasible technical alternatives for sanitation improvement in Katanga proved the most important phase for end user involvement. Open discussions, where users expressed their considerations and views, resulted in a better understanding among users and between users and policy-makers, ultimately helping in better decision making. During this second workshop, only users participated, but in the end they presented and discussed their conclusions to the policymakers at a plenary session. It would have been of more added value if the technical experts and scientist would also have attended this session. The results from the SWOT analysis proved very relevant because disagreements between users and between users and experts often have little to do with the technology per se but rather with the importance of user considerations, such as convenience and religious habits. Increased insights in end user views allow for a better understanding of why the adoption of a technological improvement in practice differs from what experts expect (and/or hope).

During the trade-off phase, users ranked the feasible sanitation options individually, often only as 'best' and 'worst' options. Interestingly, there was no visible and identifiable connection with the list of criteria they developed before, so the individual ranking provided little additional information about user views. For example, during the discussion about pour flush toilet systems, the users concluded that a pour flush toilet is an expensive option and not easy to maintain. Still, the individual ranking showed that users ranked the pour flush toilet system as cheap to build and with low maintenance costs. Confronted afterward with their ranking, the users explained that they wanted to make very clear that the pour flush toilet system was their number one choice. After the plenary discussion about the consequences of each option, no new information was brought up. Therefore, user 
involvement proved most relevant in the phases of problem analysis and of formulating and identifying consequences, whereas technological expertise was crucial in the screening phase.

\subsection{Conclusions}

Current improvements in sanitation facilities for the urban poor are facing a number of challenges, including lack of user acceptance of innovative technologies, but this factor tends to be ignored by technical experts and municipal decision-makers. Providing effective sustainable sanitation solutions in slum areas requires, however, in-depth understanding of life and preferences among the inhabitants of these informal settlements. This can best be achieved by engaging the future end users in the decision making process on improving sanitary infrastructures. Realizing this would result in identifying feasible sanitation options that are more sustainable, more flexible, and more accessible for the poor because technological and social dimensions are combined and end user expectations taken into account. This article developed Proact 2.0 as a methodological tool to make the participation of different stakeholders feasible and most effective in particular phases of the decision making process. Compared with other multi criteria decision analysis methods, Proact 2.0 differs because end user involvement proves most important in the phase of problem analysis and in the phase of the consequences as technological expertise is crucial in the intermediary, screening phase. Proact 2.0 has shown to be a useful method for participatory decision making on improving sanitation facilities because it (a) combines the information, knowledge, and 'expertise' from experts, policy-makers, and users; (b) balances these various sources of input to ensure that none dominates; and (c) excludes stakeholder groups from phases where they have little to contribute, making the participatory process more efficient and feasible.

Applying Proact 2.0 will result in information gathered from differentstakeholders during the different phases of the decision making process, and this may be expected to contribute to realizing options that will effectively improve the sanitation situation of the urban poor. This is fully in line with the objectives of the modernized mixtures approach, and therefore the Proact 2.0 methodology succeeded in adding the appropriate methodological mixture to the modernized mixtures approach. 


\section{How to dance? The Tango of Stakeholder Involvement in Marine Governance Research ${ }^{4}$}

\subsection{Abstract}

The added value of involving stakeholders in research, especially related to marine governance, seems to be understood today by many researchers and policy-makers. This is clearly reflected by the many (EU) research calls explicitly asking for stakeholder involvement. The way in which to involve stakeholders in a meaningful way is however not all that clearly defined. In the EU funded project Options for Delivering EcosystemBased Marine Management (ODEMM) an explicit question was the development of options for alternative governance settings, including stakeholder involvement, to implement the Marine Strategy Framework Directive in the EU. In order to arrive at these possible alternative governance set-ups the ODEMM project developed a layered methodology, including structured and unstructured interviews, a survey and roundtable discussions to develop diverse governance options for future ecosystembased models at the regional seas. This paper describes the methodologies used, compares them with best practice from literature, and finally classifies the approach as a joint knowledge production, a tango, in which scientists take the lead but need the stakeholders to come to a dance.

\subsection{Introduction}

The need to involve stakeholders in marine management and related research, especially associated with ecosystem-based management, and more in particular with

\footnotetext{
${ }^{4}$ This chapter has been published as: Kraan, M., A. Hendriksen, L. van Hoof, J. van Leeuwen, C. Jouanneau (2014). How to dance? The tango of stakeholder involvement in marine governance research. Marine Policy (50) 347-352.

Both Marloes Kraan and Astrid Hendriksen are first authors of this paper.
} 
marine governance, increasingly seems to get acclaimed: "a common assumption is that stakeholder participation and Ecosystem- Based Approach are natural bedfellows and, indeed, the two appear together too often for the connection to be ignored" (Gray and Hatchard 2008). The EU Common Fisheries Policy had incorporated stakeholder participation more than ten years ago in its former reform (2002) by establishing the Regional Advisory Councils and by including stakeholders in the reform process itself (Gray and Hatchard 2003). Also the EU research funding system in fact has the view that stakeholder participation is a desirable component (Gray and Hatchard 2008); the EU capacities program of FP7 clearly establishes stakeholders as a specifically targeted group, as Small and Medium Enterprises or Civil Society Organizations have become research grant recipients, and their inclusion in research proposals has become a precondition.

The way in which to effectively include these stakeholder groups - the "how to involve stakeholders in a meaningful way' is however not all that clearly defined yet. This lack of clarity on how to involve stakeholders has three possible, unwanted side-effects. Firstly, because actively and meaningfully involving stakeholders requires distinct skills and knowledge researchers do not always reach the full potential of stakeholder involvement. Secondly, as stakeholder involvement becomes an end in itself, there is a risk that all factors that hinder meaningful cooperation, such as a lack of time, difference in access to needed resources and the fact that power relations among the parties involved do play a role, lead to a process in which stakeholders are invited to the process but rather as a mere window-dressing exercise. And thirdly, prior negative experiences of stakeholder involvement often lead to 'stakeholder fatigue' [Hendriksen et al. 2012; Dunn 2005; Bulkeley and Mol 2003; Beierle 2002).

Besides, stakeholder participation has a strong normative stance to it; considering major marine management propositions without stakeholder involvement is nowadays not looked favorably upon. The influential article of Arnstein (1969), portraying participation by using the image of a ladder, has had the connotation of 'the more the participation the better' resonating the 'political correctness' of stakeholder participation (Reed 2008; Jonsson et al. 2007). Seminal work of Raakjær and Vedsmand $(1995,1999)$ already portrayed a more distinct system of levels of stakeholder 
participation in fisheries management, not necessarily portraying a normative view but a more analytical perception of degrees of stakeholder participation. Noting possible different levels of stakeholder participation is much more useful to align the level of participation with the specific process in hand.

While a lot has been written and discussed about stakeholder involvement and participation in policy-making, amongst others resulting in theory on interactive governance (Kooiman et al. 2005; Fung and Wright 2001), there has been much less reflection yet on the process of stakeholder participation in (marine governance) research. This paper describes the way in which stakeholders were involved in the EU FP7 funded ODEMM project (Options for Delivering Ecosystem-based Marine Management) and aims to contribute to the emerging field of joint knowledge production. The main objective of the Marine Strategy Framework Directive (MSFD) is to achieve environmentally healthy marine waters by 2020 (Commission of the European Communities 2008). The research project ODEMM dealt with the question: 'what are the governance options for implementing the MSFD?'. The MSFD poses a challenge to EU marine governance, with multiple governing actors at multiple levels being involved, as well as to multiple sectors throughout the European countries and the non-European neighboring states. Governance options for ecosystem-based management, what the MSFD is all about, ask for participatory governance. The next section shows best practices of stakeholder involvement after which the methodology that was followed in the ODEMM project to include stakeholders in discussing the options for governance implementing the MSFD is explained. This paper will close with the lessons learnt from the ODEMM methodological approach. 


\subsection{Best Practices of Stakeholder Involvement in Scientific research}

Reed (2008) identifies eight features of best practices of stakeholder participation (see Box 3.1) thereby emphasizing the need to replace the 'tool-kit' approach with a participation-as-processapproach.

Box 3.1 Best Practices of stakeholder participation. Source: Reed 2008.

1. Stakeholder participation needs to be underpinned by a philosophy that emphasises empowerment, equity, trust and learning.

2. where relevant, stakeholder participation should be considered as early as possible and throughout the process.

3. Relevant stakeholders need to be analysed and represented systematically.

4. Clear objectives for the participatory process need to be agreed among stakeholders on the outset.

5. Methods should be selected and tailored to the decision making context, considering the objectives, type of participants and appropriate level of engagement.

6. Highly skilled facilitation is essential.

7. Local and scientific knowledge should be integrated.

8. Participation needs to be institutionalized.

Participation of stakeholders in management or research is not all that straightforward; in fact Reed comments on his list of 'best practices of stakeholder participation' as having emerged out of 'post- participation disillusionment' (Reed et al. 2005). In the EU research context one can recognize the image that scientists are increasingly 'forced' to 
include stakeholder participation in their research, resulting in them seeking ways to deal with the requirement in such a way that not a lot of resources need to be used, wishing to save that for 'real' research, delivering 'hard data'. Others will be looking for 'tool kits' in order to be able to take care of the job. However useful guides, kits and toolboxes are (they will most likely be less optimal) both for the participating stakeholders as well as for the researchers because these tools are never tailor made for a specific case. What is rather needed is the composition of multidisciplinary research teams working with stakeholders; teams with boundary-crossing skills, to be able to synthesize knowledge of different fields of expertise in a critical and creative way (Fortuin and Bush 2010; Huitema and Turnhout 2009). Methods are not simply neutral tools (Bryman 2004). According to Reed (2008), a theme running through this literature is the need to replace the 'tool-kit' approach to participation, which emphasizes selecting the relevant tools for the job, with an approach that views participation as a process'.

In the next paragraph the governance and stakeholder participation approach taken in the ODEMM project is described.

\subsection{The ODEMM Tango of Stakeholder Involvement}

The ODEMM project sought to support the EU and its Member States with the implementation of the Marine Strategy Framework Directive. The MSFD explicitly calls for an implementation of reaching Good Environmental Status in a structure of cooperation between the riparian states, be it EU Member States or other states. The challenge of the implementation in governance terms is that such a structure for cooperation is lacking at the regional seas level, resulting in institutional ambiguity (Van Leeuwen et al. 2012). Within the ODEMM project this issue was addressed by developing possible scenarios' and governance options for the implementation of the MSFD.

Developing a governance structure at the regional sea level automatically requires involvement of stakeholder groups, not only as marine governance impacts on a multitude of marine users and uses, and as explicitly mentioned in the MSFD policy 'public consultation and information', but also to develop an institution that is perceived 
as being legitimate, especially in the sense of being accepted by the stakeholders, policy makers and marine managers alike. Hence involving stakeholders in the ODEMM research was a sine qua non.

Previous work in the ODEMM project had already identified different stakeholder groups working in or for the marine environment: fisheries, offshore oil and gas, offshore renewable energy, coastal tourism, transport and shipping industries, environmental agencies, scientists, environmental 'NGOs and policy decision-makers (Ounanian et al. 2012). It had also become clear that a number of marine sectors in European regional seas are on unequal footing in policy decision making processes, whilst a range of stakeholders and sector representatives have provided input and expertise into the policy implementation process for the MSFD; equal inclusion in the process across stakeholder groups has not been achieved (Ounanian et al. 2012). In addition designing a stakeholder participation process across four regional seas, at different organizational levels and through- out sectors, would be quite a challenge.

\subsubsection{Step by Step Layered Approach}

Subsequently a step by step methodology was designed, tailored to the decision making context, considering the objectives, type of participation and appropriate level of engagement (see Figure 3.1). 
Driving Forces

\section{Scenarios}

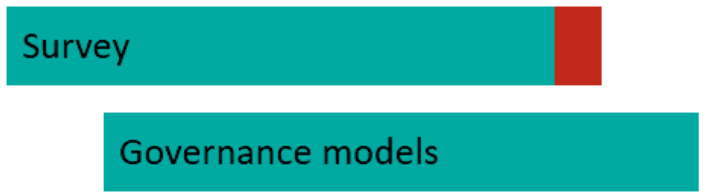

Regional focus groups

Brussels focus group

\section{Policy Brief}

Figure 3.1 Overview of stakeholder involvement in the different steps of the ODEMM approach

Starting with a review of the current institutional setting of the MSFD framework different stakeholder groups involved in the MSFD process were identified (Ounanian et al. 2012). However it can be difficult to involve stakeholders in a meaningful way due to differences in strategies and the (political) traditions member states use for participation, knowledge environments, priorities of interests and beliefs, differences in challenges they face or the formation of unexpected subgroups in this broad field (Van Leeuwen et al. 2014; Verweij et al. 2010). Based on the results of the interviews with key players from government, Regional Sea Convention, industry and the NGO community, the following driving forces that have the potential to have an impact on regional cooperation in implementing the MSFD were selected: institutional ambiguity; stakeholder involvement; (economic) efficiency; member state's willingness to cooperate and member state's capacity to cooperate. Semi-structured interviews with experts from the marine field were held testing the 5 driving forces. All 
stakeholders confirmed those driving forces and came up with an additional driving force: decision making (see Figure 3.2 and Figure 3.3).

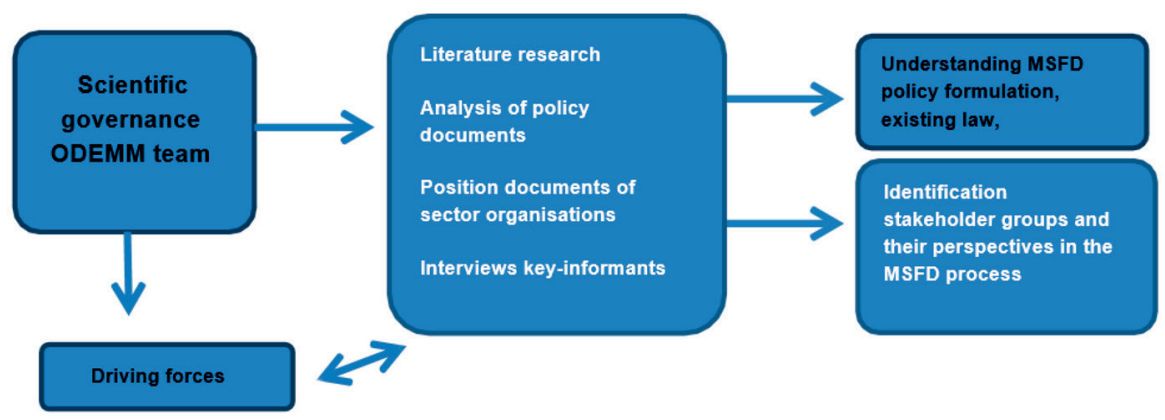

Figure 3.2 Step 1: Selecting driving forces by identifying the current institutional MSFD framework and stakeholder groups associated with the MSFD process

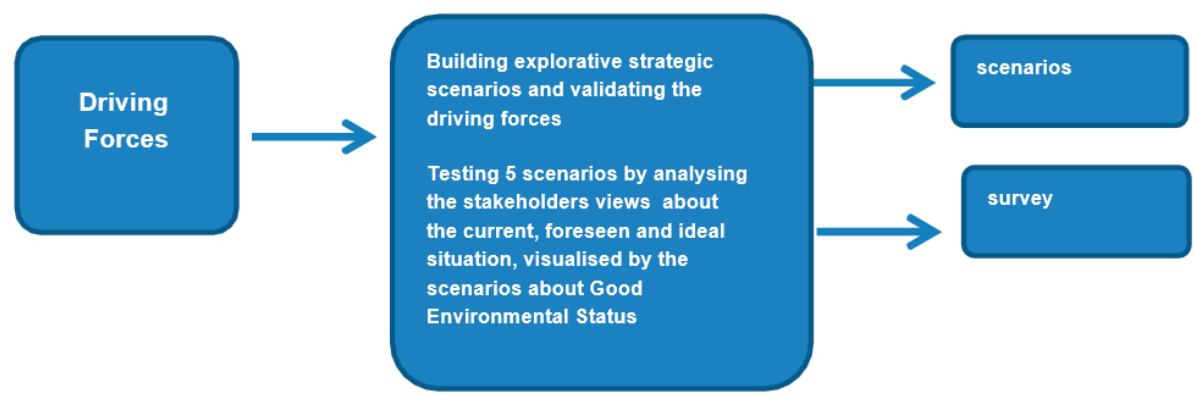

Figure 3.3 Step 2: Building and testing scenarios based on the 6 driving forces

Based on the driving forces, 5 exploratory strategic scenarios were built focused on 'what can happen if we act in a certain way?' (Van Hoof et al. 2014). The 5 scenarios were presented at an ODEMM conference for all researchers working in the ODEMM project. As the ODEMM governance team was looking for strategies in future governance, it became important to examine stakeholder perspectives as an approach to reveal ideas and to discover feasible future options from a stakeholder's point of view. A 
large online survey, translated in 12 languages, was sent to 650 stakeholders across 18 EU countries and 5 non-EU countries that surround the Black Sea, Baltic Sea, Mediterranean Sea and the North East Atlantic Ocean. The overall response rate was $37 \%$. The results were quantitatively analyzed with the statistical program SPSS (Hendriksen et al. 2014).

The next step was to involve stakeholders in the building of the alternative governance models (see Figure 3.4).

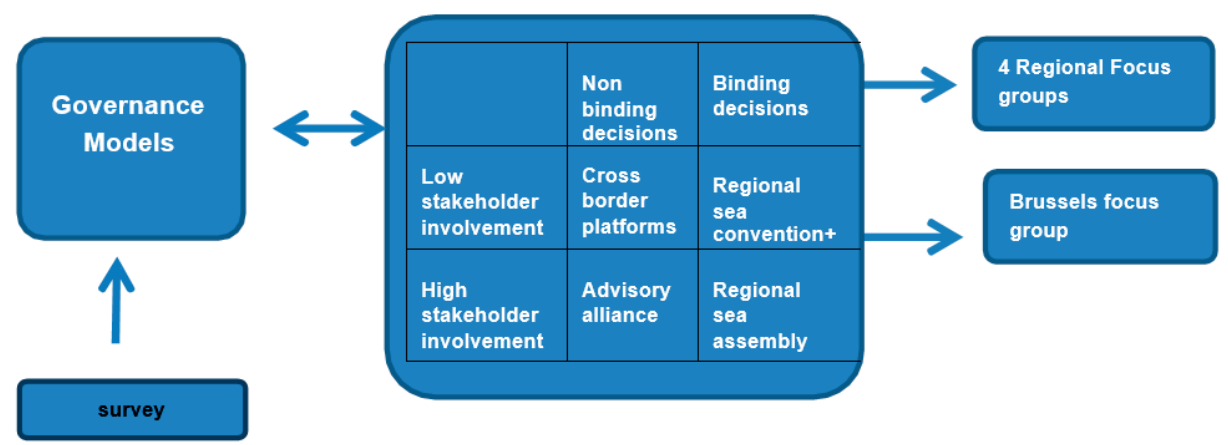

Figure 3.4 Step 3: Building and testing governance models based on the results of the survey

One of the main conclusions of the survey was that there was a strong preference from all stakeholder groups across all regional seas for being involved in all (decision making) phases of the MSFD implementation (Hendriksen et al. 2014). Based on the driving forces the governance models presented possible future governance settings in any European regional sea (Van Tatenhove et al. 2014). In order to discuss these governance models, roundtable discussions were held around the Mediterranean Sea, Black Sea, Baltic Sea and North-East Atlantic Ocean on 'future governance options to best implement Ecosystem-Based Management'. A crucial element of these meetings was that the selected stakeholders were seen as experts, and not approached as representatives of their constituency (e.g. fisheries, NGOs, tourism representatives) or of their country. 
Nevertheless the experts involved were drawn from a carefully built up stakeholder database that had been used consistently throughout the project, in order to make sure to have a representation of all crucial sectors with a stake in a particular regional sea.

Selection of stakeholders remains difficult dealing with a complex topic in 4 different regional settings, resulting in a lot of diversity, with at least nine countries per regional sea, some of which are EU Member States and some non-EU states, complicated further by gender, age, sectors and years of experience issues. To counter this complexity, roundtable meetings were held with participation limited to small groups of approximately 15 people. The various governance models were during 4 two day sessions discussed with experts with a so called focused group discussion. This approach led to deliberative and reflexive information exchange. Participants were able to probe each other's reasons for holding a certain view; they could argue and challenge each other and could modify their views based on what others said (Bulkeley and Mol 2003; Bryman 2004). An example of how this has worked in the Black Sea meeting is given as follows:

Facilitator: "Before we did the Opportunities and Treats session, you wrote down your preferred model. Who changed his mind after the Opportunities and Treats session?"

One participant raises his hand. He says: "I first believed the 2nd model (Regional Sea Convention) was best, but now I understand that if we complement it with Advisory Alliance it will be best I think'". Interestingly it is the same participant who in the Strengths and Weaknesses session had felt a lot of opposition to even think about the strengths and weaknesses of the third model (Advisory Alliance) as he said it was 'too unrealistic'. [notes by Kraan]

Feedback from the participants revealed that they had enjoyed the sessions also because the experts invited were not always part of the 'regular' crowd of experts. They met new people, leading to more discussion with fresh insights as this was not an 'old boys network' of regulars, meeting each other continuously in the EU meeting cycle, to whom you 'do not have to explain your point of view anymore'.

The ODEMM governance team acted in all roundtable meetings as catalysts rather than experts on a specific topic. According to Hordijk and Baud (2006) this is a process not 
yet strongly acknowledged within or outside the scientific world that validates knowledge production and its results. The ODEMM team supported the roundtable meetings by presenting background information and the aims of the meeting, by observing, listening and making notes of what was said and what happened in interactions. Working with a professional facilitator is an important element as there are quite some challenging issues to deal with, some of which are: balancing between getting out of the group and what you aim for (it should be productive and not wander off too much), but allow the group to develop its own process (what they feel is important in relation to the topic) allowing for an insiders perspective to the issue in hand (Bryman 2004). It means finding a balance between steering the process where needed (for instance when some participants dominate the process too much) or letting go when needed (for instance in letting room for 'chaos' and misunderstanding, allowing for stakeholders to steer themselves out of such situations again and creating their own perspective to an assignment).

The meetings started with a creative session, during which participants were asked to find strengths and weaknesses for each of the potential governance models. The next session labelled smart choices was about possible opportunities and threats for each of the models. Finally participants were invited to a free speech session where they could think beyond and discuss their preferred model for the future governance of their regional sea. Fruitful collaboration within the focus groups directed the participants to come up with adaptations of the different proposed models or with mixed varieties of the individual models. Although models had been prepared by the ODEMM governance experts, allowing the invited stakeholder experts to assess them thoroughly and come up with new ideas and models makes that research move away from its outsiders perspective.

A fifth roundtable discussion was organized in Brussels with participants from all regional seas. The idea was that stakeholders working on topics related to the MSFD have a more EU broad perspective and will not be operating at the regional seas level. The main question in this meeting was not so much on preferred governance models, but rather on how to create decision making structures which have a regional sea perspective. The sharing of knowledge provided the basis for the understanding of how 
to move forward with the design and implementation of management measures for the MSFD in supporting a more sustainable future for European Seas (see Figure 3.5).
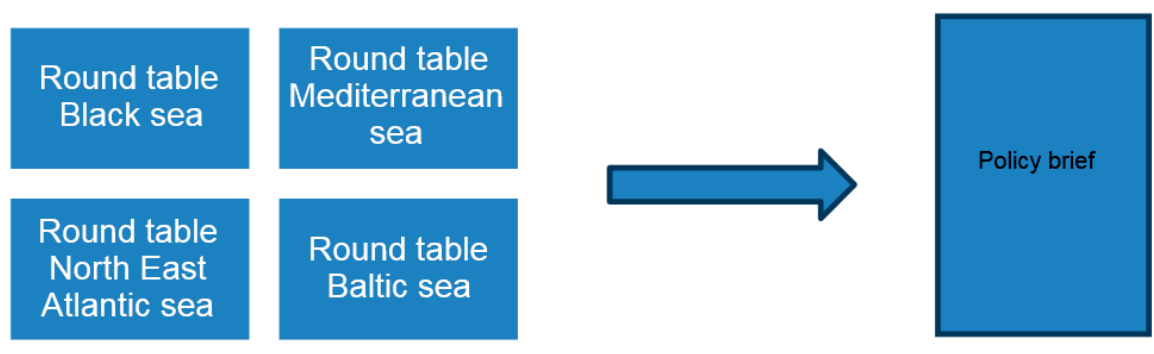

\section{Round table \\ Brussels}

Figure 3.5 Step 4: Testing the governance models in 5 roundtables and writing the policy brief based on the outcomes

The last step was that based on the outcome of the governance analysis and the development of new governance models for the implementation of the MSFD at the regional sea level, a policy brief was written. The policy brief has been provided in an attempt to facilitate the uptake of knowledge at the policy level, by translating the outcomes of the processes of building alternative regional governance structures for the implementation of the MSFD, into practical ideas for policy development. This final step reflects the eminent general desire of stakeholders to have their input being used in not only the research outcomes but also in policy development. The policy brief provided a set of alternative tailor-made governance models for European regional seas facilitating regional collaboration and coordination and allowing for genuine stakeholder involvement in accordance with the principle of subsidiarity.

\subsubsection{Characteristics of the Approach taken}

As a way of evaluating our approach we used the best practice list of Reed (see table 3.1). It shows how, by looking back, most best practices have been used in the ODEMM chosen approach of stakeholder involvement. Bringing all this together summarizes the ODEMM approach with 3 main characteristics. 
The first characteristic of the ODEMM approach was the iterative process in the continuous search for governance options to support decision making processes among all stakeholder groups involved.

Table 3.1 Assessing the ODEMM approach by comparing it to Reed's best practices of stakeholder involvement (2008).

\begin{tabular}{|c|c|}
\hline Reed's best practices & The ODEMM approach \\
\hline $\begin{array}{l}\text { Stakeholder } \\
\text { participation needs to } \\
\text { be underpinned by a } \\
\text { philosophy that } \\
\text { emphasizes } \\
\text { empowerment, equity, } \\
\text { trust and learning. }\end{array}$ & $\begin{array}{l}\text { During the step by step approach a one-way flow of } \\
\text { information from scientists to stakeholder groups was } \\
\text { avoided. Participants learnt to influence the research process } \\
\text { due to its iterative set-up. Stakeholders were approached as } \\
\text { experts, underlying the value given to the knowledge they } \\
\text { provided. There was a two-way learning among participants } \\
\text { with different knowledge and perspectives and between } \\
\text { stakeholders and scientists. }\end{array}$ \\
\hline $\begin{array}{l}\text { Where relevant, } \\
\text { stakeholder } \\
\text { participation should } \\
\text { be considered as early } \\
\text { as possible and } \\
\text { throughout the } \\
\text { process. }\end{array}$ & $\begin{array}{l}\text { Stakeholder participation was a step by step approach used } \\
\text { continuously in the ODEMM project. The methodology of } \\
\text { meaningful involvement depended on the step that needed to } \\
\text { be undertaken. Stakeholders were however not involved in } \\
\text { the preparation phase of the research proposal work } \\
\text { package, the scientists set that stage. }\end{array}$ \\
\hline
\end{tabular}




\begin{tabular}{|c|c|}
\hline $\begin{array}{l}\text { Clear objectives for } \\
\text { the participatory } \\
\text { process need to be } \\
\text { agreed among } \\
\text { stakeholders on the } \\
\text { outset. }\end{array}$ & $\begin{array}{l}\text { The stakeholder database of the work package was carefully } \\
\text { constructed, with the help of regional ODEMM researchers, to } \\
\text { identify stakeholders. The 'pool' of stakeholders was used } \\
\text { consistently throughout the project. Stakeholders have been } \\
\text { categorised in various ways. This has been used for } \\
\text { systematic analysis. } \\
\text { In all interactions with stakeholders, it has been explained } \\
\text { why their participation was important. The objective was } \\
\text { research, nevertheless - knowing that the uptake of } \\
\text { knowledge is important for stakeholders - it was explained } \\
\text { that the link with policy would be made via a policy brief. } \\
\text { Both with the interviews, as with the survey as with the } \\
\text { roundtables, clear explanations were given on the goal of the } \\
\text { interaction as well as on the process (agenda). Results of the } \\
\text { roundtable discussions have been shared with the } \\
\text { participants. }\end{array}$ \\
\hline $\begin{array}{l}\text { Methods should be } \\
\text { selected and tailored } \\
\text { to the decision making } \\
\text { context, considering } \\
\text { the objectives, type of } \\
\text { participants and } \\
\text { appropriate level of } \\
\text { engagement. }\end{array}$ & $\begin{array}{l}\text { A mixture of quantitative and qualitative methods has been } \\
\text { used, chosen by the ODEMM research team, dependent on } \\
\text { the context, scale, resources available and time frame } \\
\text { adapted to the relevant phase in the process. Flexible } \\
\text { utilisation of these methods enabled the facilitator to adapt } \\
\text { to changing conditions. }\end{array}$ \\
\hline $\begin{array}{l}\text { Highly skilled } \\
\text { facilitation is essential. }\end{array}$ & $\begin{array}{l}\text { A professional and experienced facilitator was present at all } \\
\text { five roundtable discussions. }\end{array}$ \\
\hline
\end{tabular}




\begin{tabular}{|l|l|}
\hline $\begin{array}{l}\text { Local and scientific } \\
\text { knowledge should be } \\
\text { integrated. }\end{array}$ & $\begin{array}{l}\text { The whole set-up of an iterative process with varying inputs } \\
\text { from science experts and stakeholder experts allowed for } \\
\text { joint knowledge construction. }\end{array}$ \\
$\begin{array}{l}\text { Participation needs to } \\
\text { be institutionalized. }\end{array}$ & $\begin{array}{l}\text { The participatory process during the ODEMM project gave } \\
\text { room to opportunities for long term cooperation among the } \\
\text { stakeholders involved. The ODEMM project is not facilitating } \\
\text { this kind of cooperation. }\end{array}$ \\
\hline
\end{tabular}

This allowed the ODEMM team to actively share knowledge and use the results of stakeholder input into shaping the next step in developing alternative governance models tailored to local regional circumstances.

The second characteristic of the ODEMM approach is that stakeholders' selection was carefully built up and used consistently throughout the project. A common principle used throughout ODEMM is that stakeholders were used as experts- in the survey were quantitatively asked for their expert opinions, and in the roundtable discussions were qualitatively asked for their expert views. The experts involved were representing all crucial sectors having an interest in European regional seas.

Thirdly, methodological triangulation was used to interact with all stakeholder groups, both qualitative (varying from focused groups, expert interviews, video conferences, and Skype meetings) as well as quantitative (survey). There are so many ways to involve stakeholders and more is not always more meaningful. The choice for a survey, an interview or focused group depends on the type of input needed, the scale of interaction needed, and the question posed, obviously bound by resources This approach resulted in outcomes developed by an interplay between stakeholder expert knowledge and scientific expert knowledge. 


\subsection{Lessons Learned: Reflection on Stakeholder Involvement in ODEMM's Governance Research}

The main lesson learnt leads towards a new perspective on joint knowledge production. In the ODEMM project both scientists as well as stakeholders have been viewed as experts, each from their own experiences, perspective and expertise. The 'expert assumptions' were continuously tested, in interviews, survey and focused group sessions. The multidisciplinary research team acted more as a facilitating force in the deliberations than as experts in a specific field. Although the scientists in this project had the lead in the tango, their dance is meaningless without input of the stakeholders. The scientists set the stage and chose the methods, yet they had to remain open to changes, allow for improvisation in the process and for change of their perspective in content. There is no point in involving stakeholders when the stakeholder's input cannot make a difference.

Building up and using an approach to stakeholder involvement that was iterative in process perceived and treated stakeholders and scientists alike, both being considered as experts. The use of a variety of methods allowed for triangulation of findings and finally resulted in a new perspective on knowledge production. This joint knowledge production let itself be portrayed as a tango, in which it takes both sides in interaction to become successful.

In order to come to improved methods of stakeholder involvement best practices and tool boxes can be instrumental. They can be meaningfully used as checklists of what should be thought of. However it is clear that tool boxes by themselves do not carry the entire process of stakeholder involvement. Meaningful involvement asks for a joint process to make sure that knowledge is generated by all stakeholders involved.

Experiences of meaningful inclusion of stakeholders in research projects (related to marine governance) need to be shared more, not only amongst scientists but also among other stakeholder groups. Discussing the methodologies used will result in learning from each other as well as improving the process that is necessary for meaningful involvement of stakeholders. 
Joint knowledge production in marine governance is a young scientific field, which can benefit from reflection on increasing experiences with stakeholder involvement in scientific research projects. ODEMM developed an extensive step by step process with several moments of stakeholder involvement aiming to contribute to the debates on joint knowledge production by reflecting on this process. 


\section{Sometimes you cannot make it on your own; Drivers and Scenarios for Regional Cooperation in Implementing the EU Marine Strategy Framework Directive ${ }^{5}$}

\subsection{Abstract}

Implementing the EU Marine Strategy Framework Directive explicitly calls for regional cooperation between the EU Member States in the different regional seas. This regional cooperation, although set in a general framework of EU Member States and non-EU states utilising existing Regional Sea Conventions as focal point, develops along different tracks. Based on a series of interviews with different stakeholder groups in the different regional seas the drivers for this regional cooperation were determined. These drivers were used to develop a set of scenarios to depict possible ways and structures for cooperation at the different regional seas. In this paper the result of this analysis and the different scenarios developed are presented. The five scenarios developed were very helpful in elaborating alternative governance models for regional cooperation. From the validation by the stakeholders it became clear that both the drivers used, as the scenarios developed were found to be relevant. There is no single solution that is going to fit all regional seas, or that is going to appeal to all stakeholders within a regional sea. Especially in this setting the scenario approach does help people to explore the full range of possibilities that exists for the development of alternative governance models

\footnotetext{
5 This chapter has been published as: Van Hoof, L., A. Hendriksen, HJ. Bloomfield (2014). Sometimes you cannot make it on your own; drivers and scenarios for regional cooperation in implementing the EU Marine Strategy Framework Directive. Marine Policy (50) 339-346.
} 
that address two issues raised but not detailed in the MSFD: cooperation and participation.

\subsection{Introduction}

European legislators have adopted ambitious policy initiatives for the oceans, seas and coasts, to be implemented over the next two decades. These initiatives include e.g. the 2007 Integrated Maritime Policy, the 2009 Renewable Energy Directive, the 2012 Motorways of the Sea initiative and the Blue Growth Strategy and the recent reform of the Common Fisheries Policy (Commission of the European Communities 2013). With the introduction of the Marine Strategy Framework Directive (MSFD) in 2008, the European Union (EU) has made a firm commitment to implement an ecosystem-based approach to marine management. The MSFD provides a comprehensive framework for the protection of the marine environment.

The main objective of the MSFD is to put in place measures to achieve or maintain "Good Environmental Status" (GES) of Europe's regionals seas by 2020 (Commission of the European Communities 2008; Knights et al. 2008). Europe's seas differ in terms of ecosystem components, and the sectors and activities that exert pressures upon them (Commission of the European Communities 2008; Knights et al. 2008); thus different and specific solutions at both the regional and sub-regional levels are required in working towards GES (Commission of the European Communities 2008). Whilst the MSFD calls for individual Member States (MS) to develop a marine strategy based on the specific needs and challenges identified for its own waters, it also requires cooperation and coordination of activities between Member States, and where possible with third countries sharing a region, in both the development and implementation of strategies to ensure that the overall perspective of the marine region or sub-region is not overlooked (Commission of the European Communities 2008). The MSFD states that "where practical and appropriate" regional level working makes use of existing regional institutional cooperation structures, such as the Regional Sea Conventions, but contains no specific legal framework nor specifies governing structures to ensure cooperation (Van Tatenhove et al. 2014). Furthermore, the regional level is not formally reflected in the European Treaty (Van Leeuwen et al. 2012). Achieving regional cooperation thus 
poses challenges for MSFD implementation, particularly given that neighboring Member States within a region may have different, and potentially contradicting, priorities and that for all regional seas, neighbors include third countries that are not bound to the MSFD (Freire-Gibb et al. 2014).

Hence the 'governance model' or way in which cooperation in implementing the MSFD is organized at the regional sea level needs to be further developed. The key objective of the EU FP7 funded ODEMM project (Options for Delivering Ecosystem-based Marine Management) was to develop scientifically-based operational procedures to assist in the transition towards fully integrated management over sectors, actions and policy domains. Given this remit, the challenge of regional coordination in implementing the MSFD was clearly apparent.

The regional seas differ both in ecosystem characteristics and governance settings. Given that different governance solutions could be used to address regional organization, the choice was made to develop several alternative governance models using a scenario approach. The scenario approach allows for an exploration of future developments and at the same time analyzing the current situation. Drivers for the scenarios were identified based on a series of interviews with key informants from around the main regional seas in Europe, representing the main sectors and policy fields and were used to construct scenarios of alternative regional governance models. These models were used in further discussions conducted with regional sea level focus groups to determine which model would have the best 'fit' with the regional circumstances.

In the next sections the basic methodology of scenario development is presented; starting from the identification of drivers, micro-scenarios and macro-scenarios are being developed. In Section 3 the methodology is detailed and in Section 4 the different drivers are being described. Section 5 presents the micro-scenarios used and in Section 6 the (macro-) scenarios are presented. In Section 7 a reflection is given on the findings and the use of the scenario methodology in developing alternative governance models. 


\subsection{Building Scenarios for Governance Models}

The challenge addressed in this study is how to develop governance models at the regional sea level that will facilitate implementation of the MSFD. More specifically it addresses two issues raised but not detailed in the MSFD: cooperation and participation. Basing on the EU's marine and maritime policies the Ecosystem Approach has policy design implications. Policy development should be regionally (ecosystem) orientated and should be integrated over all sectors and activities (Van Hoof et al. 2012). With the process of increased attention for cooperation and integration at the regional level the Member States are challenged to jointly develop policies for a specific spatial area which will require a form of unification of policy by Member State. Not only are the Member States challenged to bring together complex volumes of policy but also the differing signatures of different sectors (Van Hoof and Van Tatenhove 2009).

Given the different circumstances in the different regional seas and the numerous activities and sectors operating in Europe's regional seas, no one-size-fits-all solution to these challenges is likely or logical. In order to deal with this variety in circumstances in the regional seas a three step approach was chosen. In the first step, reported in van Leeuwen et al. (2012) and Ounanian et al. (2012), interviews with key players from government, Regional Sea Convention, industry and the NGO community were held. The main findings were that in all four regional seas institutional change is taking place, although the extent to which differs per regional sea. The institutional ambiguity between the regions differs, with the Baltic Sea having the lowest level of institutional ambiguity and the Mediterranean Sea the highest (Van Leeuwen et al. 2012). In addition the consistency of the overall legal frameworks and specific regulations related to marine management have created legal vagueness and subsequently caused legal uncertainties leading to conflicting policies and regulations having unclear boundaries. Furthermore, it is found that different sectors are unequally prepared to participate in this policy (Ounanian et al. 2012). These results were used as input for the development of scenarios for possible governance models for the 4 regional seas. Based on the analysis of the scenarios 4 alternative governance models were built. These models were presented and discussed during regional sea focus groups in which key informants 
looked at the applicability of the different models in their regional sea. In this section the scenarios that were built will be presented.

Scenarios, as a prime technique of future studies, have long been used as powerful tools to aid decision making in the face of uncertainty. The idea behind them is to establish thinking about possible futures which can minimize surprises and broaden the span of managers' thinking about different possibilities (Mietzner and Reger (2005). They are extremely helpful in cases where elements of the system cannot be modelled and where subjective interpretations need to be included. The basis of scenario building lies in developing hypothesis about possible futures (foresight) rather than making predictions.

According to De Jouvenel (2000) a scenario comprises the following three elements: (a) the base, nothing more than the representation that we create of the current reality and of the dynamics of the system that we are studying; (b) the paths created in looking at the system according to a time scale, with the knowledge that as we advance, the questions we face will necessarily imply more hypotheses (the 'if this, then, that' process). Specifying conditions each time, using deduction, we build the trees of possible futures, potential descendants of the present; and (c) the last images are obtained at different periods, and according to the horizon line of the study, the result of the paths or routes mentioned thus far. According to Durance and Godet (2010) in order for scenarios to be both credible and useful they have to respect the following five conditions: pertinence, coherency, likelihood, importance, and transparency.

Scenarios can contribute to policy decision making by identifying and anticipating potential developments (desirable and undesirable) and information gaps and inconsistencies. Generating 'images of the future' and 'focusing attention on causal processes and decision points' are important ways by which better strategies can be devised to address today's and tomorrow's environmental problems (European Environmental Agency 2000).

According to Borjeson et al. (2006) scenario typologies explore possible, probable and/or preferable futures. Within this broad definition various approaches for designing scenarios, leading to a large diversity in scenario typology, can be found in the literature 
(Borjeson et al. 2006; Postma and Liebl 2005; Notten et al. 2003); Höjer et al. 2008).

Figure 4.1 shows a clear overview of the different scenario typologies and outlines three scenario categories and six scenario types (Borjeson et al. 2006).

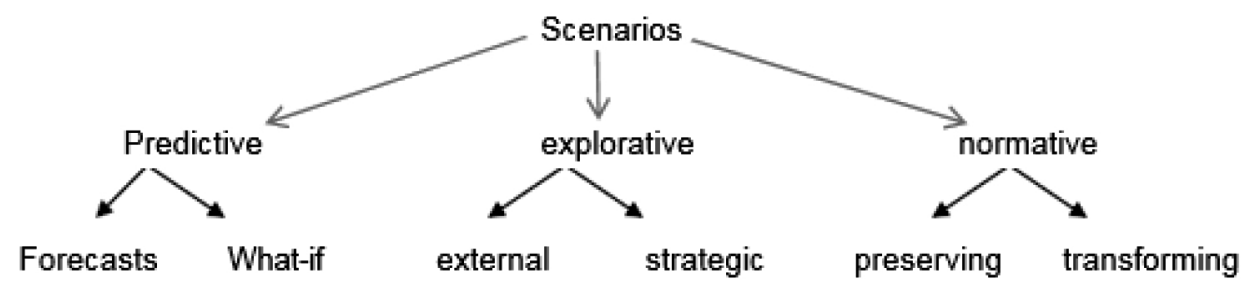

Figure 4.1 Scenario typology with three categories and six types

In order to be able to reach the main objective of the MSFD scenarios should answer the question 'What can happen when we act in a certain way?' Explorative strategic scenarios refer to that question. This type of scenarios can be useful in cases where the decision-makers may have good knowledge regarding how the system works at present and are interested in exploring a range of possible consequences of alternative developments (Borjeson et al. 2006; Notten et al. 2003) stated that when building explorative scenarios, the process is crucial. Important aspects are awareness raising and stimulation of creative thinking. According to Wollenberg et al. (2000) techniques for stimulating creativity include: using extreme outcomes, not only predictable ones; creating disruptions to historic trends; selection of scenarios that are distinct, not ones that reflect a gradient such as high medium and low values, or a positive and a negative scenario; including undesirable scenarios; starting the construction of the scenario from an imagined future, rather than from extrapolation of current trends.

The methodology used in this study consisted of the following main steps: the system that was considered was the regional seas and how regional cooperation and participation in implementing the MSFD could be achieved between the relevant Member States (and other non-Member States riparian states), the Regional Sea Convention and the several stakeholder groups. Based on the interviews the driving forces influencing the system were determined: driving forces, or drivers, are those 
variables in a system that have a more than average impact on the future state of the system.

For each of the drivers micro-scenarios were established. Micro-scenarios are hypotheses about the possible states of the individual drivers. Based on a combination of hypothesis of the individual drivers potential scenarios ('outlooks') for the entire system were drawn. Below the drivers, the micro-scenarios for the individual drivers and the macro-scenarios (stories or narratives) for the entire system are presented.

\subsection{Drivers}

Driven by the MSFD Member States may seek a governance solution for regional cooperation best fitting the circumstances of the regional sea and the numerous activities and sectors operating in Europe's regional seas. They will 'where practical and appropriate' make use of existing regional institutional cooperation structures, such as the Regional Sea Conventions. Furthermore, Article 19(1) (Public consultation and information) of the MSFD (Commission of the European Communities 2008) dictates “(...) Member States shall ensure that all interested parties are given early and effective opportunities to participate in the implementation of this Directive..." and the need for "stakeholder involvement and raising public awareness". On the one hand, stakeholder participation in decision making is considered as a positive democratic move (Long 2011), is consistent with the principles of an Ecosystem Approach (upon which the MSFD is based), and can enhance both the legitimacy of the MSFD process and the resultant management, and thus the likelihood of management success. On the other hand, it can be difficult to reach agreement due to differences in priorities of private sector stakeholders and other members of society (Freire-Gibb et al. 2014; Long 2012). The current economic recession in Europe poses an additional obstacle to both regional cooperation and greater stakeholder involvement in implementing the MSFD FreireGibb et al. 2014).

Given these challenges, and based on the results of the interviews with key players from government, Regional Sea Convention, industry and the NGO community (Van Leeuwen et al. 2012; Ounanian et al. 2012), the following driving forces that have the potential to impact on regional cooperation in implementing the MSFD were selected: institutional 
ambiguity; stakeholder involvement: (economic) efficiency; Member States willingness to cooperate; Member States capacity to cooperate; and decision making.

\subsubsection{Institutional Ambiguity}

In the European Treaty the regional level, in between Member States and the European Institutions, is not reflected. Hajer (2003) argues that when policy moves beyond established institutional or polity arrangements it moves into an 'institutional void'. This does not mean that there are no institutions, nor that existing institutions or treaties are no longer meaningful, but there are 'no generally accepted rules and norms according to which policy making and politics is to be conducted ' and policy measures to be agreed (Hajer 2003). Building on this, van Leeuwen et al. (2012) define 'institutional ambiguity' as the 'interference zone between different institutional settings that come together as new policy practices'. Institutional ambiguity of implementation of the MSFD is driven by two key factors: (1) the establishment of marine regional and sub-regions, in relation to the authority and competencies of the European Commission, the Regional Sea Conventions and the Member States; and (2) the framework nature of the MSFD and the interlinks with other (marine) policies, for example the Common Fisheries Policy and the Integrated Maritime Policy (Van Leeuwen et al. 2012; Ounanian et al. 2012; Rätz et al. 2010).

As a consequence, uncertainty and confusion arise about the rules of the game that define, for example, the way in which policy- and decision making will take place and the actors involved in this process. Moreover, the larger this mismatch, the more room actors have to manoeuvre when negotiating and greater potential to change the institutional rules (Ounanian et al. 2012) due to the absence of generally accepted rules and norms. Thus, institutional ambiguity drives the outcome of regional cooperation by providing more or less freedom for those involved in the implementation of the MSFD to develop, (re)define or (re)negotiate institutional rules (Van Leeuwen et al. 2012). Indicators of institutional ambiguity include the existence of specific institutions at the regional level, the extent to which existing institutions concur or conflict, the level at which regional cooperation is being shaped and the complexity of the issues to be dealt with at the regional level. The degree of institutional ambiguity, with regards to the implementation of the MSFD at the regional level, varies between the regional seas (see 
Table 4.1), principally due to differences in the relative dominance of Member States in the regional seas conventions and in progress made with respect to adapting national policy to implement the MSFD (Van Leeuwen et al. 2012).

Table 4.1 Level of institutional ambiguity for each regional sea associated with implementation of the MSFD (taken with permission from Van Leeuwen et al. 2012)

\begin{tabular}{lllll}
\hline Regional Sea Convention & $\begin{array}{l}\text { Mismatch definition } \\
\text { environmental } \\
\text { quality-aim of GES }\end{array}$ & $\begin{array}{l}\text { Institutional change to } \\
\text { become platform for coordination }\end{array}$ & $\begin{array}{l}\text { Overall level of } \\
\text { institutional ambiguity }\end{array}$ & $\begin{array}{l}\text { Future institutional } \\
\text { ambiguity }\end{array}$ \\
\hline Baltic Sea & Low & Low & Low & Low to moderate \\
North Sea & Low & Moderate & Low to moderate & Low \\
Mediterranean Sea & Moderate & Low for MAP, high for informal EU MS group & High & High to moderate \\
Black Sea & High & Low, not started yet & Moderate & Moderate to high \\
\hline
\end{tabular}

MAP: Mediterranean Action Plan countries.

\subsubsection{Stakeholder Involvement}

The degree of stakeholder involvement in the MSFD implementation processes at the regional level will influence the outcome of the process. Enhanced stakeholder participation is considered to improve the openness and transparency of policy- and decision making processes, and ultimately the legitimacy of the decisions taken and thus likelihood of achieving management objectives (Jentoft 1989; Raakjær 2003; Van Tatenhove 2013). Key challenges lie in identifying who the stakeholders are and what their role should be in the MSFD implementation process (see section 4.4.6).

Indicators for stakeholder involvement include considerations of which stakeholders are involved in the process of regional cooperation in implementing the MSFD, and in which parts of the process those stakeholders are involved, and the nature of their involvement (e.g. where on the scale from 'informed of the process', 'consulted on the process' through to 'directly involved in decision making'). Ounanian et al. (2012) reported that whilst a range of stakeholders and sector representatives have provided input and expertise into the policy implementation process for the MSFD, equal inclusion in the process across stakeholder groups has not been achieved. Furthermore, stakeholder perceptions of the relative relevance of the MSFD compared to other EU policies affecting their activities (e.g. the fisheries sector remains focused on the Common Fisheries Policy and proposals coming out of DG MARE), and limited time and 
resources have affected both stakeholders willingness and ability to be involved in the MSFD process (Ounanian et al. 2012).

\subsection{3 (Economic) Efficiency}

(Economic) Efficiency is considered in terms of the cost of implementing a particular model of regional cooperation against its ability to deliver the requirements of the MSFD, namely good environmental status at a regional sea level. Each model of regional cooperation will have specific characteristics in terms of resources required and costs involved for those that participate; as such this driver is closely linked to the drivers Stakeholder Involvement and Member States capacity to cooperate. Indicators for this driver include the direct costs involved in organizing the regional model, the manpower and resources required to support this model and the transaction costs involved. Given the current financial crisis in Europe it is unlikely that funds for regional cooperation will be available widely, and models for regional cooperation that are (perceived to be) very costly or less efficient in achieving objectives are unlikely to be supported.

\subsubsection{Member States Willingness to Cooperate}

The willingness of Member States to cooperate is defined as the commitment of a Member State to partake in the process of regional cooperation in implementation of the MSFD. This willingness to cooperate at the regional level today varies widely between the regional seas and between Member States (Van Leeuwen et al. 2012). In addition, a recent survey of EU marine stakeholders found that the interests of the majority of stakeholders are not constrained by national borders of Exclusive Economic Zones (Hendriksen et al. 2014). Hence, Member States (and third countries) within a regional sea, and their stakeholders, may have different management priorities from their neighbors which will affect both how they implement the MSFD and how they interact with regional cooperation. Indicators for the willingness to cooperate include: current levels of participation of a Member State in activities at the regional level; the (positive or negative) attitude of a Member State towards decision making processes at the regional level; and the willingness to commit to the process of regional cooperation politically and financially, and in terms of the content of the process. 


\subsubsection{Member States Capacity to Cooperate}

The capacity of Member States to cooperate is defined as the resources (financial and otherwise) available to a Member State to take part in a process of regional cooperation. It is perceivable that a Member State could have a clear willingness to cooperate and coordinate actions in support of GES at the regional sea level with neighboring Member States (and third parties), as an important constituent of the MSFD implementation process, but due to differences in the financial budgets they have available for marine conservation (Van Leeuwen et al. 2012) or a lack of capacity, for example in terms of manpower, knowledge and understanding of the MSFD process, this willingness to cooperate is not able to be translated into active cooperation.

\subsubsection{Decision Making}

The driver 'decision making' has two main facets for regional cooperation: the decision making process and the decision making structure. This driver to a large extent is influenced by, and is influencing, the drivers of Institutional Ambiguity (see section 4.4.1), Stakeholder Involvement (see section 4.4.2) and Member States willingness to cooperate (see section 4.4.4). Whereas Stakeholder Involvement focuses on participation of distinct stakeholder groups in decision making, this driver focuses on the level of influence that stakeholder groups have on decision making and thus reflects power structures in the decision making process. Decision making structures are also affected by the way the decision making process is organized (top-down or bottom up; centralized or decentralized) and thus is linked to Institutional Ambiguity as it reflects the presence or absence of a decision making structure at the regional level (e.g. the Regional Sea Conventions). The presence of a decision making structure may have both positive and negative effects on the outcomes of the MSFD process.

Decision making comes in a wide array of arrangements, such as self-management, consultation, regional partnerships or deliberative decision making.

\subsection{Micro-Scenarios}

In this section the micro-scenarios for each of the drivers, which are hypotheses of possible developments for each of the individual drivers, are considered; these 
hypotheses (or micro- scenarios) are used as the building blocks for the macro-(or final) scenarios in section 4.6.

\subsubsection{Institutional Ambiguity}

Institutional ambiguity in this case varies between the extreme of fragmentation of rules and the full integration of rules at the regional level. In a situation of fragmentation, there is a diffusion of rules and actors have the possibility to choose from different sets of institutional rules either set by different institutions or set at different levels of organization (e.g. Member State, the regional level, the European Union level). In a highly institutionalized setting, there is integration of rules at one level. Somewhere half-way between these extremes one can find a situation in which there are some generally accepted rules at the regional level, yet stakeholders have the ability to choose rules from different institutional settings.

\subsubsection{Stakeholder Involvement}

Participation, or stakeholder involvement, varies between a low degree or even absence of participation to a situation in which all relevant stakeholder groups are involved in the process of implementing the MSFD. The participation can vary between the degree of involvement of the stakeholders as well as in which steps in the decision making process the stakeholders are involved. The degree of involvement of stakeholders typically moves between being informed and being consulted, to being allowed to provide advice and input to the decision making process to obtaining a more formal role in decision making such as under co-management or co-decision or self-management (Van Hoof et al. 2012; Raakjær and Vedsmand 1999; Van Hoof 2010).

\subsubsection{Willingness to Cooperate}

The willingness to cooperate, considered here as the political will to collaborate at the regional level, of Member States and non-Member States, can range from complete absence of this willingness to a high degree of willingness to cooperate. 


\subsubsection{Capacity to Cooperate}

The capacity of Member States to cooperate is determined by the availability of resources to fuel the process of regional cooperation and the actual deployment of those resources. Hence the capacity to cooperate ranges from a lack of resources to cooperate at the regional level to a situation in which ample resources are available and are being deployed.

\subsubsection{Efficiency}

Efficiency can be expressed in terms of costs and benefits of regional cooperation. These costs and benefits can be both in financial terms, i.e. resources deployed, but can also be in social terms, for example transaction costs involved in attending meetings. The cost/benefit ratio for different options is of course both determined by the required inputs (the costs) as well as by the outcomes (the benefits). Hence a low cost-benefit ration can either be attributed to low costs given the outcome, high benefits given the required resources or both moderate inputs and outputs. This implies that a highly efficient option for regional cooperation not automatically supersedes a low efficient option. It is up to individuals to value the costs and the benefits vis-a-vis each other.

\subsubsection{Decision Making}

The presence or absence of decision making structures shapes the decision making process at the regional level. A highly centralized decision making structure can be perceived as efficient and certainly speeds up the decision making process. Yet, the lasting effects are less likely to be effective in terms of commitment from the different stakeholder groups who are not involved in the decision making process. On the other hand creating a decision making structure that allows for input from all stakeholder groups involved is usually associated with high costs as there is a need for extensive communication, meetings, and consultation. Deliberative decision making, in which a range of options is considered in terms of the various pros and cons, and attempts to determine the best option is central to political decision making, can be viewed as the middle ground between the two extremes. 
Behind the more visible structure and process of decision making are the more concealed factors that determining shape and outcome of the decision making process

such as the power balance between the actors involved in the decision making, the strive to reach a decision, the strive to have participation enabling a decision, and not to thwart the process, and the degree to which the decision making structure itself can hamper deliberative decision making.

\subsection{Macro-Scenarios}

This section presents and describes the macro-scenarios developed based on different scores for each of the drivers. The tables are used to visually represent the score on the driver between the two extremes.

\subsubsection{Where the streets have no name}

In this scenario, there is a low level of institutionalization at the regional level and an evident absence of rules (see figure 4.2). This scenario is characterized by a high degree of institutional ambiguity. Both Member States and stakeholders are passive and do not have an interest in regional cooperation; stakeholder involvement is very low and Member States have little or no willingness and resources available to support regional cooperation. Given that regional cooperation is required under the MSFD, this scenario is not likely to be efficient. No actor takes the lead in developing a regional development, so outputs are limited. There is no clear decision making process or structure.

\subsubsection{With or withoutyou}

This scenario is characterized by a focus on participation and the unequal footing in participation that can occur between groups of stakeholders. In this scenario there is some understanding between actors that a form of regional cooperation is required and needs to be developed (see Figure 4.3). However the Member States have a low willingness to stimulate and support cooperation. Some resources are allocated to the process of regional cooperation. Stakeholder groups are involved in this developing process, be it at different levels for different groups of stakeholders. In the decision making process there is no convergence between the different stakeholder groups as stakeholder input is not structured and many stakeholder groups are involved. 
Decisions are made in a fragmented manner. In this scenario the social costs are rather high as stakeholders are required to attend a large number of events. The outcome of which is not always that clear. This is fueled by the perceived non- supportive attitude of the Member States towards regional cooperation and the role of stakeholders in such a process.

\subsubsection{Do you feel loved}

This scenario is characterized by a strong willingness to achieve regional cooperation. In this scenario Member States have a strong commitment to achieve regional cooperation (see Figure 4.4). At the regional level the institutional ambiguity is modest as there are already some agreed upon rules and institutions active at this level. Member States devote large quantities of resources to the process of regional cooperation. Stakeholder groups are actively involved in participation and are required to participate in many steps in the process of regional cooperation. Decisions are made in a deliberative process. Although the costs of the system are rather high, both financially as in terms of transaction costs, the outputs of the system are valued as being very rewarding. Hence the system is perceived as efficient.

\subsubsection{I will follow}

This scenario is characterized by a top down central European Union steering in the process of regional cooperation. In this scenario Member States are very reluctant to cooperate at the regional level and do not commit resources to this process (see Figure 4.5). Stakeholder participation is as much as possible avoided. As a result the European Union decided to no longer have the Member States organize regional cooperation but to transfer this task to the Commission. The Commission develops an institutional setting at the regional level in which the Member States are forced to jointly develop and operationalize the MSFD. At the regional level stakeholder involvement is absent. Decisions are made in a top-down centralized way. The costs of the system are rather high and the results lack general support as a result of the top down signature. Hence the efficiency can be considered to be low. 


\subsubsection{Running to stand still}

In this scenario there is a general commitment from Member States and stakeholders to develop regional cooperation (see Figure 4.6). Member States allocate resources to the process and stakeholders are involved in the important steps at the regional level. At the regional level existing institutions are used to further develop operationalization of the MSFD. Working with a set of generally accepted rules, the institutional ambiguity is relatively low. Focus in the decision making system is on building partnerships. The costs of the system are significant both for the resources to be allocated by Member States and stakeholders. The outputs are significant and supported by the stakeholder community. As a result the system is considered to be moderately efficient, yet the outcome in terms of support from Member States and stakeholders creates a perception of an optimal efficient system.

\begin{tabular}{|l|l|l|l|l|l|l|}
\hline Institutional Ambiguity & Fragmentation & & & & & Integration (Highly institutionalised) \\
\hline Stakeholder involvement & Low participation & & & & & All stakeholders involved \\
\hline Willingness to cooperate & No willingness to cooperate & & & & High degree of willingness to cooperate \\
\hline Capacity to cooperate & No resources available & & & & Resources available \\
\hline Efficiency & Low cost/benefit ratio & & & & High cost/benefit ratio \\
\hline Decision Making & Centralized top down & & & & Decentralised bottom up \\
\hline
\end{tabular}

Figure 4.2 Drivers for scenario 'Where the streets have no name'

\begin{tabular}{|c|c|c|}
\hline Institutional Ambiguity & Fragmentation & Integration (Highly institutionalised) \\
\hline Stakeholder involvement & Low participation & All stakeholders involved \\
\hline Willingness to cooperate & No willingness to cooperate & High degree of willingness to cooperate \\
\hline Capacity to cooperate & No resources available & Resources available \\
\hline Efficiency & Low cost/benefit ratio & High cost/benefit ratio \\
\hline Decision Making & Centralized top down & Decentralised bottom up \\
\hline
\end{tabular}

Figure 4.3 Drivers for scenario 'With or without you' 


\begin{tabular}{|c|c|c|}
\hline Institutional Ambiguity & Fragmentation & Integration (Highly institutionalised) \\
\hline Stakeholder involvement & Low participation & All stakeholders involved \\
\hline Willingness to cooperate & No willingness to cooperate & High degree of willingness to cooperate \\
\hline Capacity to cooperate & No resources available & Resources available \\
\hline Efficiency & Low cost/benefit ratio & High cost/benefit ratio \\
\hline Decision Making & Centralized top down & Decentralised bottom up \\
\hline
\end{tabular}

Figure 4.4 Drivers for scenario 'Do you feel loved?'

\begin{tabular}{|c|c|c|}
\hline Institutional Ambiguity & Fragmentation & Integration (Highly institutionalised) \\
\hline Stakeholder involvement & Low participation & All stakeholders involved \\
\hline Willingness to cooperate & No willingness to cooperate & High degree of willingness to cooperate \\
\hline Capacity to cooperate & No resources available & Resources available \\
\hline Efficiency & Low cost/benefit ratio & High cost/benefit ratio \\
\hline Decision Making & Centralized top down & Decentralised bottom up \\
\hline
\end{tabular}

Figure 4.5 Drivers for scenario 'I will follow'

\begin{tabular}{|c|c|c|}
\hline Institutional Ambiguity & Fragmentation & Integration (Highly institutionalised) \\
\hline Stakeholder involvement & Low participation & All stakeholders involved \\
\hline Willingness to cooperate & No willingness to cooperate & High degree of willingness to cooperate \\
\hline Capacity to cooperate & No resources available & Resources available \\
\hline Efficiency & Low cost/benefit ratio & High cost/benefit ratio \\
\hline Decision Making & Centralized top down & Decentralised bottom up \\
\hline
\end{tabular}

Figure 4.6 Drivers for scenario 'Running to stand still' 


\subsection{Validating Scenarios}

Validation of the macro-scenarios was undertaken using 2 approaches: a quantitative (survey) and a qualitative (focus groups) methodological approach. The drivers of the scenarios were tested in a large scale online survey among multiple stakeholders from different countries. The details and the results of this survey are presented by Hendriksen et al. (2014). The first section of the survey focused on the individual scenario drivers in relation to the implementation of the MSFD at the European regional sea level: institutional ambiguity, stakeholder involvement, willingness and capacity to cooperate, efficiency, and decision making. In the second section, these drivers were used to develop propositions to obtain stakeholder views on the current (in 2012), and the foreseen and the ideal governance structure (in 2020). Finally in the third section of the survey the stakeholders were asked to rank the five governance scenarios as described in section 4.6. The respondents were asked to consider the 5 proposed scenarios and evaluate them in the light of the situation for Good Environmental Status to be achieved in 2020 in terms of the expected (foreseen) situation in 2020 and their preferred situation by 2020. Especially in the propositions part of the survey there was room for initiating new drivers in order to create alternative scenarios. None of the respondents brought up new drivers or building blocks for alternative scenarios.

Based on the 5 scenarios developed and the results of the validation of the scenarios, four governance models were developed and explored in focus groups discussions to cover all potential future governance settings in the four European regional seas. This is described in more detail in van Tatenhove et al. (2014). The focus groups started with a 'creative thinking' session, during which participants were asked to find strengths and weaknesses for each of the governance models. The next session 'smart choices' focused on possible opportunities and threats for each governance model. During the last part of the focus group participants were invited to develop their preferred governance model for implementing the MSFD. Participants often preferred a mix of the models but their ideal governance model always remained within the framework of the set of scenario drivers as described above.

In general from the online survey and the focus group discussions it became clear that the drivers, developed on an earlier round of interviews of key stakeholders, and the 
scenarios, developed using these drivers, were to be found realistic in terms of seizing the main determining factors for future cooperation at the regional level and depicting in the scenarios challenging yet valid outlooks of possible situations. As such the scenarios allowed participants to both critically reflect on the current situation as well as properly develop 'most likely' and 'most desired' foresights for regional cooperation.

Both scenarios and models are methodological tools providing insight into the future. During the validation of the scenarios, both qualitative and quantitative, it was found that exploring future options using the set of drivers and scenarios was an effective way of creating decision making structures with a European regional sea perspective.

\subsection{Conclusions}

The MSFD calls for individual Member States to develop a marine strategy based on the specific needs and challenges identified for its own waters, while at the same time building cooperation and coordination between Member States, and where possible third countries sharing a region. As the regional seas differ both in ecosystem characteristics and governance settings, different governance solutions to address regional organization can be developed. In this study the scenario method was used to develop scenarios that could be used to develop alternative governance models.

The main drivers for the scenarios, hence the key factors shaping the possible cooperation and coordination at the regional sea level, were found to be institutional ambiguity (are the rules at the regional level highly fragmented or is there a highly institutionalized regional cooperation structure), the degree and extent of stakeholder involvement, the Member States willingness and capacity to cooperate, the perceived efficiency of the chosen model and the nature of the decision making system, either being top down centralized or bottom up decentralized.

Using the scenario method was very helpful in developing alternative governance models for regional cooperation. From the validation by the stakeholders it became clear that both the drivers used, as the scenarios developed were found to be relevant. The scenarios fueled a proper debate in the development of alternative governance models, which was taken forward as presented by Van Tatenhove et al. (2014). 
What is evident is that a range of key factors have a major influence on how future cooperation at the regional seas will take place. What becomes clear, when discussing the different scenarios with the stakeholder groups, is that no one single solution is the best fit; there are important differences between the ecological and institutional setting at the regional seas. But, moreover, in a single regional sea perceptions of different stakeholders may vary. Hence there is no single solution that is going to fit all regional seas, or that is going to appeal to all stakeholders within a regional sea. Especially in this setting the scenario approach does help people to consider what the future might look like and, based on this, explore the full range of possibilities that exists for the development of alternative governance models that address two issues raised but not detailed in the MSFD: cooperation and participation. The scenario debate will help to move governance forward in a direction towards regional institutions that are more likely to achieve the objectives of the MSFD. 


\section{Fishing for Opinions: Stakeholder Views on Marine Strategy Framework Directive Implementation in European Seas ${ }^{6}$}

\subsection{Abstract}

Stakeholder participation is vital when introducing and implementing ecosystem-based management (EBM) at any scale. This paper presents the results of a survey covering four European Regional Seas (Baltic Sea, Black Sea, Mediterranean Sea and North-East Atlantic Ocean) aimed to collect stakeholders' perspectives on their Regional Sea governance to implement the European Union (EU) Marine Strategy Framework

Directive (MSFD). In this survey, drivers of good governance including stakeholder involvement, willingness and capacity to cooperate, efficiency, institutional ambiguity and decision making were explored. The results indicate a clear gap in perception between the current, the ideal and the foreseen situation regarding the implementation of the MSFD. The preferences for the future governance structures vary between stakeholders and across seas although some similarities can be found. Based on the results of the survey, this paper concludes that tailor made rather than off-the-shelf solutions will be needed to accommodate regional cooperation in the European marine environment for implementing ecosystem-based management under the MSFD.

\subsection{Introduction}

The European Union Marine Strategy Framework Directive (MSFD, 2008/56/EC), adopted in

\footnotetext{
${ }^{6}$ This chapter has been published as: Hendriksen A., C. Jouanneau, R. Koss, J. Raakjaer (2014). Fishing for opinions: stakeholder views on Marine Strategy Framework Directive implementation in European Seas. Marine Policy (50) 353-363.
} 
2008 , falls within this new era of environmental management policies trying to broadly regulate activities by imposing a limit on their impact to the environment. The MSFD aims to ensure that the marine environment achieves good environmental status (GES) across 11 marine descriptors. Van Tatenhove recently assessed marine governance arrangements existing at the level of European regional seas and described it as a challenging patchwork of policies, private initiatives and regulations on different levels (Van Tatenhove 2013). The issue of fragmented governance systems plays out in very different contexts across European regional seas, with this pattern going beyond the field of marine environmental protection (Raakjær et al. in press; Jouanneau and Raakjær 2014).

It is stated in the MSFD that Member States should address regional cooperation 'using existing regional institutional cooperation structures' and include both European Union and non-European Union countries for the purpose of establishing and implementing marine strategies (Article 6 L164/27). Yet this task hides large complexities, which need to be unraveled to improve governance performance. The challenge here is to establish effective coordination structures that can deal with the large complexity of European Seas while simultaneously improving governance performance.

In order to unravel and understand current governance structures and their challenges in the four European regional seas, a large-scale survey on stakeholder perceptions was distributed across four European marine regions including Baltic Sea, Black Sea, Mediterranean Sea and North-East Atlantic Ocean (see Figure 5.1).

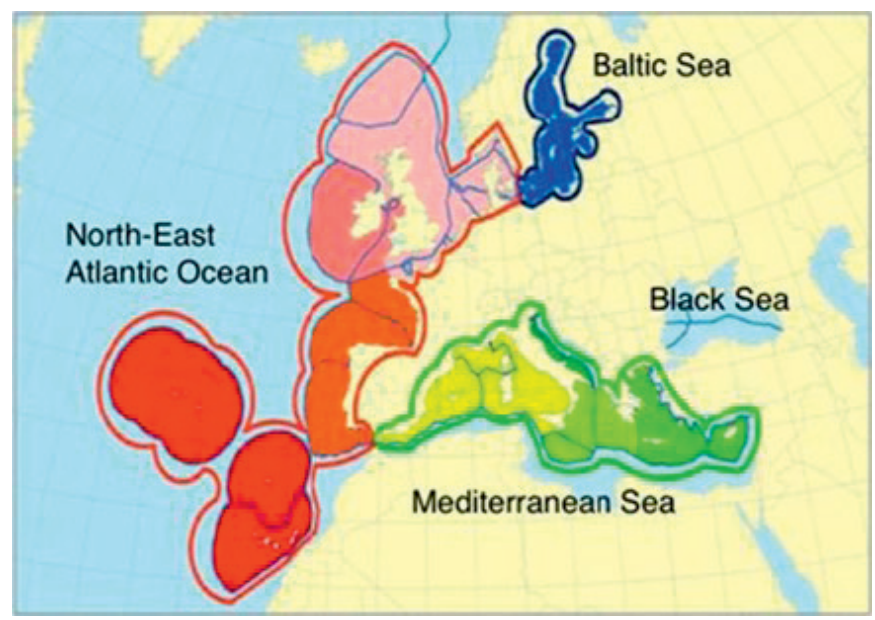

Figure 5.1 Marine regions identified in the MSFD 
The objective of this survey was to obtain an overview of views, attitudes and opinions from the main marine sectors with business activities in European regional seas, on current and future governance for the implementation of ecosystem-based management at (a) the regional level between Member States and (b) within marine eco-regions. This survey is a core task of the 7th work package of the Options for Delivering Ecosystembased Marine Management Project (ODEMM) which provides scientifically-based operational procedures that allow for a step-by-step transition from the current fragmented system to a fully integrated ecosystem-based management across European regional seas. This paper presents the main results of this survey.

\subsection{Stakeholder Involvement in European Marine Environmental Policy-making}

Stakeholder support is recognized as being essential for successful implementation of environmental policies and programs (Reed 2008). Bulkeley and Mol (2003) concluded 10 years ago that with the growing complexities and interdependencies in the field of environmental governance, new roles and positions within environmental sciences were established. This was due to the emergence of unstructured problems in the political agenda with the assumption that a more participatory approach may help to bridge the gap between a (scientifically) defined environmental problem and the experiences, values and practices of stakeholder groups who are at the root of both cause and solution of such problems (Bulkeley and Mol 2003).

Involving a variety of stakeholders in MSFD decision making processes is supported across all European regional seas. However, it is identifying when and how to engage stakeholders in different phases of decision making and implementation processes that can be problematic to policy-makers. Moving towards more frequent, intensive and influential stakeholder involvement is, according to Beierle (2002), a recognition that environmental decisions are political as well as scientific and therefore cannot be resolved with technical tools only such as risk assessment and cost-benefit analysis. Since Arnstein described the 'ladder of participation' in 1969, the degree of stakeholder participation and extent of their influence during decision making processes is a crucial factor in determining future stakeholder activities and policy implementation success. In 
the context of European Marine Policy, and specifically the MSFD, this does mean that previously established procedures need to be carefully reconsidered and redesigned to allow different stakeholder groups a place in the planning or implementation process, rather current and future processes need to consider how to engage stakeholders.

Paradoxically, involving stakeholders in decision making processes can add considerable complications, as their knowledge, experiences and preferences do not automatically synchronize with the most optimal solutions from an expert point of view. Often there is not a single best solution that fits all stakeholder groups equally (Ounanian et al. 2012; Hendriksen et al. 2012). In line with the integration of different activities, the MSFD suggests stakeholders to be involved at different stages of programme implementation:

"To ensure the active involvement of the general public in the establishment, implementation and updating of marine strategies, provision should be made for proper public information on the different elements of marine strategies, or their related updates, as well as, upon request, relevant information used for the development of the marine strategies in accordance with Community legislation on public access to environmental information." (MSFD, 2008/56/EC).

This approach ratifies the rights enshrined in the Aarhus Convention (1998)_ ${ }^{7}$ and supports greater stakeholder compliance with management due to favoring the emergence of 'credible, accepted rules that identify and assign the corresponding responsibilities appropriately' (Frid 2005; Costanza et al. 1998).

The recognition and inclusion of interests from all stakeholder groups, where possible, is fundamental to the concept of 'good governance' (Sutherland and Nichols 2004). Stakeholder participation may improve the quality of decision making by clarifying different views and interests, preventing implementation problems, fostering communication and trust and therefore establishing commitment among stakeholders (Bulkeley and Mol 2003). Participation by stakeholders has perhaps been most widely

\footnotetext{
${ }^{7}$ Aarhus Convention. Convention on Access to Information, Public Participation in Decision Making and Access to Justice in Environmental Matters, Aarhus, Denmark, 25 June 1998.
} 
encouraged in European Union fisheries governance and a number of European Union projects currently explore and support the involvement of stakeholders in developing the science and management for process implementation. This will create a trade-off between the need for stakeholder acceptance and applying evidence-based information for decision making (Reed 2008; Beierle 2002; Armstrong et al. 2013; Gray 2005). Although MSFD decision making processes will need to incorporate this trade-off, it critically lacks detail on the underlying governance structures to allow for both stakeholder involvement at the appropriate scale and the integration of evidence-based management (Van Tatenhove 2013; Raakjær et al. in press; Long 2012). The lack of a detailed governance structure for stakeholder involvement in decision making processes causing a number of marine sectors in European regional seas, including: fisheries, coastal tourism, navigation, offshore oil and gas and off- shore renewable energy, to be on unequal footing in policy decision making (Jouanneau and Raakjær 2014; Ounanian et al. 2012). This is caused when stakeholders represent a wide diversity of institutional capabilities, economic strength and political authority during their engagement in policy-making processes (Jouanneau and Raakjær 2014; Ounanian et al. 2012).

\subsection{Methodology}

\subsubsection{Stakeholder Identification}

A large scale online survey entitled 'Marine Regional Cooperation' targeted stakeholder groups from identified marine sectors of countries around each European regional sea; and examined stakeholder perspectives as an approach to reveal ideas, opinions and opportunities in future governance of the European marine environment. This survey was electronically sent to 650 stakeholders across 18 European Union countries and 5 non-European Union countries that surround the Black Sea, Baltic Sea, Mediterranean Sea and the North East Atlantic Ocean. The survey was available in 12 languages with translation of responses completed by native speakers of the respective language experts in the marine field. Considerable efforts were made by ODEMM project partners working in the European marine environment to compile a stakeholder inventory for sectors that are operational in European regional seas. This inventory flowed into an 
extensive stakeholder list of relevant organizations and representatives. This stakeholder list was cross-referenced with a literature research to identify and check if all crucial sectors in European regional seas were represented. Following the research of Ounanian et al. (2012), who identified fisheries, offshore renewable energy, offshore oil and gas, coastal tourism and transport and shipping industries as the most important sectors in European Seas, the survey targeted stakeholders within these sectors of activities. This was in addition to MSFD national coordinators under the EU Ministry of Environment, European scientists and environmental NGOs representatives.

Survey response rate was 37\% ( $n$ 239) and to keep a relevant number of respondents per subgroup it was decided to merge them into four stakeholder groups and included: economic sectors (27\%); policy-makers (35\%); researchers (24\%) and environmental NGOs (14\%).

\subsubsection{Survey Design}

The online survey consisted of three sections that included statements, propositions and scenarios. This survey aimed to

(a) understand stakeholder views of current marine governance structures and

(b) explore stakeholder views on what has been considered, in literature and by experts from the marine field, as drivers of good governance: decision making structures, efficiency, capacity and willingness to cooperate, institutional ambiguity and stakeholder involvement (Van Tatenhove 2013; Van Leeuwen et al. 2012; Van Tatenhove et al. 2014).

These drivers of good governance were tested in the online survey in various ways as to strengthen the interpretation of results. In the first section of the survey, all governance drivers were explored in four to five statements and measured on a five- point Likert scale using the following labels: 'strongly disagree'; 'disagree'; 'neutral'; 'agree' and 'strongly agree'. These statements were specific to the implementation of the MSFD at the European regional sea level in relation to each driver.

In the second section of the survey, the drivers were used to develop propositions to obtain stakeholder perspectives on the current governance structure (2012), the 
foreseen governance structure (2020) and the ideal governance structure (2020) for their organizations to create regional cooperation for the implementation of the MSFD. The propositions were measured on a five-point Likert scale that ranged from 'very low'; 'low'; 'neutral'; 'high' to 'very high'. Finally, the third section of the survey proposed five governance scenarios (see Box 5.1) formed by different combinations of governance driver emphasized with the aim to present future possibilities for European regional sea governance. The basis of scenario building lies in developing hypothesis about possible futures rather than making predictions and therefore scenarios can be helpful for decision making about the future (Van Hoof et al. 2014).

The third section of the survey asked stakeholders to rank five governance scenarios based on two contexts as follows:

(a) the situation they would expect to happen by 2020 (foreseen situation) and

(b) the situation they would find the most likely to allow "Good Environmental Status" to be achieved in 2020 (preferred situation). 
Box 5.1 The five proposed future governance scenarios presented to survey respondents in the online ODEMM survey.

\section{Scenario A: National focus}

In this scenario the countries prioritise fulfilling national obligations. Both countries and the stakeholders are not willing to be involved in regional cooperation. Decisions are not taken at the regional level and this level is perceived as unnecessary and overly costly. This situation occurs because there is no regional organisation in charge of the process and it is not known how regional cooperation should be organised.

\section{Scenario B: Regional focus without commitment}

In this scenario countries put some effort into regional cooperation but do not feel committed because regional cooperation has been imposed by the European Commission. Various stakeholder groups are involved in realizing regional cooperation. Decisions at the regional level are made in a rather unclear way. Therefore stakeholders are required to attend a large number of events, and it is not clear which forums are of real importance for the final decision. Whilst there is reluctance to commit to regional cooperation, countries are in control of the process. Some important economic sectors are represented at the regional level, whilst other stakeholders are clearly absent.

\section{Scenario C: Regional cooperation by creating new structures}

In this scenario both countries and stakeholders are committed to achieving regional cooperation. Funding and participation is not a problem. Working together at the regional level has become the norm, but in some cases it is unclear how to proceed at the regional level. New rules and procedures are rapidly developed and all stakeholder groups are actively involved in participation, and are required to do so in many steps of the process. Although regional cooperation is expensive, due to the number of meetings and effort required to reach decisions, the prevailing feeling of participants is that the final decisions are the correct and necessary ones. 


\section{Box 5.1 (continuation)}

The five proposed future governance scenarios presented to survey respondents in the online ODEMM survey.

\section{Scenario D: European Union leading regional cooperation}

In this scenario Member States and Non-European countries are very reluctant to cooperate at the regional level and are not willing to commit resources (money/time/personnel). In reaction to this, the European Commission decides to remove the responsibility for regional cooperation from the Member States and transfer these responsibilities to the European Commission. The European Commission establishes new regional councils in which the Member States are forced to jointly implement and operationalize the MSFD according to strict rules imposed by the European Commission. There is no need for stakeholder involvement at the regional level; if stakeholders wish to participate, they can only do so through their Member State.

\section{Scenario E: Regional cooperation without changing the structures}

In this scenario there is a general commitment from countries and stakeholders to cooperate regionally. Everybody agrees to use existing institutions at the regional level and to build partnerships to facilitate implementation of MSFD. Countries financially support regional cooperation and lead the process of implementing the MSFD. Stakeholders are involved in the important steps at the regional level. The focus is clearly on obtaining plans that will ensure that GES is achieved by 2020. 
Survey respondents were asked to rank the scenarios from 1 to 5 , using each ranking number once. In the analysis the mean score of all sectors was calculated and resulted in an overall ranking between 1 and 5, where the smallest ranking being the preferred option. Since the initial ranking positions were ordinal variables, relative values were used to calculate the mean rank in order to interpret distances. The ranking of the scenarios was an average of the ranking per sector (see Figure 5.2).

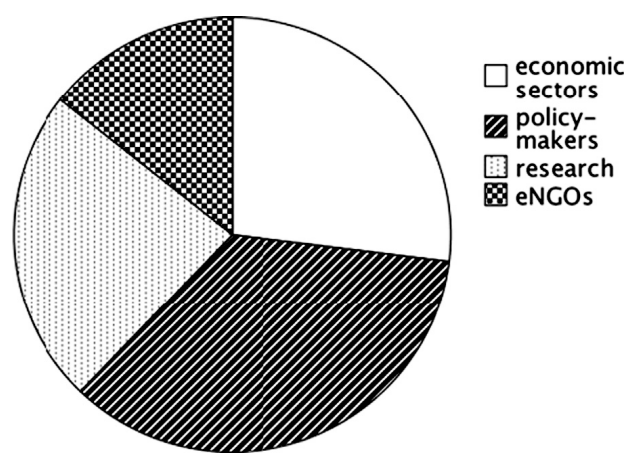

Figure 5.2 Representation of the sectors in the survey results

\subsubsection{Survey Respondent Background}

The survey results were analyzed with the statistical programme SPSS. The overall response rate of the survey was 37\% (239 completed questionnaires). The respondents were experienced in the marine field (mean = 16 years), having an average of 12 years of seniority in their present organization. Of these organizations, $81 \%$ have a national focus. The remaining 19\% of the organizations work at the international level, such as, the European Union, the Regional Sea Conventions, the Regional Advisory Councils, transboundary eNGO programmes, international environmental agencies, that cover more than one regional sea. Of the survey respondents, $82 \%$ stated that they had represented their organization in relation to policy making, whereas $57 \%$ of all the respondents have executive power in their own organization. An analysis of the 
organizations revealed that $11 \%$ are not involved in MSFD implementation processes; $34 \%$ of the organizations are informed; $40 \%$ are asked for advice and $36 \%$ of the organizations participate directly in MSFD implementation processes (see Table 5.1) Involvement here is defined as being informed and/or asked for advice and/or participates directly in MSFD implementation processes.

Respondents were able to tick more than one of the applicable boxes for this question. Of interest is the higher result for eNGOs as compared to other sectors in response to being informed or asked for advice in the implementation process of the MSFD, and at the same time their low score as compared to other stakeholders for participating directly in MSFD implementation processes. The survey analysis is presented as overall results from two groupings: (a) stakeholders and (b) regional seas. Following the line of thought of unequal footing (Ounanian 2012) results were disaggregated into these two main groups as it allows a comparison of drivers across European regional seas to identify and understand which specific drivers are influential in the governance structure for implementing the MSFD.

Table 5.1 The type of involvement for each stakeholder group in the implementation process of the MSFD (\% per sector

\begin{tabular}{lcclc}
\hline Engagement in the MSFD implementation process & Not involved (\%) & Informed (\%) & Asked for advice (\%) & Participates directly (\%) \\
\hline Economic sectors & 17 & 39 & 45 & 26 \\
Policy-makers & 8 & 26 & 25 & 51 \\
Researchers & 15 & 26 & 39 & 37 \\
eNGOs & 3 & 64 & 58 & 24 \\
\hline
\end{tabular}

\subsection{Stakeholder Views on Governance Structures}

\subsubsection{Drivers of Good Governance}

The first section of the survey focused on stakeholder views on drivers of good governance: decision making structures, efficiency, capacity to cooperate, willingness to cooperate, institutional ambiguity and stakeholder involvement. Each of the drivers were included and operationalized into four or five statements (see Table 5.2). 
The importance of stakeholder involvement in the MSFD process is demonstrated significantly by the analysis of responses by survey respondents to these statements. Survey respondents state that active involvement of stakeholders in all phases of the implementation of the MSFD is crucial. Only 3\% of the survey respondents agreed that for the implementation of the MSFD at the regional sea level, stakeholder involvement is not required. Survey respondents expressed and showed willingness of wanting to cooperate at the regional sea level and would be in favor of investing more in securing regional cooperation at this level. Only $3 \%$ of the survey respondents answered that their organization was not interested in cooperating, while $54 \%$ of the survey respondents stated that their organization would like to take on more responsibilities to achieve the objective of the MSFD. Concurrently, 38\% of the stakeholders lacked sufficient resources to participate in the implementation of the MSFD.

From an efficiency perspective, there might be benefits through regional cooperation dependent on improving existing- or creating new institutional structures. Of the survey respondents, $73 \%$ agreed that participation in regional cooperation is economically costly, but the benefits achieved are greater than without participation. Currently, it is unclear how stakeholder participation will influence total management costs. In order to achieve ecosystem-based management in European regional seas, 81\% of the survey respondents believed that clearly defined and transparent decision making structures need to be established. At present, $47 \%$ of the survey respondents answered that they were properly informed about the implementation of the MSFD in their regional sea. The majority of the survey respondents (64\%) believed that regional corporation is not possible when different authorities select their own rules. Consequently, coordination among all institutions responsible for implementing the MSFD is needed for cooperation at regional sea level. These findings support Van Leeuwen (2012) who found that institutional ambiguity is a severe impediment and challenge to MSFD implementation and emphasized the need to explore alternative governance structures

\subsubsection{Propositions for the Current-, the Foreseen- and the Ideal Situation}

This section of the survey was introduced with the statement: "The overarching objective of the MSFD is to achieve Good Environmental Status by 2020 across Europe's 
marine environment which will be assessed at the regional sea level". This was followed by a number of propositions that included the drivers: level of participation; willingness to cooperate; capacity to cooperate; resources; institutional ambiguity and influence on decision making at the regional sea level to obtain stakeholders' organization views on the current (2012), the foreseen (2020) and the ideal (2020) governance situation. Survey respondents' perspectives are presented per regional sea and per sector (see Table 5.3). The percentages represent how survey respondents rank each driver (very low/low, neutral, very high/high).

All stakeholder groups ranked the level of participation lower in the current situation (2012) than in the foreseen situation (2020), which again was ranked lower than what was considered to be the ideal situation (2020). In the ideal situation, $100 \%$ of research and the eNGOs, $80 \%$ of the policy-makers and $55 \%$ of the economic sectors selected a high level of participation. The gap between the foreseen and the ideal situation is big for the economic sectors, where $30 \%$ foresees a low level of participation and $10 \%$ of these economic sectors believes a low level of participation is ideal. The same gap counts for the policy-makers who scored 3\% low level of participation in the ideal situation and $25 \%$ low level of participation in the foreseen situation. Around $6 \%$ of the eNGOs and research foresee a low level of participation.

There is a clear interest in willingness and capacity to cooperate among all stakeholder groups. It can be noticed that there is not much change in willingness to cooperate between the current and the foreseen situation. In the ideal situation again eNGOs and research most strongly reported high willingness and capacity to cooperate. Concurrently, economic sectors (39\%), researchers (48\%), policy-makers (62\%) and eNGOs (69\%) selected low rankings for resources under the current situation. All stakeholder groups foresee an improvement in resources available in 2020. Of the researchers' $25 \%$ ranked high on resources available in the current situation improving towards a ranking of $58 \%$ in the foreseen situation. The economic sectors scores and the eNGOs score $16 \%$ resources available in the foreseen situation, as policy-makers score 26\%. 
Table 5.2 Stakeholder answers about the six drivers of good governance to achieve Good environmental Status for the MSFD. Negative percentages correspond to the disagreements and the positive to the agreements. The neutral answers are centered on zero. The missing answers (boxes non-applicable and do not know) are expressed in percentage of the total answers to each statement but are not included in the bars

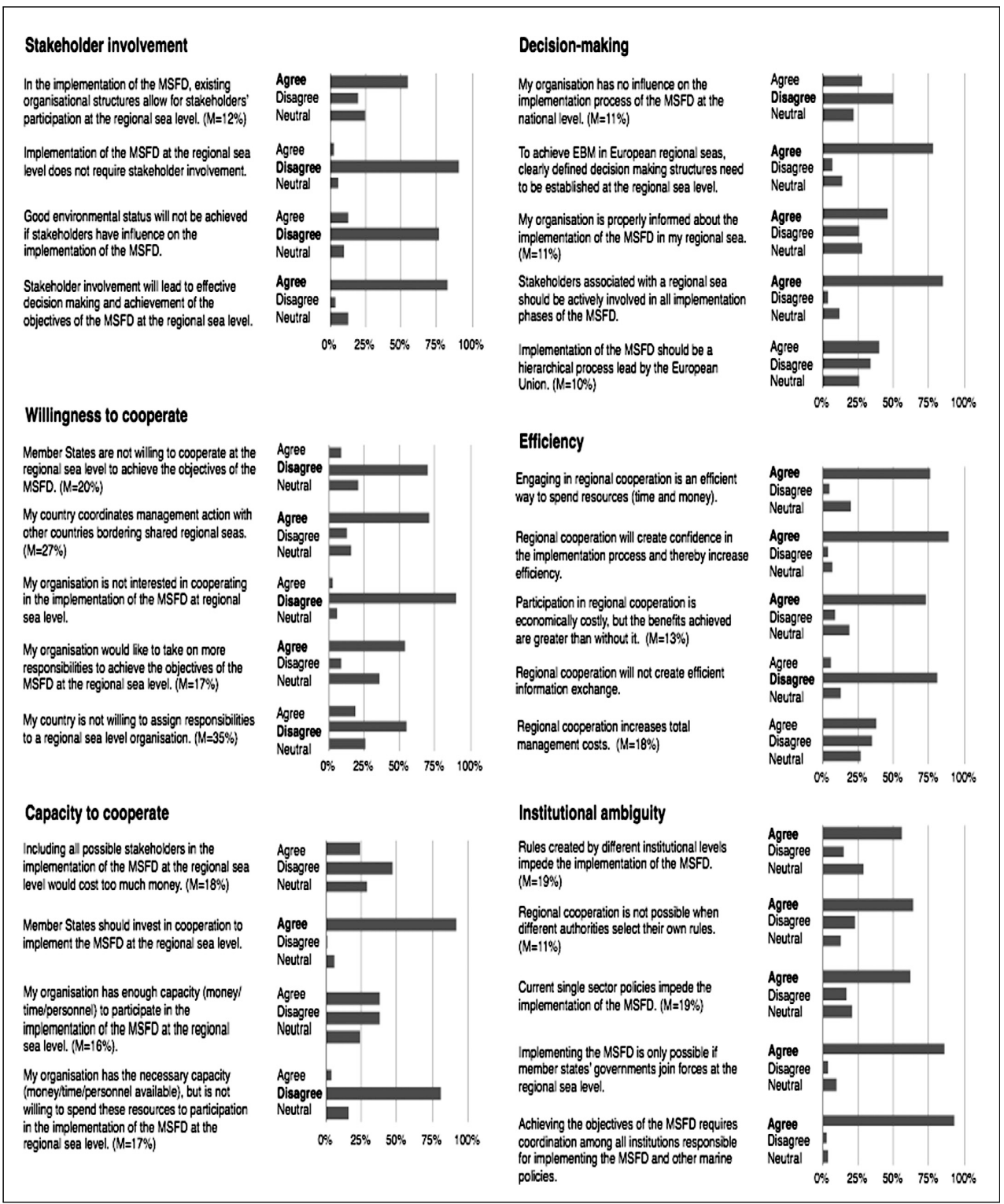


Table 5.3 Baltic Sea sector perspectives about the current, foreseen and ideal situation for regional cooperation for MSFD implementation based on governance drivers

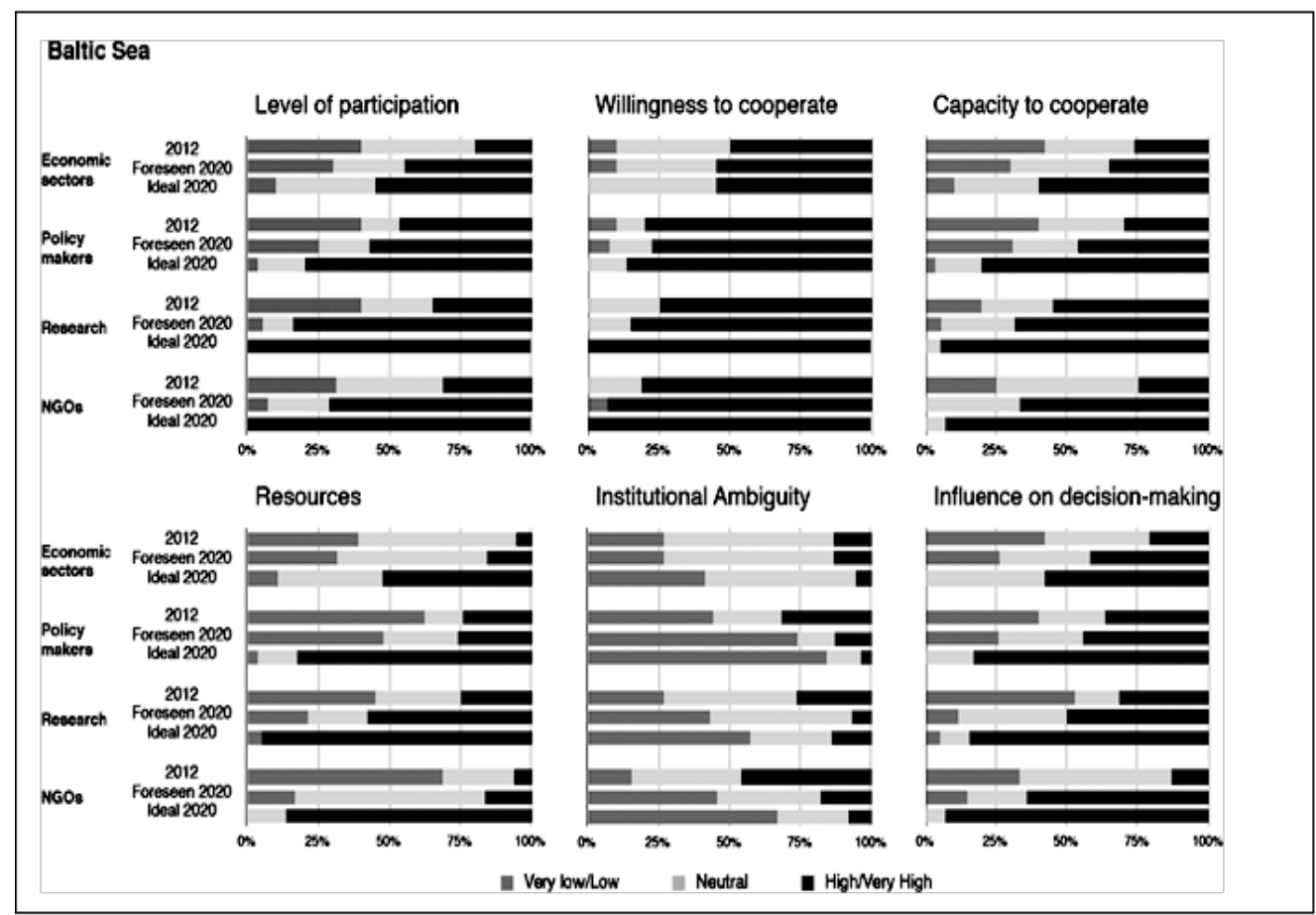

Selecting for the current situation, survey respondents applied a low ranking to the driver influence on decision making, changing to a high ranking for the foreseeable situation in 2020. Institutional ambiguity rated low across all stakeholder groups for all situations. Up to $60 \%$ of the survey respondents ranked neutral on the propositions about institutional ambiguity. It is a bit surprising that in the ideal situation low ambiguity is not ranked closer to $100 \%$ (see Table 5.4).

Within the Black Sea, the overall results show a low level participation in the current situation to high level of participation in the foreseen and ideal situations, indicative that survey respondents envisage greater involvement during MSFD implementation. None of the eNGOs scored on high involvement in the current situation. In the ideal situation 
$100 \%$ of the eNGOs, policy-makers and research select a high level of participation. The economic sector prove a distinctive score for the level of participation in the ideal situation with $25 \%$ neutral and $75 \%$ high ranking. Concerning the level of willingness to cooperate, the economic sector is distinct too in its rankings, ranking much lower than the other sectors in the foreseen situation. Of all respondents, 93\% accept that in the ideal situation the capacity to cooperate should be high.

Table 5.4 The ranking of drivers into current, foreseen and ideal situations by survey respondents disaggregated by stakeholder group for the Black Sea

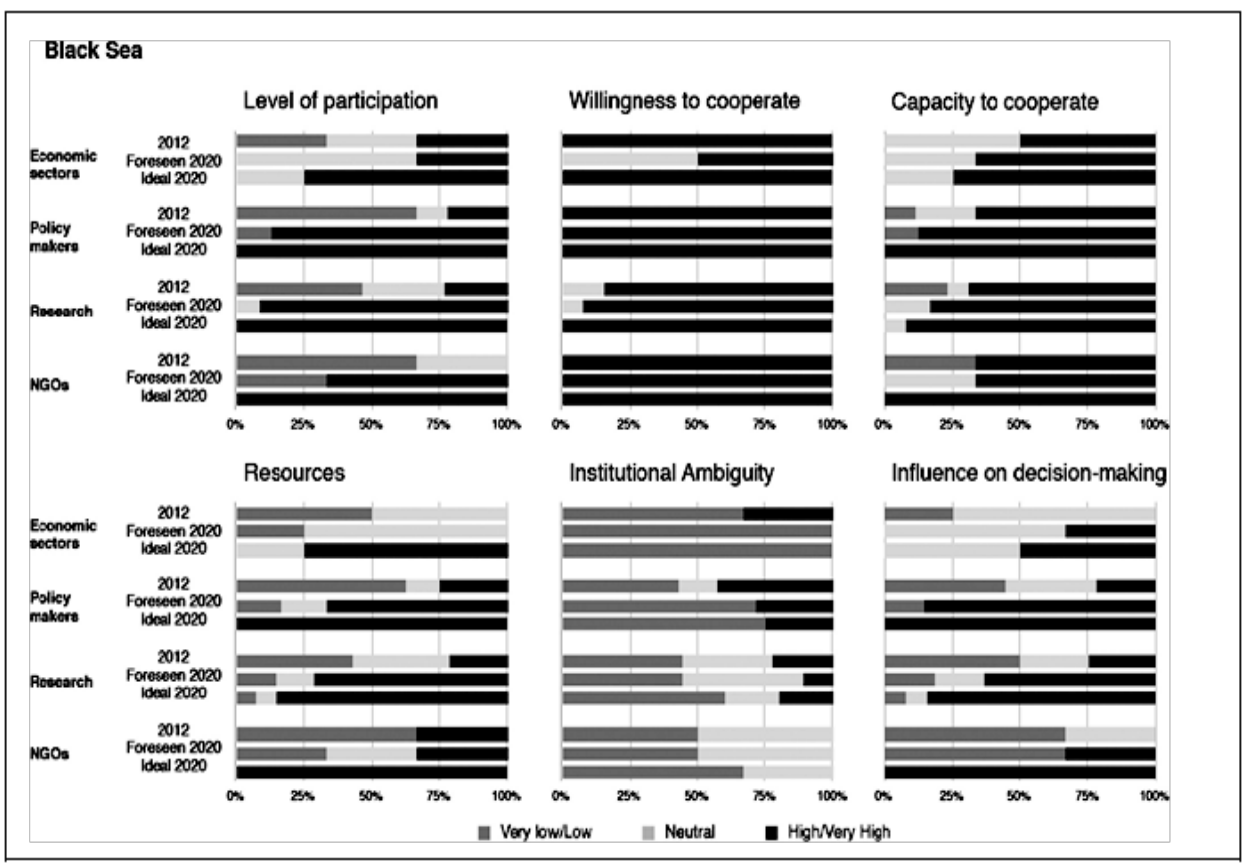

Responses to the driver resources, found $52 \%$ of the stake- holders judge their current situation as having low available resources to participate in the implementation of the MSFD at the regional sea level with specific results including: 50\% for economic sectors, $62 \%$ for policy makers, $43 \%$ for research and $67 \%$ for eNGOs. This percentage drops in the foreseen situation (mean $1 / 4$ 19\%) across all stakeholder groups. A majority of respondents, 97\%, believe a high amount of resources is necessary in the ideal situation. 
The economic sectors and eNGOs believe there should be no institutional ambiguity for implementing the MSFD in the ideal situation, whereas $20 \%$ of the researchers and $25 \%$ of the policy- makers prefer conflicting rules and procedures in the ideal situation.

Economic sectors and eNGOs believe that their organizations have low influence in decision making in the current situation, however this changes to high influence in the ideal situation. All stakeholders indicate that they will have greater influence on decision making in the foreseen situation, where low influence on decision making is not the ideal situation (see Table 5.5).

Table 5.5 Mediterranean Sea perspectives about the current, foreseen and ideal situation

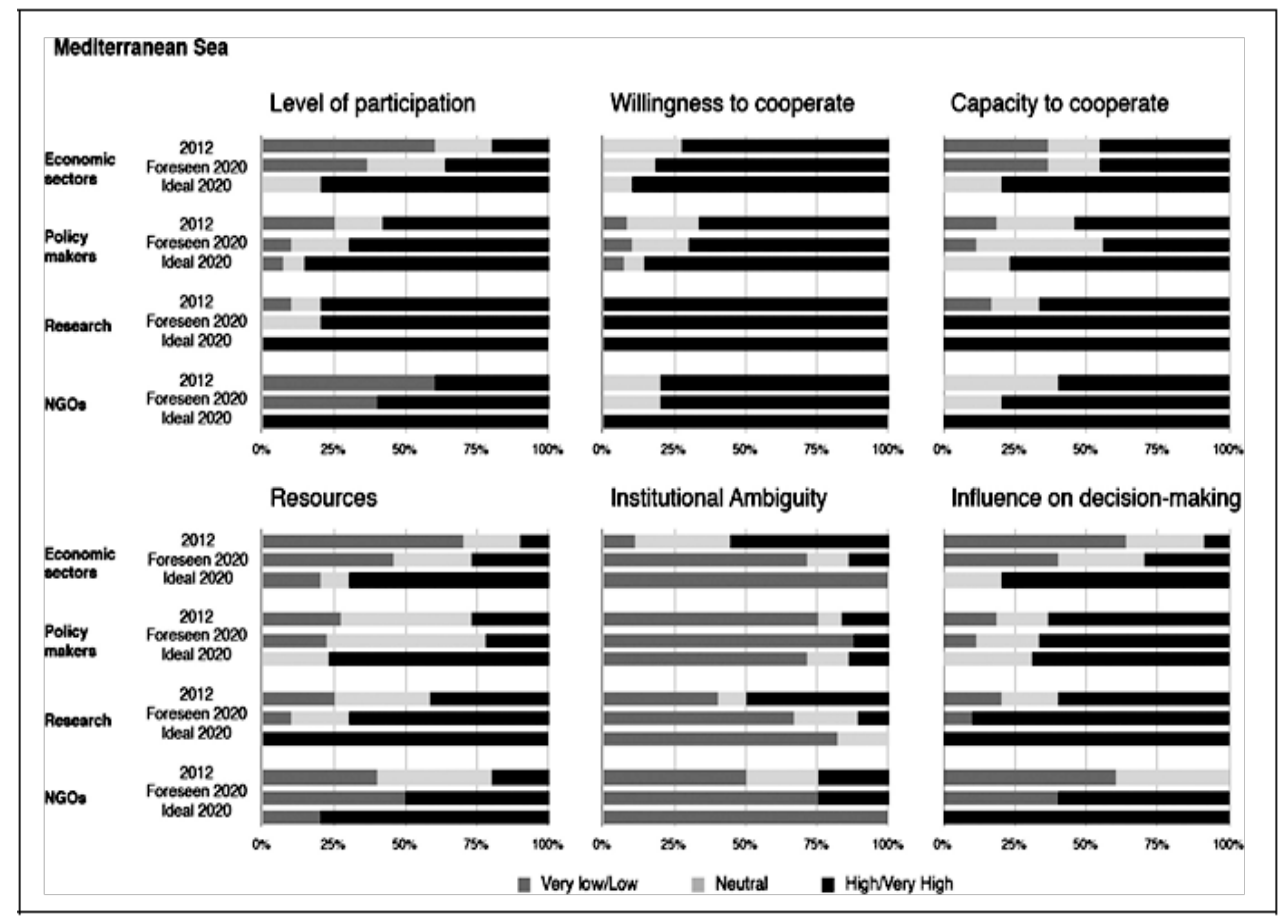

Regarding the level of participation in the current situation the different stakeholder groups acted rather mixed in the Mediterranean. Of the eNGOs 60\% ranked the level of participation low and 40\% ranked it high. Economic sectors present a similar response with $60 \%$ low, $20 \%$ neutral and $20 \%$ high scores. $25 \%$ of the policy- makers and $10 \%$ of research ranked low on the current level of participation. Although the current situation 
reflects lower levels of participation across all stakeholder groups, there is an overall positive and strong interest for a high level of participation across all stakeholder groups, 91\%, in the foreseen and ideal situations within the Mediterranean Sea. There is a clear overall picture that all stakeholder groups are willing to cooperate for all situations; however, their capacity to cooperate is ranked lower for all situations.

All stakeholder groups believe that in the ideal situation, their resources will be high comparatively to the lower resources available in both the current and foreseen situation. The policy- makers foresee fewer resources available in the foreseen situation (22\% high score on available resources) then in the current situation (27\% high score on available resources). The other sectors foresee more resources available in the near future.

Institutional ambiguity is believed to be lower in the foreseen and ideal situations by all stakeholder groups as compared to the current situation, where researchers and economic sectors score this driver higher than policy makers and eNGOs.

The influence on decision making is in the current situation clearly held by policymakers and research stakeholders respectively $60 \%$ and $64 \%$ ranked it high. On the contrary, $64 \%$ of economic sectors respondents and 60\% of NGO respondents ranked their influence on decision making in 2012 low. NGOs are more optimistic to see their influence on decision making improving, $60 \%$ ranked a high foreseen situation than the economic sectors that scored a 30\% high ranking. Research foresees a status quo of their influence on decision making by $67 \%$ high ranking and policy-makers foresee much improvement by $90 \%$ high ranking (see Table 5.6).

Aside from willingness to cooperate, all rankings of drivers across all situations in the North-East Atlantic Ocean, present a scattered picture for all stakeholder groups. In the ideal situation, eNGOs rank all propositions high, while two thirds of the economic sector ranked the preferred situation as high. There is a similar response rate across all stakeholder groups for level of participation for all scenarios, where in the ideal, the levels of participation would be high. Willingness to cooperate remains high for all stakeholder groups across all situations. Interestingly, economic sectors and policy makers ranked capacity to cooperate lower across all situations as compared to 
researchers and eNGOs. Similar to results presented across other regional seas, all stakeholder groups believe that high level of resources would be available in the ideal situation, while realistically the availability of these resources would be lower in the foreseen situation. Only 53\% of all survey respondents from the North East Atlantic answered that their organization has the necessary resources to participate in the implementation of the MSFD at the regional sea level, with the economic sector being the lowest at $7 \%$ followed by eNGOs at $9 \%$.

Of interest, is the higher level of institutional ambiguity as ranked by the economic sector and eNGOS in the current situation comparatively to policy makers and researchers. However, all stakeholder groups believe there will be lower institutional ambiguity in the foreseen and ideal situations. The influence on decision making in terms of regional cooperation for the implementation of the MSFD in the current situation is ranked low by $37 \%$ of the sectors and at the same time ranked high by $37 \%$ of the sectors. Differences between the sectors are sizeable: $13 \%$ of the research sector answered that their organization has low influence on decision making. $20 \%$ of the NGOs stated that their organizations have a low influence on decision making. $36 \%$ of the policy-makers and 55\% of the economic sectors sector believe that their organizations have a low influence on decision making. Considering the ideal situation, except $7 \%$ of the research sector and $3 \%$ of the policy-makers all respondents stated that a low influence on decision making is not the ideal situation 
Table 5.6 North East Atlantic Ocean sectors perspectives about the current, foreseen and the ideal situation

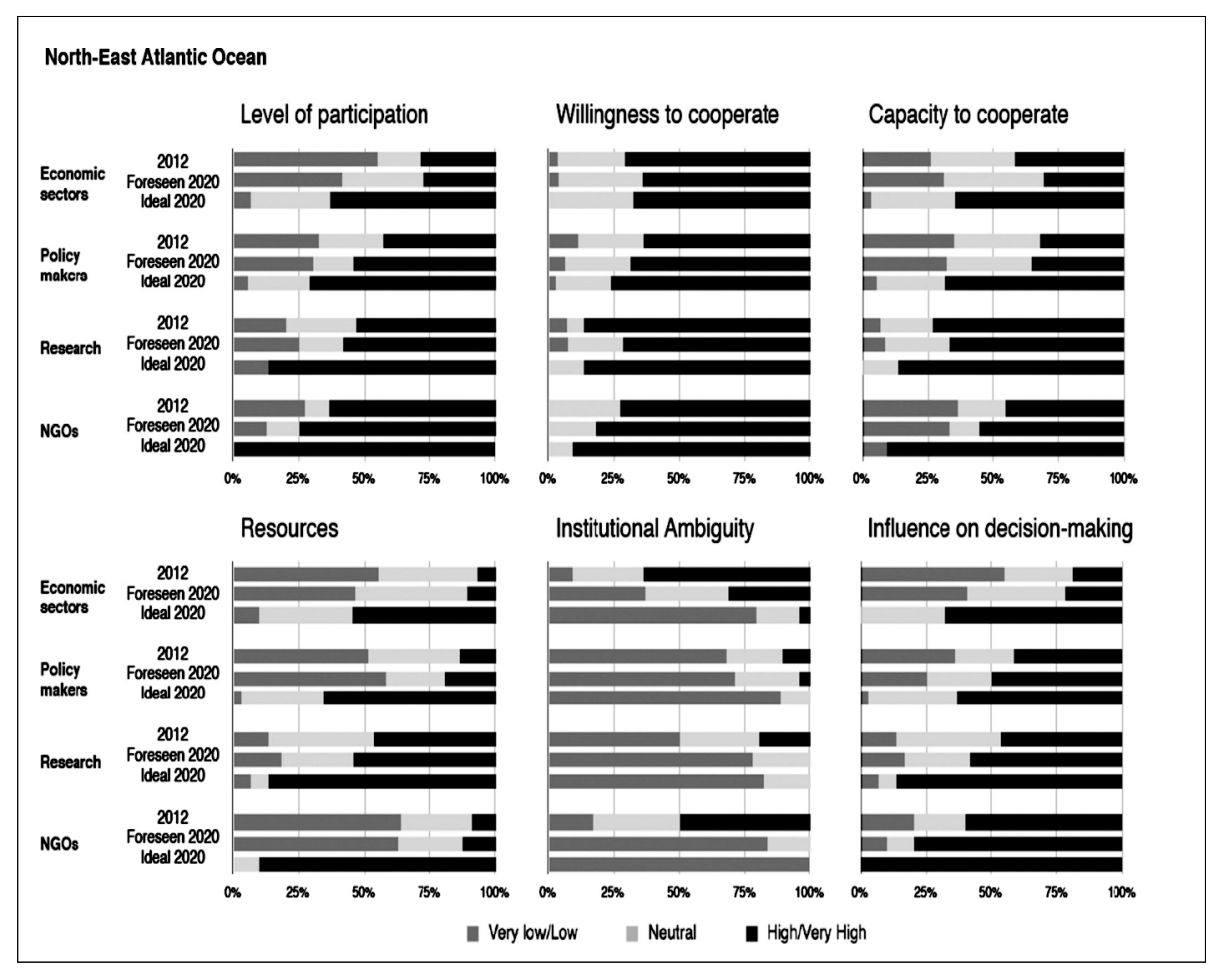

\subsubsection{Governance Scenario Preference ${ }^{8}$}

\section{Baltic Sea}

Overall, scenario B "Regional focus without commitment" ranked the highest amongst all survey respondents for the foreseen future in 2020 (see Table 5.7). This scenario is described as a model that the European Commission would impose. Decision making at the regional level happens in a rather vague manner. Only the eNGO stakeholder group foresee scenario E "Regional cooperation without changing the structures" as a

\footnotetext{
${ }^{8}$ A full description of the scenarios has been given in the methodology part. " 1 " counts the most preferred scenario and " 5 " counts the least preferred scenario. The scores represent the mean of all rankings scored by the concerned stakeholder group and shows an overall rank presented in the different table per regional sea.
} 
governance preference in 2020. The main difference between scenarios B and E, is that scenario E demonstrates a general commitment from countries and stake- holder groups to cooperate at a regional level. The least likely ranked scenario foreseen in 2020 by policy makers, researchers and eNGOs was scenario D "EU leading regional cooperation" while the economic sector ranked scenario A "National focus" as the least likely scenario. In both scenarios A and D, countries and stake- holders are reluctant to cooperate at the regional level.

It should be noted that there is complete agreement across all stakeholder groups for the ideal scenario in 2020. Scenario E "Regional cooperation without changing the structures" is the preferred scenario followed by scenario C "Regional cooperation by creating new structures". Scenario A "National Focus" is the least preferred scenario across all stakeholder groups. In the Baltic Sea a unanimous view prevails according to the preferred future.

\section{Black Sea}

the foreseen scenario in 2020 for the economic sectors and researchers is scenario B: "Regional focus without commitment", where decision making at the regional level is vague ( see Table 5.8). eNGOs foresees scenario A: "National Focus" in 2020, whilst policy- makers rank scenario D: "EU leading regional cooperation" as their preference in 2020. In both scenarios A and D, countries and stakeholders are reluctant to cooperate at the regional sea level.

All stakeholder groups agree that the ideal scenario in 2020 is Scenario E "Regional cooperation without changing the structures" followed by scenario C "Regional cooperation by creating new structures". Scenario A "National Focus" is the least preferred ideal scenario across all stakeholder groups. Interestingly, there is a large disparity between the foreseen and the ideal scenario in relation to regional sea cooperation in 2020 .

\section{Mediterranean Sea}

The foreseen scenario for 2020 is mixed across stakeholder groups for the Mediterranean Sea (see Table 5.9). Scenario B "Regional focus without commitment" is 
chosen by researchers and the economic sector; while policy-makers and eNGOs prefer scenario E "Regional cooperation without changing the structures". The least foreseen scenario in 2020 as ranked by eNGOs and the economic sectors is scenario C, scenario D for policy-makers and scenario E for researchers.

The ideal scenario as ranked by policy-makers and researchers is scenario E "Regional cooperation without changing the structures", while the economic sector and eNGOs favour scenario C "Regional cooperation with new structures" The least preferred ideal scenario for three stakeholder groups was scenario A "National focus", excluding researchers, who selected scenario D "EU leading regional cooperation".

\section{North East Atlantic Ocean}

In the North-East Atlantic Ocean (NEAO) researchers, policy-makers and eNGOs ranked scenario B "Regional focus without commitment" as the foreseen scenario in 2020 (see Table 5.10). This scenario is described as the model the European Commission would impose, where decision making at the regional level is vague. Only the economic sector ranked scenario E "Regional cooperation without changing the structures" as the foreseen 2020 scenario which states general commitment from countries and stakeholder groups to cooperate regionally. The two least ranked foreseen scenarios by all stakeholder groups were scenarios C "Regional cooperation by creating new structures" and D "EU leading regional cooperation". Excluding eNGOs, all other stakeholder groups ranked scenario E "Regional cooperation without changing the structures" as the ideal scenario in 2020, whereas scenario C "Regional cooperation by creating new structures" is preferred by eNGOs. Scenario A "National Focus" is the least ideal scenario for 2020 as ranked by all stakeholder groups. 
Table 5.7 Baltic Sea respondents' foreseen and the ideal scenarios of regional cooperation in 2020

\begin{tabular}{|c|c|c|c|c|c|c|c|}
\hline Baltic Sea & & & Scenario A & Scenario B & Scenario C & Scenario D & Scenario B \\
\hline \multirow[t]{4}{*}{ Reserarch } & Foreseen & Kank & 3 & 1 & 4 & 5 & 2 \\
\hline & & Score & 3.06 & 1.06 & 3.39 & 4.22 & 2.78 \\
\hline & Ideal & Kank & 8 & 3 & 2 & 4 & 1 \\
\hline & & Score & 4.33 & 3.39 & 2.00 & 3.67 & 1.61 \\
\hline \multirow[t]{4}{*}{ Policy'makers } & Foreseen & Rank & 3 & 1 & 4 & 6 & 2 \\
\hline & & Score & 3.11 & 2.11 & 3.33 & 4.19 & 2.26 \\
\hline & Ideal & Rank & 5 & 3 & 2 & 4 & 1 \\
\hline & & Score & 3.89 & 3.26 & 2.37 & 3.31 & 1.67 \\
\hline \multirow{3}{*}{ NGOS } & Forteeen & Kank & 3 & 2 & 4 & 5 & 1 \\
\hline & & Score & 3.00 & 2.56 & 3.31 & 3.75 & 2.38 \\
\hline & Ideal & $\begin{array}{l}\text { Rank } \\
\text { Score }\end{array}$ & $\begin{array}{l}5 \\
4.38\end{array}$ & $\begin{array}{l}3 \\
3.69\end{array}$ & $\begin{array}{l}2 \\
1.75\end{array}$ & $\begin{array}{l}4 \\
3.75\end{array}$ & $\begin{array}{l}1 \\
1.44\end{array}$ \\
\hline \multirow[t]{4}{*}{ Economic activities } & Foreseen & Rank & 8 & 1 & 3 & 4 & 2 \\
\hline & & Score & 3.47 & 2.41 & 3.06 & 3.24 & 2.32 \\
\hline & Ideal & Rank & 5 & 4 & 2 & 3 & 1 \\
\hline & & Score & 4.41 & 3.24 & 2.41 & 2.38 & 2.06 \\
\hline \multirow[t]{4}{*}{ TOTAL Baltic } & Foreseen & Rank & 3 & 1 & 4 & 5 & 2 \\
\hline & & Score & 3.15 & 2.14 & 3.28 & 3.90 & 2.53 \\
\hline & Ideal & Kank & 8 & 3 & 2 & 4 & 1 \\
\hline & & Score & 4.21 & 3.37 & 2.17 & 3.56 & 1.69 \\
\hline
\end{tabular}

Table 5.8 Black Sea respondents' foreseen and the ideal scenarios of regional cooperation in 2020

\begin{tabular}{|c|c|c|c|c|c|c|c|}
\hline Mediterranean & & & Scenario A & Scenario B & Scenario C & Scenario D & Scenario $B$ \\
\hline \multirow[t]{4}{*}{ Research } & Foreseen & Fank & 2 & & 4 & & 5 \\
\hline & & Score & 2.79 & 2.43 & 3.36 & 2.86 & 3.57 \\
\hline & Ideal & Rank & 3 & 4 & 2 & 5 & 1 \\
\hline & & Score & 3.07 & 3.21 & 3.00 & 3.36 & 2.36 \\
\hline \multirow[t]{4}{*}{ Policy malers } & Foreseen & Eank & 3 & 2 & 4 & 5 & 1 \\
\hline & & Score & 3.08 & 2.46 & 3.38 & 3.77 & 2.31 \\
\hline & Ideal & Fank & 5 & 4 & 2 & 3 & 1 \\
\hline & & Score & 3.92 & 3.38 & $2.7 \pi$ & 3.23 & 1.69 \\
\hline \multirow[t]{3}{*}{ NGOA } & Foreseen & Rank & 4 & 2 & 5 & 3 & 1 \\
\hline & & Score & 3.6 & 2.2 & 4.4 & 3.4 & 1.4 \\
\hline & Ideal & $\begin{array}{l}\text { Rank } \\
\text { Score }\end{array}$ & $\begin{array}{l}5 \\
4.8\end{array}$ & $\begin{array}{l}3 \\
3.2\end{array}$ & $\begin{array}{l}1 \\
1.2\end{array}$ & $\begin{array}{l}4 \\
3.6\end{array}$ & $\begin{array}{l}2 \\
2.2\end{array}$ \\
\hline \multirow[t]{4}{*}{ Bconomic activities } & Foreseen & Eank & 3 & 1 & 5 & 4 & 2 \\
\hline & & Score & 3.18 & 2.55 & 3.36 & 3.27 & 2.64 \\
\hline & Ideal & Rank & & 4 & & & \\
\hline & & Score & 4.27 & 2.91 & 2.45 & 2.73 & 2.64 \\
\hline \multirow[t]{4}{*}{ TOTAL } & Foreseen & Fank & 3 & 1 & $\tilde{5}$ & 4 & 2 \\
\hline & & Score & 3.07 & 2.44 & 3.49 & 3.30 & 2.70 \\
\hline & Ideal & Rank & 5 & 3 & 2 & 3 & \\
\hline & & Score & 3.84 & 3.19 & 2.58 & 3.19 & 2.21 \\
\hline
\end{tabular}


Table 5.9 Mediterranean Sea respondents' foreseen and the ideal scenarios of regional cooperation in 2020

\begin{tabular}{|c|c|c|c|c|c|c|c|}
\hline Black Sea & & & Scenario A & Scenario B & Scenario C & Scenario D & Scenario E \\
\hline \multirow[t]{4}{*}{ Research } & Foreseen & Rank & 2 & 1 & 4 & 5 & 3 \\
\hline & & Score & 2.91 & 2.27 & 3.27 & 3.55 & 3.00 \\
\hline & Ideal & Kank & 5 & 4 & 2 & 3 & 1 \\
\hline & & Score & 3.73 & 3.55 & 2.73 & 2.91 & 2.09 \\
\hline \multirow[t]{4}{*}{ Policy'makers } & Foreseen & Rank & 4 & 2 & 2 & 1 & 5 \\
\hline & & Score & 3.00 & 2.89 & 2.89 & 2.78 & 3.44 \\
\hline & Ideal & Kank & 5 & 4 & 2 & 3 & 1 \\
\hline & & Score & 4.33 & 3.22 & 2.44 & 3.11 & 1.39 \\
\hline \multirow[t]{3}{*}{ NGO= } & Foreseen & Eank & 1 & 2 & 4 & 5 & 3 \\
\hline & & Score & 1.33 & 2.00 & 4.00 & 4.33 & 3.33 \\
\hline & Ideal & $\begin{array}{l}\text { Rank } \\
\text { Score }\end{array}$ & $\begin{array}{l}5 \\
4.00\end{array}$ & $\begin{array}{l}4 \\
3.67\end{array}$ & $\begin{array}{l}1 \\
2.00\end{array}$ & $\begin{array}{l}3 \\
3.00\end{array}$ & $\begin{array}{l}2 \\
2.33\end{array}$ \\
\hline \multirow[t]{3}{*}{ Economic activities } & Foreseen & Rank & 3 & 1 & 2 & 5 & 3 \\
\hline & & Score & 3.20 & 2.40 & 2.60 & 3.60 & 3.20 \\
\hline & Ideal & $\begin{array}{l}\text { Kank } \\
\text { Score }\end{array}$ & $\begin{array}{l}8 \\
4.20\end{array}$ & $\begin{array}{l}4 \\
3.60\end{array}$ & $\begin{array}{l}1 \\
2.20\end{array}$ & $\begin{array}{l}3 \\
2.30\end{array}$ & $\begin{array}{l}1 \\
2.20\end{array}$ \\
\hline \multirow[t]{4}{*}{ TOTAL Black Sez } & Foreseen & Rank & 2 & 1 & 3 & 5 & 4 \\
\hline & & Score & 2.82 & 2.46 & 3.11 & 3.39 & 3.21 \\
\hline & Ideal & Rank & 5 & 4 & 2 & 3 & 1 \\
\hline & & Score & 4.04 & 3.46 & 2.46 & 2.96 & 2.07 \\
\hline
\end{tabular}

Table 5.10 North East Atlantic Sea respondents' foreseen and the ideal scenarios of regional cooperation in 2020

\begin{tabular}{|c|c|c|c|c|c|c|c|}
\hline Mediterranean & & & Scenario A & Scenario B & Scenario C & Scenario D & Scenario B \\
\hline \multirow[t]{4}{*}{ Researcb } & Foreseen & Rank & 2 & 1 & 4 & 3 & $\delta$ \\
\hline & & Score & 2.79 & 2.43 & 3.36 & 2.36 & 3.57 \\
\hline & Ideal & Eank & 3 & 4 & 2 & 5 & 1 \\
\hline & & Score & 3.07 & 3.21 & 3.00 & 3.36 & 2.36 \\
\hline \multirow[t]{4}{*}{ Policy'makers } & Foreseen & Rank & 3 & 2 & 4 & 5 & 1 \\
\hline & & Score & 3.08 & 2.46 & 3.38 & 3.77 & 2.31 \\
\hline & Ideal & Eank & 8 & 4 & 2 & 3 & 1 \\
\hline & & Score & 3.92 & 3.38 & 2.77 & 3.23 & 1.69 \\
\hline \multirow[t]{4}{*}{ NGO= } & Foreseen & Rank & 4 & 2 & 5 & 3 & 1 \\
\hline & & Score & 3.6 & 2.2 & 4.4 & 3.4 & 1.4 \\
\hline & Ideal & Rank & 8 & 3 & 1 & 4 & 2 \\
\hline & & Score & 4.8 & 3.2 & 1.2 & 3.6 & 2.2 \\
\hline \multirow[t]{4}{*}{ Economic activities } & Fortseen & Eank & 3 & 1 & 8 & 4 & 2 \\
\hline & & Score & 3.18 & 2.05 & 3.36 & 3.27 & 2.64 \\
\hline & Ideal & Rank & 5 & 4 & 1 & 3 & 2 \\
\hline & & Score & 4.27 & 2.91 & 2.45 & 2.73 & 2.64 \\
\hline \multirow[t]{4}{*}{ TOTAL } & Fortseen & Eank & 3 & 1 & 5 & 4 & 2 \\
\hline & & Score & 3.07 & 2.44 & 3.49 & 3.30 & 2.70 \\
\hline & Ideal & Rank & 8 & 3 & 2 & 3 & 1 \\
\hline & & Score & 3.84 & 3.19 & 2.58 & 3.19 & 2.21 \\
\hline
\end{tabular}

\subsection{Perspectives for Future Governance Structures}

Stakeholder views on the MSFD implementation demonstrate that within the different contexts across the four European regional seas, a challenging patchwork of future governance structures exist. All stakeholder groups strongly support the need and establishment of a clearly defined and transparent decision- making and support structure. Such a structure should ensure coordination among all institutions that are 
responsible for MSFD implementation at the regional sea level in order to adopt Ecosystem-based Marine Management in European regional seas. However, in the current fragmented governance system cooperation at the regional sea level could be jeopardised if different authorities can determine their own rules, as suggested by the majority of stakeholder groups in this research. This response supports the work of Van Leeuwen (2012) who described that institutional ambiguity is a severe impediment and challenge to MSFD implementation at the regional sea level.

Stakeholder perspectives on the survey governance drivers, propositions and scenarios showed a strong preference from all sectors across all regional seas for being involved in all phases of the MSFD implementation. The overall picture suggests that stakeholder involvement in regional sea cooperation will depend on improving existing or creating new institutional structures. As participation in regional sea cooperation is economically costly for all survey stakeholder groups, they still believe that the benefits achieved would be greater than without participation. Although the majority of the survey stakeholder groups wish to participate in regional sea cooperation, they do find themselves in a position where they have little influence on the decision making processes. The lack of detailed governance structures for stakeholder involvement in decision making processes causing the different marine sectors to be on unequal footing. Taking into account the different contexts across the European regional seas, a major step forward for MSFD implementation shows a need for the regional adjustment of governance procedures to allow different sectors a place in the planning and implementation process of the MSFD. It is important to acknowledge that even if all stakeholder groups aim for stakeholder involvement and improved decision making processes, the differences in starting points per sea and per sector are crystal clear and calls for tailor-made solutions. The survey point to two crucial building blocks: Stakeholder involvement and decision making power to be the back-bone in to developing governance arrangements for regional cooperation and ensure coordination at the regional sea level and providing for stake- holder enhanced involvement. Van Tatenhove et al. (2014) deal with these challenges and based on the survey results develop four governance models and do an ex ante assessment on how the four alternative models. 


\section{Conclusions}

\subsection{Introduction}

In this thesis, a number of challenges have been touched upon in the search for meaningful stakeholder participation in decision making on sustainability issues. The concepts 'meaningful stakeholder participation' and 'decision making on sustainability issues' have been considered as guiding principles in this thesis, following the strong emphasis on both concepts and their mutual connections in the World Commission on Environment and Development report “Our Common Future” (1987). As these concepts do not provide clear guidelines for operationalisation, most stakeholder groups invented their own definitions and meanings for these concepts (Bruyninckx 2005). The main reason for not reaching a mutual understanding is that environmental risks, such as climate change or reduction of $\mathrm{CO}_{2}$ emissions are characterized by complexity and uncertainty and have proven to give rise to worldwide consequences that are difficult to control (Beck 2007). Yet everyone is at a certain point vulnerable to environmental risks and has to make decisions on sustainability issues for one's own, like choices in daily commuting or energy demand. Stakeholder groups ranging from private companies, scientists, public authorities and civil society groups have shown widely different preferences when it comes to solving environmental challenges. In addition, no stakeholder group involved in decision making on complex sustainability issues has the expertise or a complete overview to judge the consequences and impact of decisions taken. The debates about sustainability and participatory decision making provided evidence that there is no consensus in what vital stakeholder groups, like scientists, policy-makers, private sectors and society consider as meaningful stakeholder participation in decision making on sustainability issues (Cottrell et al. 2015; Reed 2008; Fung 2006; Irvin and Stansbury 2004).

The empirical cases in the PROVIDE and ODEMM programmes have clearly shown the differences between participation and meaningful participation in decision making processes on sustainability issues. In the former, different stakeholder groups are provided formal access to decision making processes while meaningful participation 
moves beyond formal access and comes with actual inclusion and influence. Meaningful participation adds value to the participation of the stakeholder groups involved as well as to the quality, legitimacy and output of decision making. It solves the three dilemmas around decision making on environmental issues presented in Chapter 1: the extent of access to, and inclusion in participatory decision making; the ability of joint knowledge generation; and the legitimacy of sustainability decisions. These dilemmas are connected. If certain stakeholder groups are excluded and therefore not capable to influence the decision making process, successful implementation of environmental solutions is complicated as implementation is often dependent on the support of a diverse group of stakeholders (Silver et al. 2010). Even if all relevant stakeholder groups have access to the decision making process, shared knowledge generation is often complicated, fragmented and non-transparent (Hordijk and Baud 2006). This hampers the effectiveness and problem solving capacity of environmental risks and with that, the legitimacy of decision making processes (Shirk et al 2012). Within this thesis a participatory decision making methodology has been designed, tested and evaluated with a focus on inclusiveness, joint knowledge generation and the legitimacy of meaningful and participatory decision making on sustainability issues.

The preceding chapters in this thesis have examined the dilemmas and potentials around meaningful stakeholder participation in decision making on sustainability issues in the research programmes PROVIDE and ODEMM in a multiple case study research. This concluding chapter answers the research questions and formulates the conclusion of this thesis with the objective of designing, testing and evaluating a methodology for participatory and meaningful decision making processes on sustainability issues.

Three research questions guided the research:

> How to ensure access to and inclusion in participatory decision making on sustainability issues?

> What enables stakeholder groups to generate joint knowledge in decision making on sustainability issues?

> How can stakeholder involvement contribute to improved legitimacy of sustainability decisions? 
Furthermore this final chapter reflects on the research findings and the case study approach through which the results were obtained. Section two synthesises the research findings in order to answer the research questions. In section three I will argue under what circumstances the case study results can be applied to other decision making processes and contexts related to sustainability (external validity). Section four provides a future research outlook.

\subsection{Research Findings}

This thesis designed, tested and evaluated a participatory decision making methodology that meets the conditions for meaningful stakeholder involvement. The underlying idea is that relevant stakeholder groups involved in decision making processes on sustainability issues, such as scientists, public authorities, private parties and societal actors, often have different forms of knowledge, perspectives, values and experiences on environmental issues, and hence they should join forces in order to reach sustainable solutions. The design of the participatory decision making process, the participation and inclusiveness of stakeholders, the degree of shared knowledge production and the legitimacy were found to be critical factors for meaningful and participatory decision making processes on sustainability issues.

\section{Design of the participatory decision making process}

The developed participatory decision making methodologies, Proact 2.0 and the ODEMM approach, have two innovative and strongly intertwined characteristics in how they are designed to enable meaningful stakeholder involvement: (1) the division of the participatory decision making process in different chronological phases; (2) the assignment of only the relevant stakeholder groups for distinct phases of the decision making process.

By dividing the participatory decision making process in different phases, relevant stakeholder groups could be assigned to distinct phases of the decision making process. In the first two phases of the decision making process -problem analyses and setting 
objectives- involvement of all relevant stakeholder groups was considered important. In these two phases it has been essential that the problem at stake could be considered from as many different angles, interests and perspectives as possible and that all stakeholder groups agreed on common objectives in dealing with the sustainability issue at stake. This changed in the third phase. During the third phase of defining alternatives, scientific experts were leading and came up with alternatives, usually in the form of distinct scenarios, which fit in the local or regional conditions and were based on objectives set by all relevant stakeholders in the previous phase. These alternatives were subsequently tested by potential users and/or public and private actors in the fourth phase of considering consequences, where no major role was assigned to scientific experts. Finally, in the fifth phase of trade-offs policy makers were informed about the alternatives assessed and chosen, including -the positive and negative considerations different stakeholder groups assigned to the relevant alternatives. This enabled policy-makers to assess the trade-offs, confirm the final decision and ensure implementation (see Table 6.1).

By assigning different sets of stakeholder groups to different phases, participation extended beyond formal access and offered possibilities for actual and meaningful inclusion and influence. Actual inclusion is important because it allows stakeholders to exert influence in phases where they are considered to be able to provide relevant contributions, while excluding stakeholder groups in phases of the decision making process where they have little to contribute. Moreover, in all cases in this research the input of stakeholder groups was used in specific phases to shape the next phase in the decision making process, allowing continuation of stakeholder influence in phases in which they did not participate. 


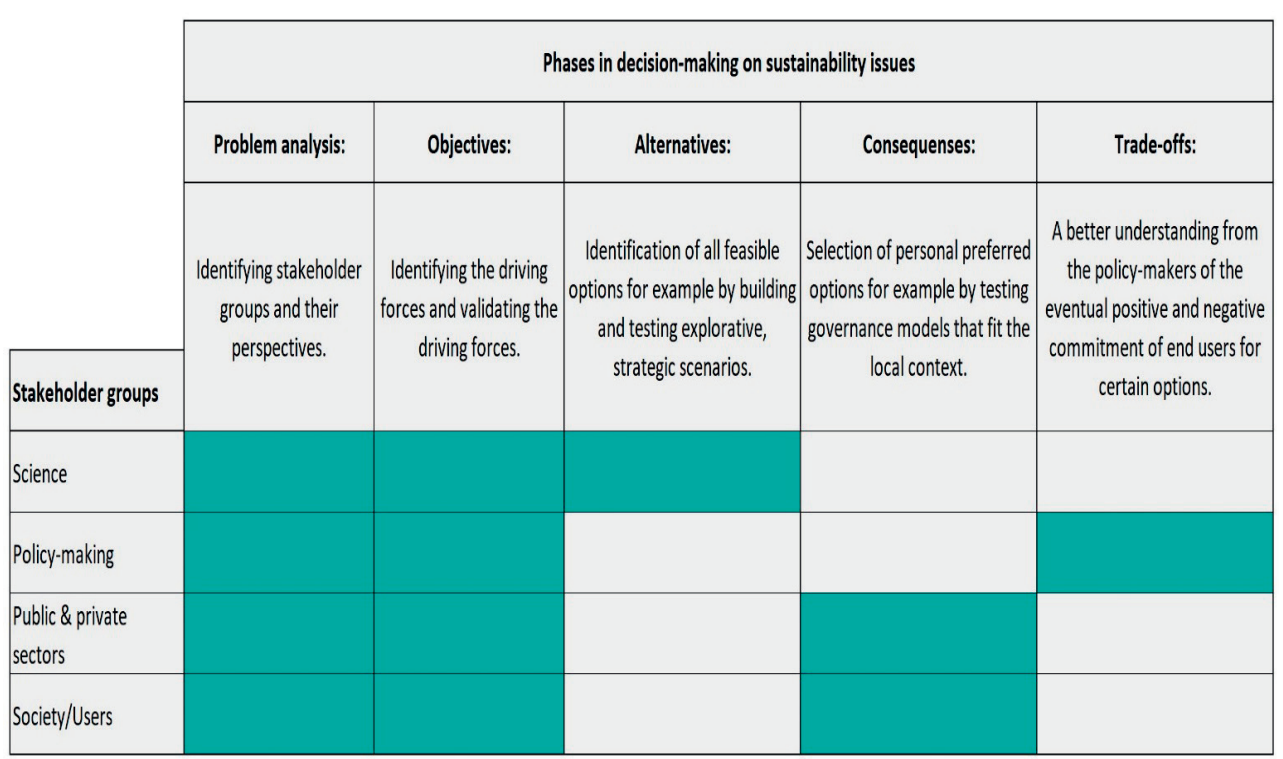

The designed, tested and evaluated decision making methodology differs from other participatory methodologies in how the decision making process has been organised. The specific set up of the Proact 2.0 and the ODEMM approach have created conditions for inclusiveness and shared knowledge production leading to improved legitimacy of sustainable solutions. I will first elaborate on the critical factors "inclusiveness" and "shared knowledge production" before discussing legitimacy.

\section{Access to and inclusion in participatory decision making on} sustainability issues

Several questions have emerged regarding how to grant vital stakeholder groups access and to get the appropriate stakeholders around the table to meaningfully participate in decision making processes on sustainability issues. Who should be invited to participate and how to make sure that all voices are heard and can meaningfully participate? Having recognized the importance of incorporating a broad range of perspectives in decision 
making on sustainability issues, Ounanian et al. (2012) amongst others, revealed differences in organizational capacity, available resources and access to information, leading to unequal footing in terms of the ability to participate and to influence decision making. Dewulf and Elbers (2018) supported this statement by arguing that power strategies in and over cross-sector partnerships can be understood as the ability of stakeholders to influence the results of collective decisions of the partnership to their own advantage, in a variety of ways.

When it comes to ensuring access to and inclusion in participatory and meaningful decision making, in the PROVIDE programme scientific experts in the field of sanitation have played a decisive role in offering access and inclusiveness to a broad range of stakeholder groups. In the ODEMM programme, scientific experts in the field of marine governance have fulfilled that role. Stakeholders were identified by a variety of methods, such as snowball sampling, literature review, stakeholder lists from previous research, semi-structured interviews and a considerable number of informal meetings with informants in the field. The PROVIDE and ODEMM programmes have shown that the search for whom should be invited at the decision making table can adequately be performed by (scientific) experts. Usually, these experts are part of an academic network, have access to literature sources and have the knowledge and skills to explore different stakeholder groups who could play a key-role in the consecutive phases of a participatory decision making process on sustainability issues. Two strategies proved helpful in preventing a biased selection of stakeholder groups by scientists. First, triangulation of research methods has been a useful strategy for a wide identification and subsequent invitation of a diversity of stakeholder groups. Second, as experts are often specialised in one research field, a risk exists that by unintentional focusing on their own research domain experts can easily overlook a more general perspective of who are relevant stakeholders and what kind of activities are needed for a participatory and meaningful decision making process. Cooperating in a multidisciplinary research team that consists of researchers from different backgrounds such as technical sciences, social sciences and environmental sciences can help to avoid such researchers' biases.

When the participatory decision making process started, all identified stakeholders were invited to indicate the criteria that should be considered when designing and 
comparing alternatives for improved sanitation facilities or regional cooperation in European Seas. The various stakeholder groups brought different criteria to the fore. For example, technological experts in the field of sanitation mentioned criteria such as a robust and safe construction, while potential users of sanitation facilities came up with criteria such as hygiene and easiness to clean. A similar example can be given for the cases in marine governance where different stakeholder groups identified different driving forces. For example 'efficiency' has been expressed in terms of economic costs and benefits by the off shore oil and gas sector, while NGOs primarily mentioned social efficiency, such as costs involved in attending regional meetings. In this phase, all stakeholder groups were treated as 'experts' and were not approached as (interest) representatives of their organisation, neighbourhood, sea or country. As various stakeholder groups were showing different perspectives for the same environmental problem, and as a result identified different criteria, most stakeholders involved found it complicated to explain their perspectives on the problem to other stakeholder groups. It turned out that deliberatively discussing perspectives on sanitation or marine governance and thus constantly testing each other's underlying assumptions, contributed to understanding each other's perspectives.

Stakeholder groups were invited to participate in specific phases of the decision making process (see Table 6.1). During the decision making process there were no indications that stakeholders wanted to be involved in phases other than those assigned to them, with the exception of policy-makers. Especially in the phase of consequences, when different sanitary options or scenarios for regional cooperation in European seas were discussed, public authorities thought it important to attend several meetings as observers in order to gain a better understanding of the positive and negative arguments for a specific sanitary option or scenario for regional cooperation in European Seas.

\section{Joint knowledge generation}

This thesis has shown that joint knowledge generation is essential for a participatory and meaningful decision making process on sustainability issues. Joint knowledge generation is regarded as an interaction process between societal actors, private parties, 
policy-makers and (scientific) experts resulting in a common knowledge base, which gives meaning to - and legitimizes - decisions taken (Brugnach and Ingram, 2012;

Edelenbos et al. 2011; Feldman et al. 2006). According to Hordijk and Baud (2006) joint knowledge generation could lead to the building of cross-sectoral sustainable relations and the development of boundary-crossing skills, such as the ability to change perspective, to cope with complexity and to synthesize knowledge of different fields of expertise in a critical and creative way. At the same time the worlds of decisive stakeholder groups in decision making processes on sustainability issues, are rather different and these differences may hinder the knowledge co-production processes (Edelenbos et al. 2011).

The process of knowledge generation refers to how knowledge is processed and how new knowledge is created (Brugnach and Ingram 2012). Feldman et al. (2006) have introduced the 'ways of knowing model' as a way to understand the structure of knowledge that is associated with policy issues (see Box 6.1 for examples of ways of knowing). The way stakeholders view environmental issues changes over time in relation to other environmental issues or technological developments. As a consequence, ways of knowing associated with a public issue are dynamic and fluid. This helps to bring together different ways of knowing and to create opportunities for new ways of knowing to emerge. A vital role is assigned to knowledge coalitions, which may consist of various stakeholder groups, like scientists, policy-makers, public and private actors and societal actors and permit joint knowledge generation. 


\section{Box 6.1 Examples of ways of knowing}

(1) Sanitation in unplanned urban settlements, eco-san toilets.

Multiple ways of knowing can be identified around the design and implementation of sanitation in unplanned urban settlements such as eco-san toilets. Improving sanitary facilities can be helpful in the fight against diseases and improve safety issues for the urban poor. Experts in the field of health, Community Based Organisations and international organisations like the United Nations could be part of this way of knowing. Another way of knowing eco-san toilets can be that eco-san toilets are an environmental friendly and a technological innovative sanitary facilitation. Technological and environmental experts, constructors and environmental NGOs may adhere to this way of knowing. Depending on the local and cultural context potential users can be part of yet another way of knowing. The co-existence of multiple ways of knowing may cause conflicts. For example, resources may be available for innovative and environmental friendly eco-san toilets, while from a cultural point of view waterless toilets are not seen as hygienic by potential users and therefore not suitable as a sanitary facility in a specific local context.

\section{(2) Marine Governance in European Seas, offshore windfarms.}

Offshore windfarms can be seen by environmental NGOs, wind turbine designers, and the energy sector as unavoidable for a sustainable energy future. This way of knowing may conflicts with the way of knowing from sectors like fisheries and tourism as certain parts of the sea would be closed for carrying out their preferred activities and this can be felt as a loss of freedom and an economic loss. 
The case of improved sanitation shows that in the phases of problem analysis and setting objectives, new knowledge coalitions came up with, and comprehensively discussed the criteria that were important to improve sanitary facilities. These criteria were leading for the scientific experts, who were going to develop sanitary alternatives. The experts, therefore, had to take into account not only technical criteria but also social, economic, health and cultural criteria formulated and agreed upon by knowledge coalitions. When the alternatives were presented and explained, potential users were positively surprised because they had not previously thought outside the traditional, well-known, sanitary facilities. Potential users were afraid that in their slum, the pitlatrine was the only feasible sanitary possibility, which was in their opinion not a civilized alternative. A SWOT-analysis of each alternative was performed by the potential users and presented to all relevant stakeholders and with the newly created knowledge, it became possible to choose a feasible and accepted sanitary alternative, the elevated double-pit latrine.

The decision making process in the cases of marine governance was organised in a similar way. All relevant stakeholders were included in the decision making in the phases of problem analysis and of setting objectives about the driving forces. Scientific experts used the driving forces as guiding principles to develop explorative scenarios. All relevant stakeholder assessed the scenarios and based on these results alternative governance models were developed. A SWOT analyses of each governance model was carried out by a new knowledge coalition and after extensive discussions and adjustments to the presented governance models, this knowledge coalition agreed on 'the best' governance model. What stakeholders considered the best governance model differed per regional sea.

By recognizing and paying extensive attention to multiple ways of knowing, and by providing different stakeholders the opportunity to collaborate and understand each other's perspectives, Proact 2.0 and the ODEMM approach have shown how joint knowledge generation can occur among and between various stakeholder groups. 
Van Buuren and Edelenbos (2004) amongst others, propose three conditions to restructure the relationships among different knowledge coalitions. In line with the first condition, the composition of new knowledge coalitions, in all cases of this thesis new knowledge coalitions were formed, consisting of different stakeholder groups involved. Especially in the phases of problem analysis, objectives and consequences there have been extensive opportunities for the assigned participants to take on board each other's views, experiences and preferences, to share knowledge and to generate choices. In contemplating on and arguing for what they consider to be the best solution, participants have deliberatively been trying to convince one another. In this way, all stakeholder groups have been considered co-producers of knowledge who were able to have an influence on the joint knowledge base and finally the decisions taken. It turned out that even if their deliberative participation did not result in one common recommendation, stakeholder values have become noticeable and identifiable in the ultimate decision.

In line with the second condition, the design and testing of a decision making strategy in mutual interaction, composing a new knowledge coalition became a continuous and natural process. In the case studies carried out in this thesis, scientific experts in the field of marine governance (ODEMM programme) and in the field of sanitation (PROVIDE programme) have been designing and testing a decision making methodology in which all stakeholders were treated as experts. Being considered as experts, stakeholders were given the opportunity to cooperate across various stakeholder groups in a knowledge coalition. As a consequence, knowledge producers were no longer seen as outsiders who gave advise about complex issues, but were able to contribute by providing relevant findings throughout the whole decision making process.

In line with the third condition, starting with an open problem definition and an open policy agenda in order to reach collective agreement about policy options and the underlying argumentation, the cases have shown active involvement of relevant stakeholder groups to jointly identify and analyse the problem to be solved and the 
objectives to be achieved. This resulted in policy options that reflected the diversity of perspectives of relevant stakeholders involved in the decision making process.

\section{Conclusion: heuristics for meaningful participatory decision making processes that are considered legitimate}

In conclusion, the designed, tested and evaluated decision making methodologies, Proact 2.0 and the ODEMM approach, provide stakeholders a meaningful and participatory decision making process on sustainability issues in the investigated cases. To take this conclusion a step further and to apply it in new projects, I propose a set of heuristics for designing meaningful and participatory decision making processes that are legitimate and that can be derived from the studied cases:

1. The participatory decision making process is divided in consecutive phases; each with a clear starting and end point. The results of stakeholder input in each case is used to shape the next phase in the decision making process.

2. Different stakeholder groups are assigned to participate in specific phases of the decision making process. This allows stakeholders to exert meaningful influence in phases where their contribution can be considered relevant, while excluding stakeholders in phases of the decision making process where they have little to contribute. Not all stakeholder groups need to be involved in each phase of the decision making process.

3. A multidisciplinary scientific team is capable to guide and facilitate the decision making process. These scientists fulfil a dual role: as process facilitators and as stakeholder participants. Their dual position does not have to endanger the (legitimate) fulfilment of both roles.

4. Inclusion of stakeholder groups reduces unequal footing between the stakeholders involved. 
5. Multiple perspectives, values, expertise and interests from included stakeholder groups are used to jointly generate knowledge. Hence, a new knowledge coalition is constructed, which - as a coalition-, exerts influence in the decision making process.

6. Participatory decision making processes can improve legitimacy of sustainable solutions through optimizing input and throughput legitimacy. Strong input and throughput legitimacy provide helpful conditions for - although do not guarantee - output legitimacy.

The generalizability of these six heuristics, which are derived from the empirical material of this thesis, need to be further tested and confirmed (or falsified) in future research on a wider set of participatory decision making experiments.

\subsection{External validity}

The research programmes PROVIDE and ODEMM provided the case studies for this thesis. Within these research programmes, multiple case studies have been carried out. Although these cases show a large variety along a number of dimensions (i.e. scale: local and regional; geographical continent: Africa and Europe; sustainability issues: sanitation and marine protection), they also have a number of commonalities. In this section, I will discuss the relevance of the conclusions based on the studied cases for a wider set of wicked sustainability problems. Subsequently, I will discuss the diversity of sustainability issues tackled by the designed model, the relevance of (and alternatives for) the facilitating role of scientists, the spatial decision making scale (local, national, regional, global) and the geo-political context.

\section{Sustainability issues}

The wicked problems studied in this thesis are in the field of sanitation and marine governance. These wicked problems have their own particularities and characteristics. 
How relevant will the used participatory decision making models be for other sustainability issues?

Proact 2.0 has been developed and tested in various other international research programmes, such as "Waste Separation at Source" and "Building a Bio-Waste Reuse Chain in South East Asian Cities" (Dieu and Oanh 2015; Van Buuren and Hendriksen 2010; Van Buuren 2010). Both projects focused on finding alternatives for dumping the huge amounts of organic waste in landfills in Ho Chi Minh City (Vietnam), Bangkok (Thailand) and Manilla (the Philippines). The findings of participatory decision making processes in these projects showed many similarities with those in the field of sanitation and marine governance as reported in this thesis. A multidisciplinary scientific team guided the decision making process; it became possible to identify all relevant stakeholder groups related to bio-waste and to organise the decision making process in a way that all voices could be heard; relevant stakeholder groups were willing to participate in new knowledge coalitions; and the final decision has been endorsed by all relevant stakeholder groups. These findings show that when specific conditions are met, Proact 2.0 and the ODEMM approach have the potential to add meaning to participatory decision making processes in other sustainability areas, such as solid waste management in metropolitan areas.

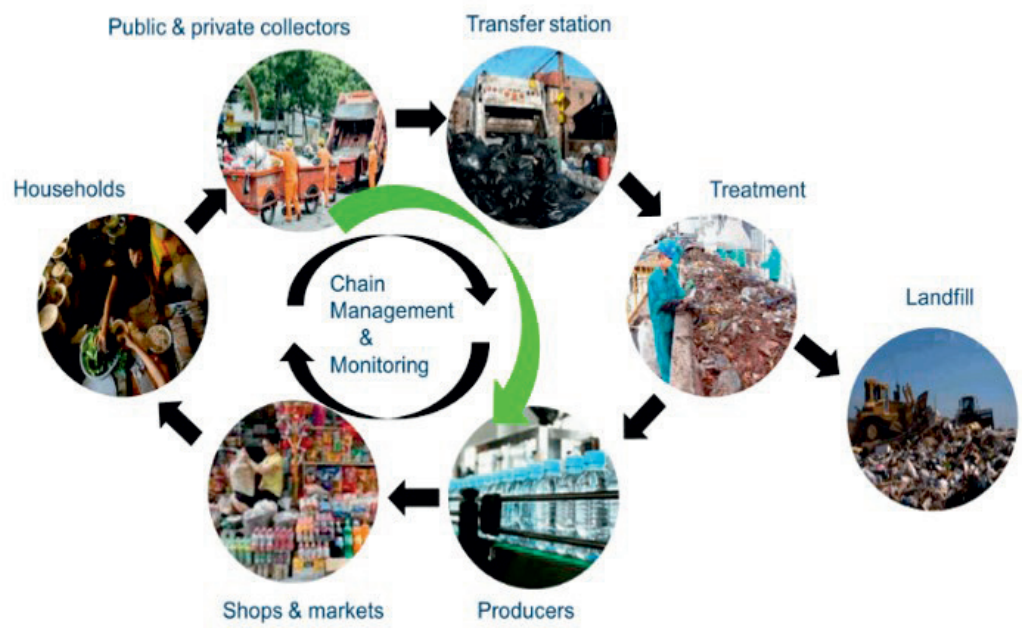

Figure 6.1 Solid Waste Management Chain 
Other wicked issues such as climate change, deforestation, loss of biodiversity or plastic pollution are just like sanitation, solid waste and marine governance, characterised by complexity and uncertainty and have proven to give rise to worldwide consequences that are difficult to control (Beck 2007). I elaborate on conditions that are vital for successfully applying Proact 2.0 and the ODEMM approach in these wicked issues. First, stakeholders should be well identifiable, accessible and willing to participate in the decision making process. Second, it should be possible to organise workshops or similar interactive sessions with all relevant stakeholder groups. Third, during the decision making process, stakeholders should learn to trust each other and show a willingness to exchange perspectives, values, knowledge and experiences in jointly building a knowledge coalition. If the mentioned conditions are met, Proact 2.0 and the ODEMM approach will have added value in decision making processes for a broader range of wicked problems.

\section{Legitimacy}

As elaborated in chapter 1, and based on Schmidt (2013), this thesis makes a distinction between input-, throughput-, and output legitimacy. Input legitimacy concerns whether the relevant stakeholders are invited to participate in the decision making process. Bäckstrand et al. (2006) amongst others, mention that representativeness depends primarily on an appropriately wide range of stakeholder groups that formally participate in the decision making process. The Proact 2.0 and ODEMM approach followed specific procedures to invite representatives of all relevant stakeholders, and ensured that these were actually participating and involved in the decision making process. On forehand, no stakeholder group has been excluded. To reduce the risk of missing specific stakeholder groups at the decision making table, various methods have been used, like snowball sampling and informal meetings.

This thesis has demonstrated that just being invited and sitting at the table is not enough, mainly because of unequal footing. Consequently, a great deal of effort has been put into designing and facilitating a decision making process in which the voices of all stakeholder groups involved were heard, stakeholders were able to put their interests, values and ideas on the table, influenced discussions and made final decisions about 
agreed options. Shirk et al. (2012) amongst others, argue that the quality of the decisions made on sustainability issues are strongly dependent on the quality of the decision making processes. This is in line with what Schmidt (2013) calls throughput legitimacy, with the emphasis on inclusiveness and openness for consultation with relevant stakeholders.

In the case of sanitation, input and throughput legitimacy have been achieved by paying special attention to get potential users to the table and include their perspectives, experiences and values in a common understanding of the problem and the setting of objectives. In this way potential users exerted influence on the decision making process and agreed on the chosen sanitary option, the elevated double pit-latrine. Inclusion of stakeholder groups in the for them relevant phases of the decision making process and joint knowledge generation were important for the acceptance and justification of shared decisions by stakeholder groups.

In the case of marine governance, a similar process that ensured input and throughput legitimacy has been arranged where relevant stakeholders in new knowledge coalitions extensively discussed different possibilities for future governance arrangements to better implement ecosystem-based management in the European seas (see Appendix 2).

Output legitimacy relates to the problem solving capacity or the 'outcome effectiveness' (Bäckstrand et al. 2006). In the current study, I have focused on the design, testing and evaluation of participatory decision making processes, and have not included the actual implementation of the decisions. Hence, based on this study it is not possible to formulate conclusions on output legitimacy. Hence, my assessment that the participatory decision making processes in sanitation and marine governance were legitimate relates to its input- and throughput legitimacy only.

\section{Facilitating team}

Proact 2.0 and the ODEMM approach have been designed, tested and evaluated by a multidisciplinary scientific research team. Scientists have set the stage and identified, invited and assigned relevant stakeholder groups to different phases of the decision 
making process. Furthermore, the same scientific team has acted as a facilitating force in the deliberations, in addition to being experts in a specific field or even stakeholders. This dual role has given the scientific team a great responsibility on the process and on the content of the decision making process. In most cases of participatory decision making on wicked sustainability problems, a multidisciplinary team of scientists will not often be selected or given the authority to design and lead the participatory decision making process. Other stakeholders are arguably better positioned to do this, such as professional external facilitators or (teams of) public policy-makers. According to Reed (2008) highly skilled facilitation for solving complex environmental issues is essential and a successful facilitator needs to be perceived as impartial, open to multiple perspectives and approachable. At the same time Reed (2008) leaves it an open question who should be capable to facilitate participatory and meaningful decision making processes. This leads to the question which other actors could be (better) able to design and facilitate such processes? According to Schmidt (2013) amongst others, trust, transparency and legitimacy are important conditions for meaningful and participatory decision making processes. When will it be a possible for external facilitators to be trusted by a diverse group of stakeholders? According to Miranda and Bostrom (1999) hiring facilitators who are not stakeholders in the decision making process can be complicated as these facilitators do not necessarily have the network, skills and expertise, like multidisciplinary expert teams, to organise the participatory decision making process. As research on facilitation in decision making processes on wicked problems is still uncommon, it is not known whether facilitators, who have to fulfil a dual role-facilitation and stakeholder- are preferable above facilitators, only hired to facilitate the process of the decision making. Policy-makers often act as process facilitators and at the same time are responsible for the implementation of the decisions made. One can imagine that in cases where the science on the wicked problem is still strongly in public debate -as used to be the case on for instance climate change or gmo's -policy-makers might make up a better facilitator than scientists.

\section{Decision making scale}

The developed decision making methodology has been tested on a local scale in East Africa, and Southeast Asia and on a regional decision making scale around the European 
seas. As some sustainability issues need to be decided upon at a global scale, the question arises if it will be possible to scale-up the decision making methodology. Brugnach et al. (2017) elaborate on the example of climate change that spans the scale from the global to the local. They observed a relation between the global view on climate change and the local communities who need to implement the designed mitigation measures. Scale and knowledge are closely connected. To understand the nature of a global problem, like climate change, a different kind of knowledge is needed than understanding climate change in a local context with specific local challenges (Adger et al. 2005). This also counts for other wicked issues, like in the cases of plastic pollution or deforestation. Studying wicked issues from a global perspective leads to sound expert knowledge and when it comes to the local level, the local context will be vital. Proact 2.0 and the ODEMM approach may contribute to effective decision making processes on local and regional scales, when stakeholder groups can be identified, all voices are heard and joint knowledge generation will enable stakeholder groups to exert influence on the final decision.

\section{Geo-political context}

Meaningful participatory decision making processes cannot be realized in all geopolitical contexts regarding sustainability issues in a similar way. The idea of meaningful participation resembles basic connotations of democracy, be it not necessarily in the formal sense of a representative democracy as we know it from post-WWII western countries. One can imagine that a Proact 2.0 methodology will be more complicated in non-democratic systems such as currently exist in, for instance, North Korea. In countries like Vietnam and China, such methodologies seems very well possible regarding local sustainability issues such as sanitation facilities, solid waste management, safe drinking water, and clean air (Dieu and Oanh 2015; Liu et al. 2015; Kostka and Mol 2013; Van Buuren and Hendriksen 2010; Zhong and Mol 2008). Yet, this might be less easy on more controversial national issues on sustainability, for instance those issues that relate to national energy provision and security, like nuclear energy or hydropower (Wu et al. 2013). Hence, the specific local and/or national geo-political system is a relevant factor in the ability to use Proact 2.0-like methodologies of participatory decision making processes, in a meaningful and successful manner. 


\subsection{Participatory and Meaningful Decision Making Processes on Sustainability Issues: a Research Agenda}

Although this thesis broke some grounds in showing how meaningful participatory decision making works in selected sustainability issues, the evidence of how to organize such decision making successfully for a wider set of sustainability problems in different context is still meagre, and comes with many unknowns. Without claiming to outline a full research agenda, I want to highlight three areas in which further research is very much needed.

Although there exists an extensive body of literature about stakeholder involvement (Rühli et al. 2017; Rondinella et al. 2017; Reed 2008; Welp et al. 2006; Beierle 2002; Freeman 1984; Arnstein 1969), it can be noticed that there is a great variety of insights in what experts consider as meaningful stakeholder participation. Moreover, how to involve stakeholders meaningfully in decision making processes is widely disputed too. Therefore, more empirical research is needed related to the organisational decision making design, the different sustainability issues for which it might (not) be relevant, the facilitating actors that can or should organize participatory decision making processes, the possibilities at different scales and geo-political contexts to better comprehend meaningful participatory decision making processes in practice.

Second, one of the characteristics of the decision making design of Proact 2.0 and the ODEMM approach is to create conditions to reduce unequal footing between different stakeholder groups involved in the decision making process. Fung (2006) argues that giving space for deliberative discussions and joint knowledge production in decision making processes on sustainability issues, may eventually lead to a more equal and transparent process in which participants trust each other and rely on arguments that others can accept. Proact 2.0 and the ODEMM approach have tried to respond to this argument by creating an environment in which opportunities for meeting each other and building trust between stakeholders were important. Concurrently, however, organising workshops, focus groups or other face-to-face interactive practices where 
different stakeholders are meeting each other several times during the decision making process may be time-consuming and costly and can exclude stakeholder groups with less money and resources available. Nowadays, digital platforms and information and communication technologies have opened up new ways of learning, communicating and jointly generating knowledge (Miranda and Bostrom 2015). Using digital technologies will be time- and cost-efficient, yet new research is needed to figure out the effects of digital technologies for successful meaningful and participatory decision making processes.

Third, this thesis has shown that the decision making design, inclusiveness and joint knowledge generation are critical factors in participatory and meaningful decision making processes on sustainability issues, and crucial - although not decisive - to enhance legitimacy of the finally proposed solution. Schmidt (2013) amongst others, argues that there is a strong connection between input-, throughput and output legitimacy. If critical interests are not represented (input legitimacy), participatory decision making processes may guide decisions towards (selective) participants whose interests are represented (throughput legitimacy) and decisions made may not be accepted by all relevant stakeholders (output legitimacy), influence strongly the quality of the decision and the success of its implementation (Purdy 2012; Bäckstrand et al. 2010; Scharpf 1997). This thesis has mainly focused on improved quality of input and throughput legitimacy and with that, to create better conditions for improved output legitimacy. The output legitimacy concerns the acceptance and justification of decisions made. It can be argued that accepted and justified decisions increase the chance for successful implementation. In this thesis, output legitimacy and the phase of implementation have not been studied. New research is needed to get a better insight in the relation between the process of decision making on sustainability issues and the output legitimacy and implementation of decisions made. 


\section{References}

Acevedo Guerrero T., (2018). Water infrastructure: A terrain for studying nonhuman agency, power relations, and socioeconomic change. WIREs Water 5 (5) 1-7.

Addo-Yobo F., C. Njiru (2006). Role of consumer behavior studies in improving water supply delivery to the urban poor. Water Policy 8 (2) 111-126.

Alsop R., J. Farrington (1998). Nests, Nodes and Niches: A system for process monitoring, information exchange and decision making for multiple stakeholders. World Development 26 (2) 249-260.

Ansell C., A. Gash (2012). Collaborative Governance in Theory and Practice. Journal of Public Administration Research and Theory 18 (4) 543-571.

Armstrong M.J., I.L. Payne, B. Deas, T.L. Catchpole (2013). Involving stakeholders in the commissioning and implementation of fishery science projects: Experiences from the UK Fisheries Science Partnership. Journal of Fish Biology 83 (4) 974-996.

Arnstein S. (1969). A ladder of Citizen Participation. Journal of the American Institute of Planners 35 (4) 216-234.

Bäckstrand K., A. Kronsell, J. Khan (2006). The promise of new modes of environmental governance. European Environment 16: 290-306.

Bär K., M. Schupp, G. Krause (2016). Engaging in meaningful science-stakeholder dialogues in polar and marine research. Alfred-Wegener Institute, Bremerhaven, Germany.

Beck S., M. Borie, J. Chilvers, A. Esguerra, K. Heubach, M. Hulme, R. Lidskog, E. Lövbrand, E. Marquard, C. Miller, T. Nadim, C. Nesshöver, J. Settele, E. Turnhout, E. Vasileiadou, C. Görg (2014). Towards a Reflexive Turn in the Governance of Global Environmental Expertise. The cases of the IPCC and the IPBES. GAIA 23 (2) 80-87.

Beck U. (1992). Risk Society. Towards a New Modernity. Sage Publications, Ltd, London, UK. 
Beck U. (2007). World at Risk. Polity Press, Cambridge, UK.

Beierle T.C. (2002). The quality of stakeholder-based decisions. Risk Analysis 22 (4) 739749.

Benn S., D. Dunphy, A. Martin (2009). Governance of environmental risk: New approaches to managing stakeholder involvement. Journal of Environmental Management 90 (4) 1567-1575.

Black M., B. Fawcett (2008). The last taboo: Opening the door on the global sanitation crisis. Earthscan, London, UK.

Blagescu M., L. de Las Casas, R. Lloyd (2005). Pathways to Accountability: The GAP Framework. One World Trust, London, UK.

Borjeson L., M. Höjer, K.H. Dreborg, T. Ekvall, G. Finnveden (2006). Scenario types and techniques: Towards a user's guide. Futures 38 (7) 723-739.

Brugnach M., M. Craps, A. Dewulf (2017). Including indigenous peoples in climate change mitigation: addressing issues of scale, knowledge and power. Climate Change 140 (1) 1932.

Brugnach M., H. Ingram (2012). Ambiguity: the challenge of knowing and deciding together. Environmental Science and Policy 15 (1) 60-71.

Brundtland G. (1987). Report of the World Commission on Environment and Development: Our Common Future. Oxford University Press, Oxford, UK.

Bruyninckx H. (2005). Sustainable Development: The Institutionalisation of a contested policy concept. In M.M. Betsill, K. Hochstetler and D. Stevis (editors), Palgrave Advances in International Environmental Politics. Palgrave Macmillan, New York, 265-298.

Bryman A. (2004). Social research methods. Oxford University Press, Oxford, UK.

Brugnach M., H. Ingram (2012). Ambiguity: the challenge of knowing and deciding together. Environmental Science and Policy 15 (1) 60-71. 
Bulkeley H., A.P.J. Mol (2003). Participation and Environmental Governance: Consensus, Ambivalence and Debate. Environmental Values 12 (2) 143-154.

Cascetta E., F. Pagliara (2013). Public engagement for planning and designing transportation systems. Procedia - Social and Behavioural Sciences 87: 103-116.

Chowdhury R.K., R. Rahman (2008). Multi criteria decision analysis in water resources management: The Malnichara channel improvement. International Journal of Environmental Science and Technology 5 (2) 195-204.

Commission of the European Communities (2008). Directive 2008/56/EC of the European Parliament and of the Council. Establishing a framework for community action in the field of marine environmental policy (Marine Strategy Framework Directive).

Commission of the European Communities (2013). Directive of the European Parliament and of the Council. Establishing a framework for maritime spatial planning and integrated coastal management COM (2013) 133 final. Brussels.

Costanza R., R. d'Arge, R. de Groot, S. Farber, M. Grasso, B. Hannon, K. Limburg, N. Shahid, R.V. O’Neill, J. Paruelo, R.G. Raskin, P. Sutton, M. van den Belt (1998). Special Section: Forum on Valuation of Ecosystem Services. The value of ecosystem services: Putting the issues in perspective. Ecological Economics 25: 67-72.

Cornell S., F. Berkhout, W. Tuinstra, J. Tàbara, J. Jäger, I. Chabay, B. de Wit, R., Langlais, D. Mills, P. Moll, I. Otto, A. Petersen, C. Pohl, L. van Kerkhoff (2013). Opening up knowledge systems for better responses to global environmental change. Environmental science and policy 28: 60-70.

Cottrell E., E. Whitlock, E. Kato, S. Uhl, S. Belinson, C. Chang, T. Hoomans, D. Meltzer, H. Noorani, K. Robinson, K. Schoelles, M. Motu'apuaka, J. Anderson, R. Paynter, J. Guise (2015). Defining the benefits of stakeholder engagement in systematic reviews. Dove Press journal: Comparative Effectiveness Research 5: 13-19.

De Jouvenel H. (2000). A brief methodological guide to scenario building. Technological Forecasting and Social Change 65 (1) 37-48. 
De Schepper S., M. Dooms, E. Haezendonck (2014). Stakeholder dynamics and responsibilities in Public-Private Partnerships: A mixed experience. International Journal of Project Management 31 (7) 1210-1222.

De Vaus D. (2009). Research Design in Social Research. Sage Publications, Thousand Oaks, CA.

Denzin N., Y. Lincoln (2005). The Sage Handbook of Qualitative Research. $3^{\text {rd }}$ edition. Sage Publications, Thousand Oaks, CA.

Devas N., U. Grant (2003). Local government decision making - Citizen participation and local accountability: Some evidence from Kenya and Uganda. Public Administration and Development 23 (4) 307-316.

Dewulf A., W. Elbers (2018). Power in and over Cross-Sector Partnerships: Actor Strategies for Shaping Collective Decisions. Administrative Sciences 8 (43) 1-15.

Dieu T.T.M., L.T.K. Oanh (2015). Possibilities and Challenges to Approach Zero-disposal of Biodegradable Organic Domestic Solid Waste in Ho Chi Minh City, Vietnam. International Journal of Innovative Science, Engineering and Technology 2 (7) 668-675.

Dunn E. (2005). The role of environmental NGOs in fisheries governance. In T.S. Gray (editor), Reviews: Methods and Technologies in Fish Biology and Fisheries (volume 4). Participation in Fisheries Governance. Springer, Dordrecht, 209-218.

Durance P., M. Godet (2010). Scenario building: Uses and abuses. Technological Forecasting and Social Change 77 (9) 1488-1492.

Edelenbos J., A. van Buuren, N. van Schie (2011). Co-producing knowledge: joint knowledge production between experts, bureaucrats and stakeholders in Dutch water management projects. Environmental Science and Policy 14 (6) 675-684.

European Environment Agency (2000). Cloudy Crystal balls. An assessment of recent European and global scenario studies and models. Experts' corner report prospects and scenarios no 4. EEA, Copenhagen. 
Feldman M.S., A.M. Khademian, H. Ingram, A.L. Schneider (2006). Ways of knowing and inclusive management practices. Public Administration Review 66 (1) 89-99.

Forsyth T. (2007). Promoting the development dividend of climate technology transfer: Can cross sector partnerships help? World Development 35 (10) 1684-1698.

Fortuin K.P.J., S.R. Bush (2010). Educating students to cross boundaries between disciplines and cultures and between theory and practice. International Journal of Sustainability in Higher Education 11 (1) 19-35.

Freeman R. (1984). Strategic Management: A Stakeholder Approach. Pitman series in Business and Public Policy. HarperCollins Publishers, US.

Freire-Gibb L.C., R. Koss, P. Margonski, N. Papadopoulou (2014). Governance strengths and weaknesses to implement the Marine Strategy Framework Directive in European waters. Marine Policy 44: 172-178.

Frid C.L.J. (2005). The role of marine science in participatory fisheries governance. In T.S. Gray (editor) Reviews: Methods and Technologies in Fish Biology and Fisheries. Participation in Fisheries Governance. Springer, Dordrecht, 231-247.

Fung A. (2006). Varieties of Participation in Complex Governance. Public Administration Review, Special Issue 66 (1) 66-75.

Fung A., E. Wright (2001). Deepening democracy: Innovations in empowered participatory governance. Politics and Society 29 (1) 5-41.

Geissel B. (2009). Participatory Governance: Hope or danger for democracy? A case study of Local Agenda 21. Local Government Studies 35 (4) 401-414.

Gray T.S. (2005). Participation in fisheries governance. Reviews: Methods and Technologies in Fish Biology and Fisheries (volume 4). Springer, Dordrecht.

Gray T., J. Hatchard (2003). The 2002 reform of the Common Fisheries Policy's system of governance-rhetoric or reality? Marine Policy 27 (6) 545-554. 
Gray T., J. Hatchard (2008). A complicated relationship: Stakeholder participation and the ecosystem-based approach to fisheries management. Marine Policy 32 (2) 158-168. Habermas J. (1996). Between Facts and Norms. MIT Press, Cambridge (MA).

Hajer M. (2003). Policy without polity? Policy analysis and the institutional void. Policy Science 36 (2) 175-195.

Hammond J.S., R.L. Keeney, H. Raiffa (1999). Smart choices: A practical guide to making better decisions. Harvard Business School Press, Boston (MA).

Hendriksen A., J.T. Tukahirwa, P.J.M. Oosterveer, A.P.J. Mol (2012). Participatory decision making for sanitation improvements in unplanned urban settlements in East Africa. The Journal of Environment and Development 21 (1) 98-119.

Hendriksen A., C. Jouanneau, R. Koss, J. Raakjær (2014). Fishing for opinions: stakeholder views on MSFD implementation in European Seas. Marine Policy 50 (Part B) 353-363.

Höjer M., S. Ahlroth, K.H. Dreborg, T. Ekvall, G. Finnveden, O. Hjelm, E. Hochschorner, M. Nilsson, V. Palm (2008). Scenarios in selected tools for environmental systems analysis. Journal of Cleaner Production 16 (18) 1958-1970.

Hordijk M., I. Baud (2006). The role of research and knowledge generation in collective action and urban governance: How can researchers act as catalysts? Habitat International 30 (3) 668-689.

Howes M., L. Worthley, R. Potts, A. Dedekorkut-Howes, S. Serrao-Neumann, J. Davidson, T. Smith, P. Nunn (2017). Environmental Sustainability: A case of policy implementation failure? Sustainability 9 (2) 165-182.

Hueskes M., K. Verhoest, T. Block (2017). Governing public-private partnerships for sustainability. An analysis of procurement and governance practices of PPP infrastructure projects. International Journal of Project Management 35 (6) 1184-1195. 
Huitema D., E. Turnhout (2009). Working at the science-policy interface: A discursive analysis of boundary work at the Netherlands Environmental Assessment Agency. Environmental Politics 18 (4) 576-594.

Irvin R., J. Stansbury (2004). Citizen participation in decision making: Is it worth the effort? Public Administration Review 64 (1) 55-65.

Isunju J.B., K. Schwartz, M.A. Schouten, W.P. Johnson, M.P. van Dijk (2011). Socioeconomic aspects of improved sanitation in slums: A review. Public Health 125 (6) 368376.

Jenkins M.W., V. Curtis (2005). Achieving the good life: Why some people want latrines in rural Benin. Social Science and Medicine 61 (11) 2446-2459.

Jentoft S. (1989). Fisheries co-management. Delegating government responsibility to fishermen's organizations. Marine Policy 13 (2) 137-154.

Jonsson A. (2005). Public participation in water resources management: Stakeholder voices on degree, scale, potential, and methods in future water management. Ambio: A Journal of the Human Environment 34 (7) 495-500.

Jonsson A., L. Andersson, J. Alkan-Olsson, B. Arnheimer (2007). How participatory can participatory modeling be? Degrees of influence of stakeholder and expert perspectives in six dimensions of participatory modeling. Water Science and Technology 56 (1) 207 214.

Jouanneau C., J. Raakjær (2014). The Hare and the Tortoise. Lessons from Baltic Sea and Mediterranean Sea governance. Marine Policy 50 (Part B) 331-338.

Kaggwa R., S. Kiwanuka, T. Okurut Okia, F. Bagambe, C. Kanyesigye (2003). Experiences in setting up eco-san toilets in shoreline settlements in Uganda. In Proceedings of the 2nd International Symposium on Ecological Sanitation. Lübeck Germany.

Karl H., L. Susskind, K. Wallace (2007). A dialogue not a diatribe. Effective Integration of Science and Policy through Joint Fact Finding. Environment 49 (1) 20-34. 
Kasemir B., J. Jäger, C. Jaeger, M. Gardner (editors) (2003). Public Participation in Sustainability Science: A Handbook. Cambridge University Press, Cambridge, UK.

Knights A.M., R.S. Koss, N. Papadopoulou, L.A.C.L.H. Robinson (2011). Sustainable use of European regional seas and the role of the marine strategy framework directive.

Deliverable 1, EC FP7 Project (244273). Options for Delivering Ecosystem-based Marine Management, University of Liverpool, Liverpool.

Kooiman J., M. Bavinck, S. Jentoft, R. Pullin (editors) (2005). Fish for life: Interactive governance for fisheries. Amsterdam University Press, Amsterdam.

Kostka G., A.P.J. Mol (2013). Implementation and Participation in China's Local Environmental Politics: Challenges and Innovations. Journal of Environmental Policy and Planning 15 (1) 3-16.

Kuenkel P. (2019). Stewarding Sustainability Transformations. Springer Nature Switzerland AG, Cham, Switzerland.

Lahdelma R., P. Salminen, J. Hokkanen (2000). Using multi criteria methods in environmental planning and management. Environmental Management 26 (6) 595-605.

Lenton R., A.M. Wright, K. Lewis (2005). United nations millennium project task force on water and sanitation. Earthscan, London, UK.

Lindeboom H.J., S. Degraer, J. Dannheim, A.B. Gill, D. Wilhelmsson (2015). Offshore wind park monitoring programmes, lessons learned and recommendations for the future. Hydrobiologia 756 (1) 169-180.

Liu W.L., J. Zhang, B. Bluemling, A.P.J. Mol, C. Wang (2015). Public participation in energy saving retrofitting of residential buildings in China. Applied Energy 147 (1) 287-296.

Long R. (2011). The Marine Strategy Framework Directive: a new European approach to the regulation of the marine environment, marine natural resources and marine ecological services. Journal of Energy Natural Resources Law 29 (1) 1-44. 
Long R. (2012). Legal aspects of ecosystem-based marine management in Europe. In A. Chircop, M.L. McConnell, S. Coffen (editors),Ocean yearbook Vol. 26. Brill Academic Publishers, Boston/Leiden, 417-484.

Mabasi T. (2009). Assessing the impacts, vulnerability, mitigation, and adaptation to climate change in Kampala City. Fifth Urban Research Symposium. Kampala, Uganda.

Meffe G.K., L.A. Nielsen, R.L. Knight, D.A. Schenborn (2002). Ecosystem Management. Adaptive, Community-Based Conservation. Island Press, Washington/Covelo/London.

Mielke J., H. Vermassen, S. Ellenbeck, B. Fernandez Milan, C. Jaeger (2016). Stakeholder involvement in sustainability science - A critical view. Energy Research and Social Science 17: 71-81.

Mietzner D., G. Reger (2005). Advantages and disadvantages of scenario approaches for strategic foresight. International Journal of Technology Intelligence and Planning 1 (2) 220-239.

Miranda S.M., R.P. Bostrom (1999). Meeting Facilitation: Process Versus Content Interventions. Journal of Management Information Systems 15 (4) 89-114.

Mol A.P.J. (2006). Environmental governance in the Information Age: The emergence of informational governance. Environment and Planning C: Government and Policy 24 (4) 497-514.

Nasiritousi N., M. Hjerpe, K. Bäckstrand (2016). Normative arguments for non-state actor participation in international policymaking processes: Functionalism, neocorporatism or democratic pluralism? European Journal of International Relations 22 (4) 920-943.

National Oceanic and Atmospheric administration (NOAA), Office for Coastal Management (2015). Social Science Tools for Coastal Programs: Introduction to Stakeholder Participation. NOAA, Office for Coastal Management, Charleston, South Carolina. 
Netssaf (2008). Netssaf-Participatory planning approach: A guideline for sustainable sanitation planning. Ttz Bremerhaven, Water, Energy and Landscape Management, Bremerhaven, Germany.

Nigim K., N. Munier, J. Green (2004). Pre-feasibility MCDM tools to aid communities in prioritizing local viable renewable energy sources. Renewable Energy 29 (11) 1775-1791.

Notten W., J. Rotmans, M. van Asselt, D. Rothman (2003). An updated scenario typology. Futures 35: 423-443.

Okot-Okumu J., P. Oosterveer (2010). Providing sanitation for the urban poor in Uganda. In B. van Vliet, G. Spaargaren, P. Oosterveer (editors), Social perspectives on the sanitation challenge. Springer, Dordrecht, 87-103.

Oosterveer P., G. Spaargaren (2010). Meeting social challenges in developing sustainable environmental infrastructures in East African cities. In B. van Vliet, G. Spaargaren, P. Oosterveer (editors), Social perspectives on the sanitation challenge. Springer, Dordrecht, 11-30.

Ounanian K., A. Delaney, J. Raakjær , P. Ramirez-Monsalve (2012). On unequal footing: Stakeholder perspectives on the marine strategy framework directive as a mechanism of the ecosystem-based approach to marine management. Marine Policy 36 (3) 658-666.

Pahl-Wostl C. (2002). Towards sustainability in the water sector. The importance of human actors and processes of social learning. Aquatic Sciences 64 (4) 394-411.

Parkins, J., R. Mitchell (2005). Public Participation as Public Debate: A Deliberative Turn in Natural Resource Management. Society and Natural Resources 18 (6) 529-540.

Pennington D. (2016). A conceptual model for knowledge integration in interdisciplinary teams: orchestrating individual learning and group processes. Journal of Environmental Studies and Sciences 6 (2) 300-312.

Postma T., F. Liebl (2005). How to improve scenario analysis as a strategic management tool? Technological Forecasting and Social Change 72 (2) 161-173. 
Purdy J.M. (2012). A Framework for Assessing Power in Collaborative Governance Processes. Public Administration Review 72 (3) 409-417.

Raakjær J. (2003). An analytical framework for studying compliance and legitimacy in fisheries management. Marine Policy 27 (5) 425-432.

Raakjær J., J. van Leeuwen, J. van Tatenhove, M. Hadjimichael (2014). Ecosystem-based marine management in European regional seas calls for nested governance structures and coordination-A policy brief. Marine Policy 50 (Part B) 373-381.

Raakjær J., T. Vedsmand (1995). Fisheries Co-Management: An alternative strategy in fisheries-cases from Denmark. Reinventing the Commons. In Proceedings of the fifth annual conference of the international association for the study of common property. Bodo, Norway.

Raakjær J., T. Vedsmand (1999). User participation and institutional change in fisheries management: A viable alternative to the failures of 'top-down' driven control? Ocean and Coastal Management 42 (1) 19-37.

Rätz H.J., H. Dorner, R. Scott, T. Barbas (2010). Complementary roles of European and national institutions under the Common Fisheries Policy and the Marine Strategy Framework Directive. Marine Policy 34 (5) 1028-1035.

Reed M.S. (2008). Stakeholder participation for environmental management. A literature review. Biological Conservation 141 (10) 1417-1431.

Reed M.S., E.D.G. Fraser, S. Morse, A.J. Dougill (2005). Integrating methods for developing sustainability indicators that can facilitate learning and action. Ecology and Society 10 (1) r3.

Rondinella T., E. Segre, D. Zola (2017). Participative Processes for Measuring Progress: Deliberation, Consultation and the Role of Civil Society. Social Indicators Research 130: 959-982. 
Rühli E., S. Sachs, R. Schmitt, T. Schneider (2017). Innovation in Multi-stakeholder Settings: The Case of a Wicked Issue in Health Care. Journal of Business Ethics 143 (2) 289-305.

Scharpf F.W. (1997). Economic integration, democracy and the welfare state. Journal of European Public Policy 4 (1) 18-36.

Scheinberg A., A.P.J. Mol (2010). Multiple modernities: Transitional Bulgaria and the ecological modernisation of solid waste management. Environment and Planning C 28 (1) 18-36.

Scheinberg A., S. Spies, M.H. Simpson, A.P.J. Mol (2011). Assessing recycling in low- and middle-income countries: Building on modernized mixtures. Habitat International 35 (2) 188-198.

Schmidt V.A. (2013). Democracy and legitimacy in the European Union revisited: input, output and 'throughput'. Political Studies 61 (1) 2-22.

Schmitt R. (2010). Dealing with Wicked Issues: Open Strategizing and the Camisea Case. Journal of Business Ethics 96 (S1) 11-19.

Schouten M.A.C., R.W. Mathenge (2010). Communal sanitation alternatives for slums: A case study of Kibera, Kenya. Physics and Chemistry of the Earth 35 (13-14) 815-822.

Shirk J., H. Ballard, C. Wilderman, T. Phillips, A. Wiggins, R. Jordan, E. McCallie, M. Minarchek, B. Lewenstein, M. Krasny, R. Bonney (2012). Public Participation in Scientific Research: A Framework for Deliberate Design. Ecology and Society 17 (2) 29-48.

Silver H., A. Scott, Y. Kazepov (2010). Participation in Urban Contention and Deliberation. International Journal of Urban and Regional Research 34 (3) 455-477.

Silverman D. (2009). Interpreting Qualitative Data. Methods for Analyzing, Talk, Text and Interaction. $3^{\text {rd }}$ edition. Sage Publications Ltd, London.

Spaargaren G., P.J.M. Oosterveer, J. van Buuren, A.P.J. Mol (2006). Mixed modernities: Towards viable urban environmental infrastructure development in East Africa 
(Discussion paper). Wageningen University, Environmental Policy Group, Wageningen, Netherlands.

Stadler L. (2016). Scrutinizing Public-Private Partnerships for Development: Towards a Broad Evaluation Conception. Journal of Business Ethics 135 (1) 71-86.

Sutherland M., S. Nichols (2004). The evolving role of hydrography in ocean governance and the concept of the marine cadastre. Hydrographic Journal 111: 13-16.

Tukahirwa J.T., A.P.J. Mol, P. Oosterveer (2010). Civil society participation in urban sanitation and solid waste management in Uganda. Local Environment 15 (1) 1-14.

Tukahirwa J.T., A.P.J. Mol, P. Oosterveer (2011). Access of urban poor to NGO/CBOsupplied sanitation and solid waste services in Uganda: The role of social and spatial proximity. Habitat International 35 (4) 582-591.

United Nations (1992). United Nations Conference on Environment and Development Rio de Janerio, Brazil.

United Nations (2001). United Nations Economic Commission for Europe, Aarhus Convention.

United Nations (2005). Millennium Project. A Practical Plan to Achieve the Millennium Development Goals. New York.

United Nations (2008). The Millennium Development Goals Report. New York.

Van Buuren J. (2010). Sanitation choice involving stakeholders: A participatory multicriteria method for drainage and sanitation system selection in developing cities applied in Ho Chi Minh City, Vietnam. Wageningen University, Wageningen, Netherlands.

Van Buuren J., A. Hendriksen (2010). A learning and decision methodology for drainage and sanitation improvement in developing cities. In J.P. Voss, D. Bauknecht and R. Kemp (editors), Reflexive governance for sustainable development. Edward Elgar, Cheltenham, UK, 337-354. 
Van Buuren M.W., J. Edelenbos (2004). Why is joint knowledge production such a problem? Science and Public Policy 31 (4) 289-299.

Van Hoof L. (2010). Co-management: An alternative to enforcement? ICES Journal of Marine Sciences 67 (2) 395-401.

Van Hoof L., J. van Tatenhove (2009). Up or out: The changing role of Member States in EU fisheries management. In Proceedings the XIX EAFE conference, Malta.

Van Hoof L., A. Hendriksen, H.J. Bloomfield (2014). Sometimes you can't make it on your own: Drivers and scenarios for regional cooperation in implementing the EU Marine Strategy Framework Directive. Marine Policy 50 (Part B) 339-346.

Van Hoof L., J. van Leeuwen, J. van Tatenhove (2012). All at sea; Regionalisation and integration of marine policy in Europe. Maritime Studies 11 (9) 1-14.

Van Leeuwen J., L. van Hoof, J. van Tatenhove (2012). Institutional ambiguity in implementing the European Union Marine Strategy Framework Directive. Marine Policy 36 (3) 636-643.

Van Leeuwen J., J. Raakjær, L. van Hoof, J. van Tatenhove, R. Long, K. Ounanian (2014). Implementing the Marine Strategy Framework Directive: A policy perspective on regulatory, institutional and stakeholder impediments to effective implementation. Marine Policy 50 (Part B) 325-330.

Van Tatenhove J. (2013). How to turn the tide: Developing legitimate marine governance arrangements at the level of regional seas. Ocean \& Coastal Management 71: 296-304.

Van Tatenhove J., J. Raakjær , J. van Leeuwen, L. van Hoof (2014). Regional cooperation for European seas: Governance models in support of the implementation of the Marine Strategy Framework Directive. Marine Policy 50 (Part B) 364-372.

Van Vliet B., G. Spaargaren, P. Oosterveer (editors) (2010). Social perspectives on the sanitation challenge. Springer, Dordrecht. 
Verweij M.C., W.L.T. van Densen, A.P.J. Mol (2010). The tower of Babel: Different perceptions and controversies on change and status of North Sea fish stocks in multistakeholder settings. Marine Policy 34 (3) 522-533.

Verweij S., G. Teisman, R. Gerrits, M. Lasse (2017). Implementing public-private partnerships: How management responses to events produce (un)satisfactory outcomes. Public Works Management and Policy 22 (2) 119-139.

Welp M., A. de La Vega-Leinert, S. Stoll-Kleemann, C. Jaeger (2006). Science-based stakeholder dialogues. Theory and tools. Global Environmental Change 16 (2) 170-181.

WHO and UNDP/World bank Water and Sanitation Program (2000). Water and Sanitation Program, participatory hygiene and sanitation transformation: A new approach to working with communities. WHO Press, Geneva, Switzerland.

WHO/UNICEF (2010). Progress on sanitation and drinking-water: Joint Monitoring Program for water supply and sanitation. WHO Press, Geneva, Switzerland.

Willets P. (2006). The Cardoso Report on the UN and civil society: functionalism, global corporatism, or global democracy? Global Governance: a review of Multilateralism and International Organisations 12 (3) 305-324.

Williams B., H. Suen, S. Brown, R. Bruhn, R. De Blaquiere, S. Rzasa (2001). Hierarchical linear models of factors associated with public participation among residents living near the U.S. Army's chemical weapons stockpile sites. Journal of Environmental Planning and Management 44 (1) 41-65.

Wollenberg E., D. Edmunds, L. Buck (2000). Using scenarios to make decisions about the future: Anticipatory learning for the adaptive co-management of community forests. Lands Urban Plan 47 (1/2) 65-77.

Wu Y.N., M. Naren, Y.L. Han, H.P. Wang (2013). Analysis on Public Participation in Decision Making of Nuclear Power in China. Applied Mechanics and Materials 291-294: $555-560$.

Yin R.K. (2009). Case study research: Design and methods. Sage, London. 
Zhong L., A.P.J. Mol (2008). Participatory environmental governance in China: Public hearings on urban water tariff setting. Journal of Environmental Management 88 (4) 899913. 


\section{Appendices}

\section{Appendix 1 ODEMM Survey on Marine Regional Cooperation}

\section{Welcome to the ODEMM survey on marine regional cooperation!}

This survey has been designed to understand stakeholder views of the current marine governance structures in European Regional Seas. Your opinion may impact on the future management of the European Marine Environment.

We will use the following definitions:

- Regional Seas refers to the geographical boundaries of the Baltic Sea, Black Sea, Mediterranean Sea, and North-East Atlantic Ocean

- Stakeholder refers to people or bodies that are involved in or have a vested interest in the marine environment.

- MSFD is the abbreviation of the Marine Strategy Framework Directive of the European Union

\section{Remarks:}

The survey is also available in other languages should you prefer not to complete it in English. If these languages are causing you problems, please send an email to charlene@ifmaau.dk and we will be glad to provide assistance

- To increase/decrease survey size on your screen, use "Ctrl +" and "Ctrl -" ("cmd +" and "cmd-" on Mac)

This survey has been developed within ODEMM WP7 (Future Governance scenarios)
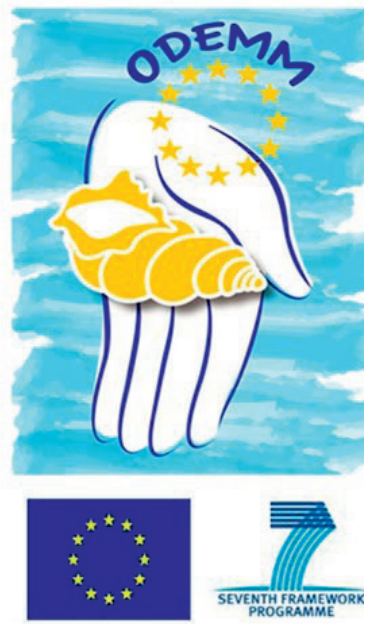

ODEMM is coordinated by the University Liverpool and funded by a grant from the under the 7th Framework Programme.

\section{Survey coordinator:}

1. What is the name of your organisation? 
2. Where is your organisation located?

$\begin{array}{ll}\square \text { Belgium } & \square \text { Latvia } \\ \square \text { Bulgaria } & \square \text { Norway } \\ \square \text { Denmark } & \square \text { Netherlands } \\ \square \text { Estonia } & \square \text { Poland } \\ \square \text { Finland } & \square \text { Romania } \\ \square \text { France } & \square \text { Russia } \\ \square \text { United Kingdom } & \square \text { Spain } \\ \square \text { Georgia } & \square \text { Sweden } \\ \square \text { Germany } & \square \text { Turkey } \\ \square \text { Greece } & \square \text { Ukraine } \\ \square \text { Ireland } & \square \text { Other EU member state } \\ \square \text { Israel } & \square \text { Other non-EU country } \\ \square \text { Lithuania } & \end{array}$

3. How many years have you worked in your organisation?

4. How many years have you worked in a role related to the marine environment?

5. Do you have executive power in your organisation?

$\square$ Yes

$\square$ No 
6. Have you represented your organisation in relation to marine policy making?

$\square$ Yes

$\square$ No

7. In which regional sea(s) does your organisation primarily work?

$\square$ Baltic Sea

$\square$ Black Sea

Mediterranean Sea

North-east Atlantic Ocean

$\square$ All

8. At which level(s) does your organisation work?

National level

$\square$ Sub-regional sea level (e.g. Aegean Sea)

Regional sea level (e.g. Mediterranean)

9. What is (are) the main focus(es) of your organisation?

Coastal tourism

Energy: oil and gas

Energy: renewable

$\square$ Environment

Fisheries/Aquaculture

$\square$ Navigation/Shipping

Other 


\section{Which category does your organisation belong to?}

$\square$ Industry

$\square$ Non-governmental organization

Research/Science

National government administration

Administration with Regional Sea Focus

$\square$ European Commission

European Parliament

Other

11. How is your organisation involved in the implementation process of the Marine Strategy Framework Directive?

$\square$ My organisation is not involved

My organisation is informed

$\square$ My organisation is asked for advice

My organisation participates directly in the implementation process

\section{Statements}

This section presents a series of statements regarding cooperation using the ecosystem-based approach for European marine management. Please score each statement according to your personal opinion. 
Opinion categories are: Strongly agree (1), Agree (2), Neutral (3), Disagree (4), Strongly disagree (5), Don't know (6), and Not applicable (if you think that the question does not apply to your organisation: 7).

\section{Stakeholder involvement (1-7)}

In the implementation of the MSFD, existing organisational structures allow for stakeholders' participation at the regional sea level.

Implementation of the MSFD at the regional sea level does not require stakeholder involvement.

Good environmental status will not be achieved if stakeholders have influence on the implementation of the MSFD.

Stakeholder involvement will lead to effective decision making and achievement of the objectives of the MSFD at the regional sea level.

\section{Willingness to cooperate (1-7)}

Member States are not willing to cooperate at the regional sea level to achieve the objectives of the MSFD. 
My country coordinates

management action with other

countries bordering shared

regional seas.

My organisation is not interested

in cooperating in the

implementation of the MSFD at regional sea level.

My organisation would like to take on more responsibilities to achieve the objectives of the MSFD at the regional sea level.

My country is not willing to assign responsibilities to a regional sea level organisation.

\section{Capacity to cooperate (1-7)}

Including all possible

stakeholders in the

implementation of the MSFD at the regional sea level would cost too much money.

Member states should invest in cooperation to implement the MSFD at the regional sea level.

My organisation has enough capacity (money/time/personnel) to participate in the implementation of the MSFD at the regional sea level. 
My organisation has the

necessary capacity

(money/time/personnel

available), but is not willing to

spend these resources to

participation in the

implementation of the MSFD at

the regional sea

level.

Institutional ambiguity (1-7)

Rules created by different institutional levels impede the implementation of the MSFD.

Regional cooperation is not possible when different authorities select their own rules.

Current single sector policies impede the implementation of the MSFD.

Implementing the MSFD is only possible if member states' governments join forces at the regional sea level.

Achieving the objectives of the MSFD requires coordination among all institutions responsible for implementing the MSFD and other marine policies. 


\section{Decision making structures (1-7)}

My organisation has no

influence on the

implementation process of the

MSFD at the national level.

To achieve ecosystem-based

management in European

regional seas, clearly defined

decision making structures

need to be established at the

regional sea level.

My organisation is properly

informed about the

implementation of the MSFD in

my regional sea.

Stakeholders associated with a regional sea should be actively involved in all implementation phases of the MSFD.

Implementation of the MSFD

should be a hierarchical

process lead by the European

Union. 


\section{Efficiency (1-7)}

Engaging in regional cooperation is an efficient way to spend resources (time and money).

Regional cooperation will create confidence in the implementation process and thereby increase efficiency.

Participation in regional cooperation is economically costly, but the benefits achieved are greater than without it.

Regional cooperation will not create efficient information exchange.

Regional cooperation increases total management costs. 


\section{Propositions}

The overarching objective of the Marine Strategy Framework Directive is to achieve 'Good Environmental Status' (GES) by 2020 across Europe's marine environment which will be assessed at the regional sea level. The following propositions have been designed to obtain the views of your organisation on:

a) The current situation of your organisation (2012)

b) The foreseen situation of your organisation in 2020

c) Where would your organisation like to be in 2020

Scale: very low (1); low (2); neutral (3); high (4); very high (5); don't know (6); not applicable (7).

What is the current (2012) situation of your organisation in terms of regional cooperation for the implementation of the MSFD?

Level of participation

Influence on decision making

Capacity to participate

Willingness to participate

Resources (money/time/staff) 
Where do you foresee your organisation in 2020 in terms of regional cooperation for the implementation of the MSFD?

$\begin{aligned} & \text { Very Low Neutral High } \\ & \text { Low }\end{aligned} \quad \begin{aligned} & \text { Very } \\ & \text { High }\end{aligned} \begin{gathered}\text { Don't } \\ \text { know }\end{gathered} \begin{gathered}\text { Not } \\ \text { applicable }\end{gathered}$

Level of participation

Influence on decision making

Capacity to participate

Willingness to participate

Resources (money/time/staff)

$\begin{array}{ll}\square & \square \\ \square & \square \\ \square & \square \\ \square & \square \\ \square & \square\end{array}$

Ideally, where would you like your organisation to be in 2020 in terms of regional cooperation for the implementation of the MSFD?

Level of participation

Influence on decision making

Capacity to participate

Willingness to participate

Resources (money/time/staff)

$\begin{array}{lll}\square & \square & \square \\ \square & \square & \square \\ \square & \square & \square \\ \square & \square & \square \\ \square & \square & \square\end{array}$


My organisation is confronted with rules and procedures at the regional level which are...

The current situation of your organisation (2012)

The foreseen situation of your organisation in 2020

Where would your organisation like to be in 2020

\section{Scenarios}

In the following section five possible scenarios are presented in relation to regional sea cooperation in 2020. We do not claim they cover all likely scenarios, but present alternatives which are sufficiently distinct for our analysis. Please read them carefully and then rank them according to:

a) their probability of happening by 2020 ;

b) your preference for the situation in 2020 . 


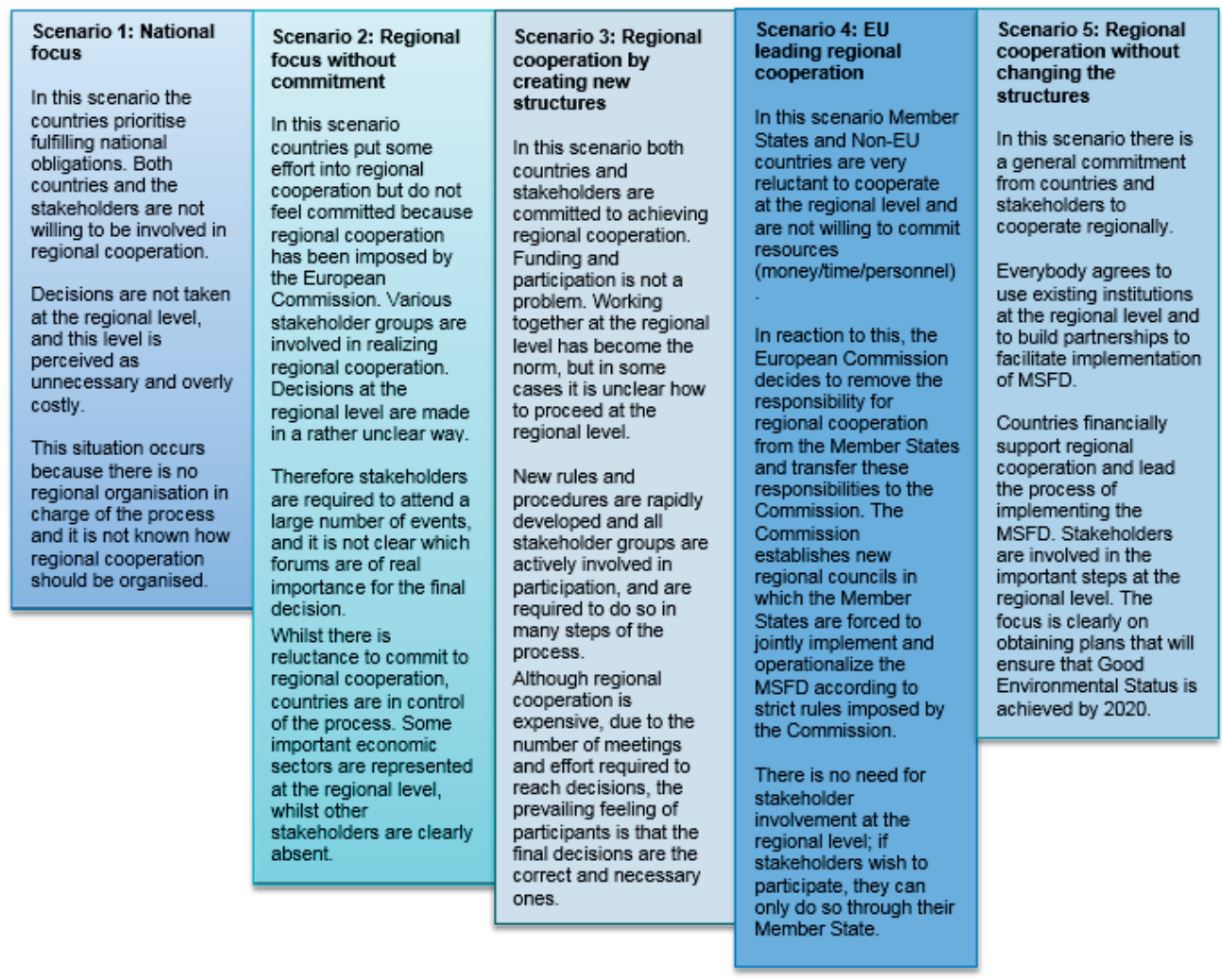

\section{Please rank from 1 to 5 the scenarios according to their} likelihood to happen by 2020. (1 the most likely to hoppen, and 5 the least, using each number once)

\begin{tabular}{|l|l|}
\hline Scenario 1 & \\
\hline Scenario 2 & \\
\hline Scenario 3 & \\
\hline Scenario 4 & \\
\hline Scenario 5 & \\
\hline
\end{tabular}

\section{Please rank from 1 to 5 the scenarios according your}

preferences for the ideal situation in 2020. (1 your most preferred and 5 your least, using each number once)

\begin{tabular}{|l|l|}
\hline Scenario 1 & \\
\hline Scenario 2 & \\
\hline Scenario 3 & \\
\hline Scenario 4 & \\
\hline Scenario 5 & \\
\hline
\end{tabular}




\title{
Final background questions
}

\author{
Gender \\ $\square \mathrm{F}$ \\ 口M
}

Year of birth :

Nationality :

In your view, who are the most important actors in the implementation of the MSFD? (optional question)

Please provide any further comments you have in regards to the implementation of the MSFD, the ecosystem- based approach in decision making process or the survey.

Thank you for taking the time to complete this survey! 
Would you like to receive the results of this study?

口Yes

№, thank you.

Would you like to receive more information about the ODEMM project?

口Yes

No, thank you. 


\section{Appendix 2 Governance Models for Regional Cooperation upon Ecosystem-Based Management}
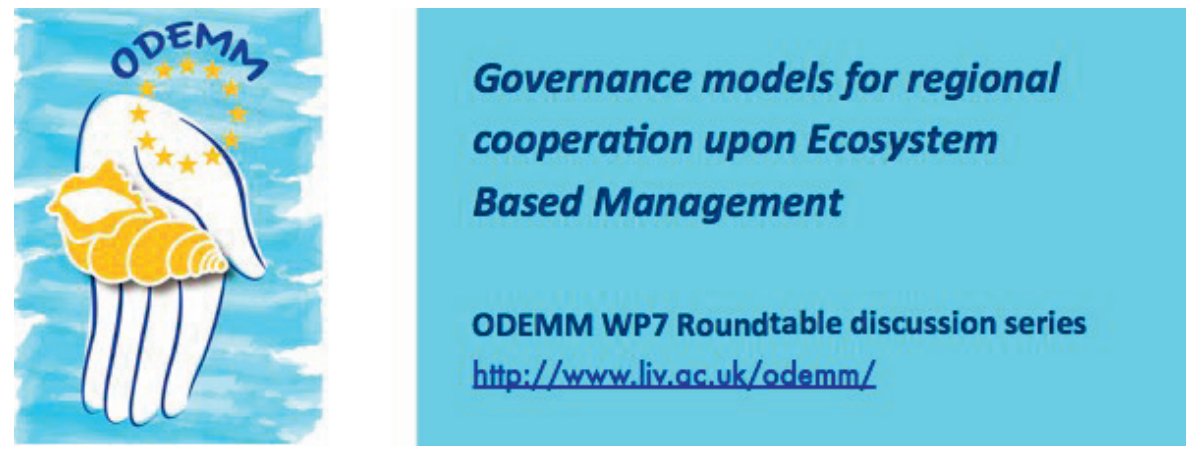

Aalborg, 10 January 2013

Dear participant,

We are pleased to welcome you on the 15 and 16 January 2013 to our roundtable discussion on "Creative thinking and Smart Choices".

As mentioned in your invitation, over the past few years the EU has engaged in a shift from sector-based regulations to integrated strategies concerning the protection of its seas. This shift requires new ways of thinking to obtain an efficient outcome from the interweaving of different organisations that have a stake in European seas. Therefore, our discussions will focus on the different possibilities for future governance arrangements to better implement Ecosystem-Based Management in the Mediterranean Sea.

This workshop is part of a Pan-European research project titled Options for Delivering Ecosystem-Based Marine Management (ODEMM). The WP7 Governance team will be organizing one roundtable discussion per Regional Sea during January 2013. Twelve participants representing various sectors (fisheries, oil and gas industry, government, research, NGO, etc.) are expected to attend each of these discussions. However, during 
these discussions you are not required to be representative of your sector. The roundtable discussion will be held in English and will apply the Chatham House Rule?

Our aim is to facilitate stakeholder creativity. To do so we have developed four 'simple' governance models that can be used to structure marine governance in European seas. These governance models were developed based on the imperative for EU Member States to implement the Marine Strategy Framework Directive (MSFD), the current legal tool aiming to enforce EBM in European Seas. During the workshop, we will conduct a SWOT Analysis (Strengths, Weaknesses, Opportunities and Threats) for each of the models to structure our discussions.

You are not required to prepare any material for this workshop, however, it would benefit discussions if you read about the different types of governance models sent with this letter. If you wish to be informed about Governance research in the ODEMM project, please consult the following website: http://www.liv.ac.uk/odemm/project_deliverables/.

\section{Governance models for Regional cooperation}

The description below presents the four governance models to be discussed at the workshop. These models were developed to cover all potential future governance settings in any European regional sea.

These models were based upon two key building blocks:

- Participation: Are stakeholders involved in the decisions?

- Decision making power: Are decisions binding or non-binding?

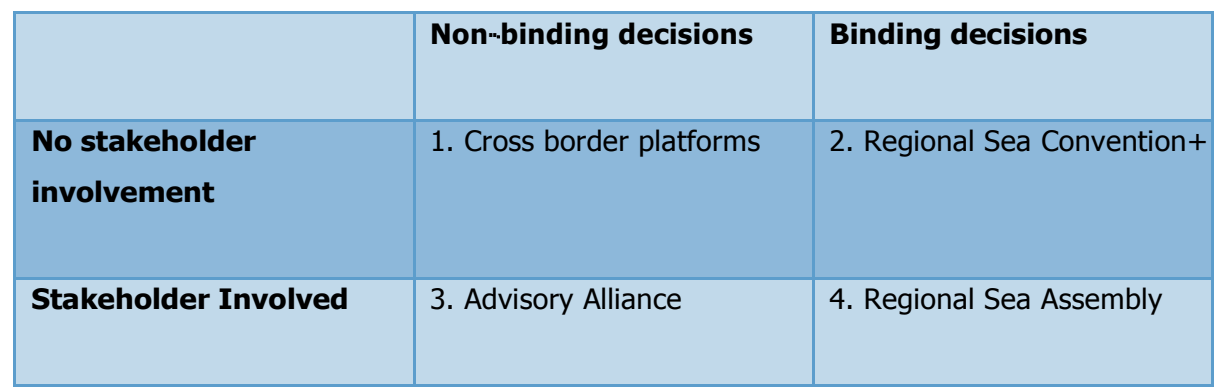

\footnotetext{
${ }^{9}$ When a meeting is held under the Chatham House Rule, participants are free to use the information received, but neither the identity nor the affiliation of the speaker(s), nor that of any other participant, may be revealed. The rule originated at Chatham House with the aim of encouraging openness of discussion and facilitating the sharing of information.
} 


\section{Cross border platforms}

Cross border platforms consists of neighboring Member States who work together coordinating their initiatives in defining GES and agree on a joint implementation strategy. Participation of representatives from marine sectors and NGO's are through consultation only in relation the implementation strategy (i.e. they are asked for comments). This mode is similar to the present way of involving stakeholders in the MSFD process and will not provide stakeholders with formal influence in the decision making process.

Furthermore, the cross $\cdots$ border platforms will not have binding decision-making power. Each individual MS remains responsible for the implementation of the MSFD. Cross - border platforms are temporary, because no formal cross-border institutional arrangements are developed. Participating Member States themselves take the initiative to organise bilateral or trilateral meetings on an ad-hoc basis or have agreed on more formal procedures for coordination and collaboration.

\section{Regional Sea Convention-PLUS (RSC+)}

This governance model is taking the existing structures between the EU, RSC and Member States a step further by providing the Regional Sea Convention a stronger role and mandate by establishing a $\mathrm{RSC}+$. This model will replace the nationally oriented implementation processes with a regional implementation process coordinated by the RSC+.

At the level of the marine region or sub-region, Member States negotiate in RSC+ regarding assessment work, defining GES, plans of measures, implementation procedures and policies that shall direct the implementation of MSFD at the regional rather than at the national level. In this model, Member States still play a key role, but the difference with the existing situation is that the RSC+ produces binding decisions. Member States have to implement these decisions and follow implementation guidelines as formulated by the RSC + .

Stakeholder involvement will be at the national level. Each Member State consults with stakeholders at the national level, however the RSC+ could consult stakeholders at the regional level. This will require new procedures for stakeholder involvement at this level. 


\section{Advisory Alliance}

The governance model of the Advisory Alliance is comparable to the Regional Advisory Councils (RACs) known from fisheries under the CFP. The RACs are advisory bodies providing recommendations to the DG for Maritime Affairs and Fisheries (DG MARE) or to national authorities of involved Member States. The Advisory Alliances consists of representatives of all maritime stakeholders (fisheries, oil and gas industry, shipping, off shore wind energy, coastal tourism, eNGOs and relevant national administrations) affected by the MSFD and Member States.

For each marine region or sub-region, an Advisory Alliance will be installed. They formulate a nonbinding advice to the EU and the Member States and leave the implementation decisions to the Member States. However, and in contrast to how RACs operate currently, it is envisioned that Member States should be active to ensure coordination and collaboration both between Member States, and between Member States and stakeholders, at the regional sea level.

This governance model is advisory, but intended to facilitate coordination and collaboration among Member States and stakeholders, with Member States having the final implementation responsibility within the EU framework.

\section{Regional Sea Assembly}

This governance model proposes the establishment of a new institution: the Regional Sea Assembly (RSA). The responsibilities and competences of the RSA are the management of marine regions (regional sea), its natural resources, habitats and its uses. An important responsibility of the RSA is to implement the Marine Strategy Framework Directive, but the RSA also makes decisions on other marine policies within a specific regional sea.

The assembly is a new governance arrangement at the level of the regional sea, with sovereign decision making power and forms a representative body of all stakeholders involved. The Members of the RSA are elected by a voting system and represent the Member States, other neighboring states and the maritime sectors.

The RSA has the decision making power for the implementation of maritime policies. There is a clear demarcation of the RSA from its bureaucracy responsible for the implementation processes. Decisions are made by all RSA members. The RSA will adopt binding policies for all Member States, industry and other uses, including marine environment conservation in a particular Regional Sea. 
Because the RSA is responsible for implementation, it will also have enforcement mechanisms at hand, such as sanctioning in the of case of non-implementation. Consultation and advice procedures will be set up for those stakeholders who do not participate in the RSA directly.

The governance models developed here are supposed to be equally "attractive" and foreseeable to stakeholders. The purpose is not to make a ranking of preferred models. The models are used to exemplify and explore the implication of changing direction of existing structures and keep us focused during our discussions. Hopefully by this approach we will cover different aspects of importance for creating appropriate governance structures to support MSFD implementation. Outputs of the workshop might suggest alternative model(s) and we look forward to these fruitful discussions with you. 


\section{Summary}

Over the past few decades environmental risks such as climate change, loss of biodiversity, drinking water contamination and air pollution have become more complex and uncertain. Nowadays, environmental dangers have proven to give rise to worldwide consequences that are difficult to control and different stakeholder groups, ranging from private companies, scientists, public authorities and civil society groups have shown widely different preferences when it comes to solving environmental challenges. In addition, no single stakeholder group involved in decision making on sustainability issues has the expertise or a complete overview to judge the consequences and impact of decisions taken. Consequently, the idea of involvement of various stakeholder groups in environmental decision making has become more and more popular. Yet, the debates about sustainability and participatory decision making provided evidence that there is no consensus in what stakeholder groups consider as meaningful stakeholder participation in decision making on sustainability issues.

This thesis analyses and discusses the challenges and potentials of meaningful stakeholder participation in decision making on sustainability issues. Searching for sustainable solutions implies dealing with complexity and uncertainty and calls for innovative and meaningful participatory decision making methodologies. Hence we are in need of methodologies that give stakeholder groups involved a justified and meaningful role and position in the process of decision making on sustainability issues. The objective of this research is therefore formulated as follows: "To design, test and evaluate a methodology for participatory and meaningful decision making processes on sustainability issues."

This objective is addressed through five case studies, which provide the empirical ground for the investigation of meaningful stakeholder involvement in decision making on sustainability issues. Three dilemmas, described in literature, are expected to have a major influence on meaningful stakeholder involvement in decision making processes: (1) the extent of access, representation and inclusion; (2) the ability to joint knowledge generation by various stakeholder groups; and (3) the legitimacy of sustainable 
solutions. These dilemmas are connected. If certain stakeholder groups are excluded and therefore not capable to influence the decision making process, successful implementation of environmental solutions will be complicated as implementation is often dependent on the support of a diverse group of stakeholders. Even if all relevant stakeholder groups have access to the decision making process, shared knowledge generation is often complicated, fragmented and non-transparent. This hampers the problem solving capacity of environmental risks and with that, the legitimacy of decision making processes. Within this thesis a participatory decision making methodology has been designed, tested and evaluated with a focus on inclusiveness, joint knowledge generation and the legitimacy of meaningful and participatory decision making on sustainability issues.

Two research programmes, in which participatory decision making on sustainability issues have been investigated, designed, tested and evaluated, are the basis of this thesis: (1) the 'Partnership for Research on Viable Environmental Infrastructure Development in East Africa' (PROVIDE) programme; (2) the 'Options for Delivering Ecosystem-Based Marine Management' (ODEMM) in European Seas programme. In both research programmes innovative participatory and meaningful decision making processes are designed and subsequently investigated.

The ODEMM programme covers four comparative cases in marine management. Each case represents a regional European Sea: the Baltic Sea, the Black Sea, the Mediterranean Sea and the North-East-Atlantic Ocean. Every regional sea needs to implement the Marine Strategy Framework Directive, based on the specific needs and challenges identified for its own waters. All case studies followed similar field procedures and general rules, data collection and analysis protocols. A step-by-step methodology is designed, tailored to the decision making context, considering the objectives, type of participation and appropriate level of engagement for all four cases.

The PROVIDE programme includes the case of Katanga village, one of the major informal settlements in Kampala, Uganda where the majority of the urban poor is accommodated. Among the multiple problems related to poverty, sanitation is one of the most prevalent ones. Previous efforts to improve the sanitation situation in Katanga village have not resulted in sustainable solutions. Although the case itself is not comparable with the 
ODEMM cases, the case study protocol is largely similar. For the Katanga case too, a participatory decision making methodology is designed, tailored to the decision making context and combining technical and social dimensions that fit the local context.

This thesis consists of six chapters and is presented in a publication-based format which means that the chapters 2,3,4 and 5 are separately written as scientific papers, all four published in international scientific peer reviewed journals. Besides, the concept of meaningful stakeholder participation in decision making on sustainability issues as well as the purpose, research questions and research design have been explored in chapter 1 . Chapter 6 draws the conclusions based on answering the research questions.

The case study in an unplanned urban settlement in Katanga, (Uganda), in Chapter 2, examines how potential users of sanitation facilities living in urban slum areas can be involved in the decision making process to realize sanitation facilities. Current improvements in sanitation facilities for the urban poor are facing a number of challenges, including lack of user acceptance of innovative technologies, and this factor tends to be ignored by technical experts and municipal decision-makers. The solution does not merely lie in the quantitative expansion of sanitation facilities in slum areas. It also lies in ensuring that sanitation facilities fit the conditions of the slums. In the past, too often newly constructed sanitation facilities were ignored by the urban poor, the potential users, because they did not fit their daily lifestyles, their religious beliefs, their cultural habits or their economic capacity. Filling the sanitation gap is therefore not only a matter of constructing more toilets, water points, and sewerage systems, but also to make sure these infrastructures fit with the practices, concerns and capacities of their users. This can best be achieved by engaging the future users in the decision making process on improving sanitary infrastructures. User acceptance of sanitation facilities is fundamental to achieve a sustainable impact, which makes a participatory decision making methodology an essential component of the system of design and implementation. The multi criteria decision analysis methodology, Proact 2.0 has been designed, tested and evaluated and has shown to be a useful method for participatory decision making on improving sanitation facilities because it (a) combines the information, knowledge, and expertise from experts, policy-makers, and users; (b) enables different stakeholder groups to jointly generate knowledge and exert influence 
on the final decision; and (c) excludes stakeholder groups from decision making phases where they have little to contribute, making the participatory process more efficient and feasible.

Chapter 3 presents the ODEMM-approach, a layered participatory decision making methodology designed and tested to develop alternative governance options for future ecosystem based models at the European regional seas. Developing a governance structure at a European regional sea level automatically requires involvement of stakeholder groups, not only as marine governance impacts on a multitude of marine users and uses, but also to develop an institution that is perceived as being legitimate, especially in the sense of being accepted by different stakeholders, like public authorities and private sectors. Hence involving stakeholders in the ODEMM research is an essential condition. However, it can be difficult to involve stakeholders in a meaningful way due to differences in strategies and the (political) traditions member states use for participation, knowledge environments, priorities of interests and beliefs, differences in challenges they face or the formation of unexpected subgroups in this broad field. In addition, designing a stakeholder participation process across four regional seas, at different organizational levels and sectors, is quite a challenge. In the ODEMM project scientists set the stage and chose the methods, yet they had to remain open to changes, allow for improvisation in the process and for change of their perspective in content. Therefore, both scientists as well as other stakeholder groups have been viewed as experts, each from their own experiences, perspective and expertise. The 'expert assumptions' were continuously tested, in interviews and focused group sessions. This decision making process finally resulted in a new perspective on knowledge production in which the ODEMM approach has been designed an extensive step-by-step process with several moments of stakeholder involvement aiming to contribute to joint knowledge production by reflecting on this process.

Chapter 4 develops, presents and zooms in on a set of scenarios to depict possible ways and structures for cooperation at the different European regional seas. Implementing the EU Marine Strategy Framework Directive explicitly calls for regional cooperation between the EU Member States in the different regional seas. This regional cooperation, although set in a general framework of EU Member States 
and non-EU states utilizing existing Regional Sea Conventions as focal point, develops along different tracks. Based on a series of interviews with different stakeholder groups in the different regional seas, the drivers for this regional cooperation were determined. These drivers were used to develop a set of explorative scenarios, focusing on 'what can happen, if we act in a certain way?' Five scenarios have been developed to support elaborating alternative governance models for regional cooperation. From the validation by the stakeholders it became clear that both the drivers used, as well as the scenarios developed were found to be relevant. There is no single solution that is going to fit all regional seas, or that is going to appeal to all stakeholders within a regional sea. Especially in this setting the scenario approach does help people to explore the full range of possibilities that exists for the development of alternative governance models that address two issues raised but not detailed in the MSFD: cooperation and participation. The scenarios fueled a proper debate in the development of alternative governance models.

Chapter 5 analyses and zooms in on the results of a survey covering four European Regional Seas (Baltic Sea, Black Sea, Mediterranean Sea and North-East Atlantic Ocean) aimed to collect stakeholders' perspectives on their Regional Sea governance to implement the European Union (EU) Marine Strategy Framework Directive (MSFD). In this survey, drivers of good governance including stakeholder involvement, willingness and capacity to cooperate, efficiency, institutional ambiguity and decision making are explored. The results indicate a clear gap in perception between the current, the ideal and the foreseen situation regarding the implementation of the MSFD. Stakeholder views on the MSFD implementation demonstrate that within the different contexts across the four European regional seas, a challenging patchwork of future governance structures exist. All stakeholder groups strongly support the need and establishment of a clearly defined and transparent decision making and support structure. Such a structure should ensure coordination among all institutions that are responsible for MSFD implementation at the regional sea level in order to adopt Ecosystem-based Marine Management in European regional seas. The survey points to two crucial building blocks: Stakeholder involvement and decision making power to be the back-bone of 
developing governance arrangements for regional cooperation and to ensure coordination at the regional sea level and enhanced stakeholder involvement.

The final chapter reflects on the case study chapters and draws conclusions related to answering the research questions of this thesis.

This thesis designed, tested and evaluated a participatory decision making methodology that meets the conditions for meaningful stakeholder involvement. The underlying idea is that relevant stakeholder groups involved in decision making processes on sustainability issues, such as scientists, public authorities, private parties and societal actors, often have different forms of knowledge, perspectives, values and experiences on environmental issues, and hence they should join forces in order to reach sustainable solutions. The design of the participatory decision making process, the participation and inclusiveness of stakeholders, the degree of shared knowledge production and the legitimacy were found to be critical factors for meaningful and participatory decision making processes on sustainability issues.

The design of the participatory decision making process consists of two innovative and strongly intertwined characteristics to enable meaningful stakeholder involvement: (1) the division of the participatory decision making process in different chronological phases; (2) the assignment of only the relevant stakeholder groups for distinct phases of the decision making process. The specific set up of the Proact 2.0 and the ODEMM approach have created conditions for inclusiveness and shared knowledge production leading to improved legitimacy of sustainable solutions.

When it comes to ensuring access to and inclusion in participatory and meaningful decision making, this thesis has demonstrated that just being invited and sitting at the table is not enough, mainly because of unequal footing. Consequently, a great deal of effort has been put into designing and facilitating a decision making process in which the voices of all stakeholder groups involved were heard, stakeholders were able to put their interests, values and ideas on the table, influenced discussions and made final decisions about agreed options. In the PROVIDE and ODEMM programme, 
a multidisciplinary scientific expert team has played a decisive role in offering access and inclusiveness to a broad range of stakeholders.

This thesis has shown that joint knowledge generation is essential for a participatory and meaningful decision making process on sustainability issues. Joint knowledge generation is regarded as an interaction process between different stakeholder groups, resulting in a common knowledge base, which gives meaning to - and legitimizes decisions taken. A vital role is assigned to knowledge coalitions, which may consist of various stakeholder groups, like societal actors, private parties, policy-makers and (scientific) and permit joint knowledge generation. By recognizing and paying extensive attention to multiple ways of knowing, and by providing different stakeholders the opportunity to collaborate and understand each other's perspectives, Proact 2.0 and the ODEMM approach have shown how joint knowledge generation can occur among and between various stakeholder groups.

This thesis makes a distinction between input-, throughput-, and output legitimacy. Input- and throughput legitimacy have been achieved by inclusion of stakeholder groups in the for them relevant phases of the decision making process and joint knowledge generation in new knowledge coalitions were important for the acceptance and justification of shared decisions by stakeholder groups. Based on this study it is not possible to formulate conclusions on output legitimacy.

In conclusion, the designed, tested and evaluated decision making methodologies, Proact 2.0 and the ODEMM approach, provide stakeholders a meaningful and participatory decision making process on sustainability issues in the investigated cases. To take this conclusion a step further and to apply it in new projects, I propose a set of heuristics for designing meaningful and participatory decision making processes that are legitimate and that can be derived from the studied cases:

1. The participatory decision making process is divided in consecutive phases; each with a clear starting and end point. The results of stakeholder input in each case is used to shape the next phase in the decision making process. 
2. Different stakeholder groups are assigned to participate in specific phases of the decision making process. This allows stakeholders to exert meaningful influence in phases where their contribution can be considered relevant, while excluding stakeholders in phases of the decision making process where they have little to contribute. Not all stakeholder groups need to be involved in each phase of the decision making process.

3. A multidisciplinary scientific team is capable to guide and facilitate the decision making process. These scientists fulfil a dual role: as process facilitators and as stakeholder participants. Their dual position does not endanger the (legitimate) fulfilment of both roles.

4. Inclusion of stakeholders in decision making processes reduces unequal footing between the stakeholders involved.

5. Multiple perspectives, values, expertise and interests from included stakeholder groups are used to jointly generate knowledge. Hence, a new knowledge coalition is constructed which exerts as a coalition, influencing the decision making process.

6. Decision making processes can improve legitimacy of sustainable solutions through optimizing input and throughput legitimacy. These provide the helpful conditions for - although do not guarantee - output legitimacy. 


\section{Acknowledgements}

Stakeholders are the foundation of this thesis. Through my fieldwork I have learned the importance of meaningful stakeholder involvement in decision making processes. As a member of various scientific research teams where fieldwork was seen as an important pillar I got many opportunities to work with different stakeholder groups. A big thank you is for all stakeholders who were involved in our research, you taught me a lot.

I really enjoy teamwork and would like to express my gratitude to all team members I have worked with in various research projects. The ODEMM team felt like a close family and I especially would like to thank Jesper Raakjær and Charlene Jouanneau for our inspiring working sessions. I would like to thank Joost van Buuren who guided me through sanitation and waste issues in Vietnam and introduced me to his dream team. Special thanks to Trần Thị Mỹ Diệu, Lê Thị Kim Oanh and Huỳnh Ngọc Phương Mai. The PROVIDE team gave me the chance to develop and test Proact 2.0 and I would like to thank Judith Tukahirwa for organising the workshops with the people from Katanga.

The Environmental Policy Group and the Wageningen University community in general have always been an open minded and stimulating workplace that educated and showed me the challenges of working in an academic setting. I enjoyed working with many of you in courses, projects and/or as a study advisor. A special thanks to Karen Fortuin, Alette Langenhoff, Marjo Lexmond, Karin Peters, Lèneke Pfeiffer and Hilde Toonen for the inspiring cooperation. I hope we will have plenty of reasons to continue.

I have experienced that writing a $\mathrm{PhD}$ thesis is quite another thing than carrying out empirical research and I would like to thank Arthur Mol and Bas van Vliet who have played a decisive role in finalizing this thesis. Your guidance, support and advice stimulated me to continuously challenge my academic boundaries. Arthur, you kept me on track and provided essential advice. Bas, you guided me in valuing my empirical data, always encouraging and supportive. I am thankful to Simon Bush and Gert Spaargaren who constantly gave me the feeling that I was able to finalize this thesis. Gert's offer to share his office helped a lot.

Without Corry, there would be no thesis at all and we both know this is true. 
I feel privileged to be part of the Honours team. With Ellis Hoffland and Maria Jaartsveld I have experienced how important teamwork is. I hope that in the coming years our relationship will broaden, deepen and further develop on a personal and professional level.

I am lucky with friends who share my dreams through the good times and in stormy weather. During the greater part of my life, Jet and Sonja stand by me and I am very happy that both agreed to be my paranymph. Thank you for our wonderful friendship. Erik and Rio, thanks for sharing our passion to make the world a better place. Nettie, thanks for never giving up. I am learning a lot from you. Thank you Linda, I am deeply touched by your professional caring. A big thanks to the Theekrans, the Hindes, the Bootcamp and the ski-boys Hidde, Aron, Simon and Sjoerd for being such an easy going distraction. Janneke en Gerda, thanks for being there at crucial moments in my life and thank you neighbours of the best neighbourhood ever.

Dearest Sebastian, Eva and Henk, you are the most amazing part of my life and make me incredibly proud. Together we make it happen! 


\section{About the author}

Astrid Hendriksen (1961) is founder of Mixed Methods BV, and works at Wageningen University in several positions at the Environmental Policy Group and the BSc Honours Programme. For many years, she has acquired experience in methodology for decision making processes with multi-stakeholder groups

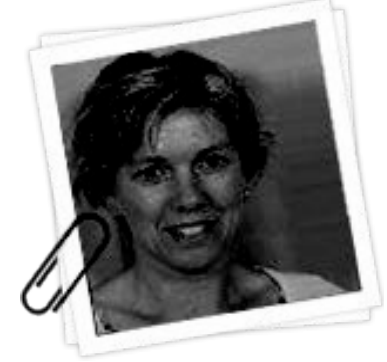
involved. This is reflected in both her $\mathrm{PhD}$ thesis and her commercial activities.

Astrid has scientific as well as practical experience in a variety of research projects, such as Options for Delivering Ecosystem Based Marine Management; Partnership for Research on Viable Environmental Infrastructure Development in East Africa; Curriculum Development in the Ethiopian Horticultural Sector; Waste Separation at Source in Vietnam; Building a Bio-Waste Reuse Chain in South East Asian Cities; Simulation and Monitoring Methods for the Inspectorate of Justice and Security; Medicines in Wastewater; International Environmental Policy Consultancy; European Workshops; and Metropolitan Solutions. Her involvement includes working as an advisor, project manager, facilitator, researcher and/or lecturer. She continues her work for Wageningen University and Mixed Methods BV.

Recently she initiated the sustainable mobility movement with the ambition to create a global bicycle network. With this network of initiatives and partners she aims to connect relevant stakeholders to enhance sustainable mobility in urban environments. 
Cover design: Hidde Deelstra 

